\title{
AVALIAÇÃO “IN VITRO” DA MICROINFILTRAÇÃO MARGINAL EM CAVIDADES CLASSE V, RESTAURADAS COM RESINAS COMPOSTAS CONDENSÁVEIS, RESINA COMPOSTA HÍBRIDA, RESINA COMPOSTA MODIFICADA POR POLIÁCIDOS E IONÔMERO DE VIDRO MODIFICADO POR RESINA
}

OSVALDO BENONI DA CUNHA NUNES

\begin{abstract}
Tese apresentada à Faculdade de Odontologia de Bauru, da Universidade de São Paulo, como parte dos requisitos para obtenção do grau de Doutor em Odontologia, área de Dentística.
\end{abstract}

(Edição Revisada) 


\title{
AVALIAÇÃO “IN VITRO” DA MICROINFILTRAÇÃO MARGINAL EM CAVIDADES CLASSE V, RESTAURADAS COM RESINAS COMPOSTAS CONDENSÁVEIS, RESINA COMPOSTA HÍBRIDA, RESINA COMPOSTA MODIFICADA POR POLIÁCIDOS E IONÔMERO DE VIDRO MODIFICADO POR RESINA
}

OSVALDO BENONI DA CUNHA NUNES

\begin{abstract}
Tese apresentada à Faculdade de Odontologia de Bauru, da Universidade de São Paulo, como parte dos requisitos para obtenção do grau de Doutor em Odontologia, área de Dentística.
\end{abstract}

(Edição Revisada)

Orientador: Prof. Dr. Alceu Berbert 


\section{C.D. OSVALDO BENONI DA CUNHA NUNES}

18 de maio de 1955

Santo Ângelo - R.S.

Oswaldo Nunes da Silva

Anadir Cunha da Silva

$1975-1979$

1980

1981

1982
Nascimento

Filiação

Curso de graduação em

Odontologia na Universidade

Federal do Rio Grande do Sul Porto Alegre.

Professor Auxiliar de Ensino na Faculdade de Odontologia de Lins, São Paulo.

Curso de Especialização em

Dentística Restauradora na Faculdade de Odontologia de Bauru da Universidade de São Paulo.

Casou-se com Nancy Alfieri 
$1986-1990$

Curso de Pós-Graduação em nível de Mestrado na Faculdade de Odontologia de Bauru da Universidade de São Paulo.

$1990-2000$

Professor Responsável pela Disciplina de Dentística Restauradora da Faculdade de Odontologia de Lins da Universidade Metodista de Piracicaba.

1997-200।

Curso de Pós-Graduação a nível de Doutorado na Faculdade de Odontologia de Bauru da Universidade de São Paulo.

2000

Professor Concursado em Regime de Tempo Integral na Faculdade de Odontologia de Lins - Universidade Metodista de Piracicaba Dentística (G.B.P.D.) 
Agradeço ao Deus Eterno, poderoso para transformar todo o mal em bem, que esteve comigo no começo, meio e fim.

(Gênesis 50:20) 
Dedico este trabalho:

Aos meus pais, Oswaldo (in memorian) e Anadir que iniciaram minha formação acadêmica, moral, ética e espiritual;

À minha esposa Nancy, fiel e companheira, que me incentivou e ajudou em todos os momentos, partilhando de tristezas e alegrias em todo o te mpo;

Aos nossos filhos Vânia, Davison e Sarah que com carinho e compreensão suportaram minha ausência. 
Ao Prof. Dr; Alceu Berbert, meu orientador, que, em momentos difíceis surgiu pela graça de Deus para minimizar dores, me orientar e para me colocar em posição de vitória,

meu agradecimento mais profundo e amoroso. 
Ao Prof. Dr. José Mondelli, líder seguro do Departamento de Dentística pelos seus passos firmes que fazem da ciência uma caminhada e da caminhada, conhecimento que aprendi a receber e a partilhar,

meus sinceros agradecimentos. 
- Ao Prof. Dr. Luiz Fernando Pegorara, Coordenador da Pós-Graduação da FOB-USP, pelo apoio recebido;

- À Faculdade de Odontologia de Lins da Universidade Metodista de Piracicaba, na pessoas do Prof. Dr; Carlos Wagner de Araújo Werner, Diretor Acadêmico, pelo seu incentivo e apoio;

- Ao Prof. Dr. José Lauris pela análise estatística;

- À minha sogra Luiza Maria Berbert Alfieri, companheira constante, pelo apoio e carinho recebidos e distribuídos a toda a nossa família;

- Ao amigo Leandro Fava dos Santos, pelo carinho, paciência, dedicação e esmero na digitação deste trabalho;

- Aos docentes da Disciplina de Clínica Integrada, Dentística Restauradora e Operatória da Faculdade de Odontologia de Lins - UNIMEP, pelo apoio e incentivo recebidos.

-Aos meus amigos e irmãos em Cristo que estiveram comigo em todos os momentos,

- A todas as pedras que rolaram em meu caminho, pois Deus as removeu umaa-uma pelo Seu poder, aproximando-me ainda mais dEle mesmo. 


\section{SUMÁRIO}

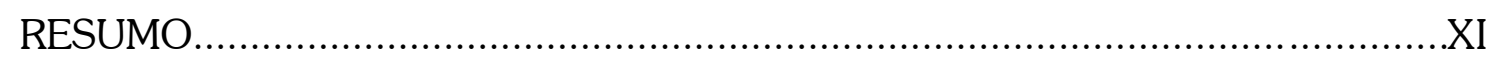

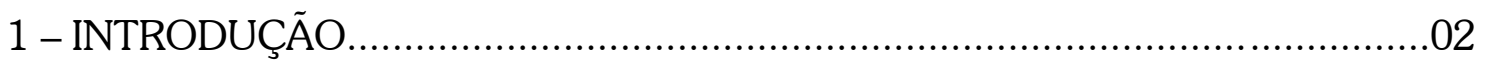

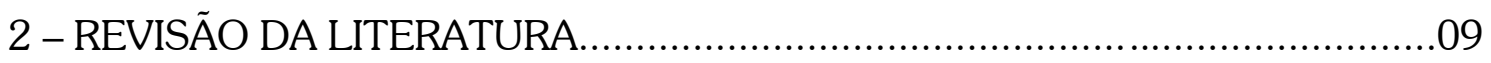

3 - PROPOSIÇÃO

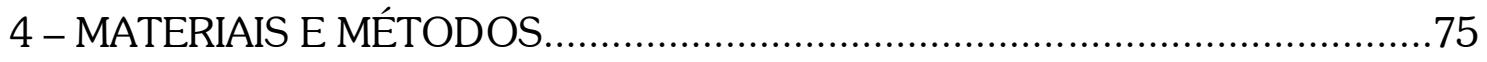

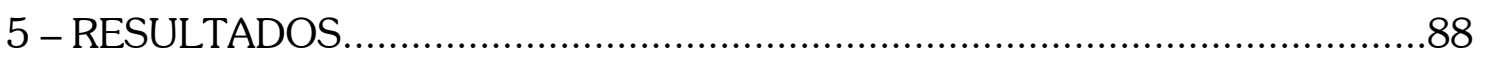

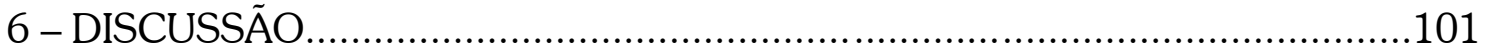

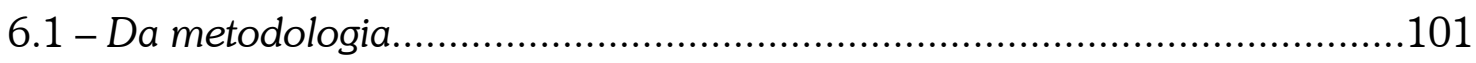

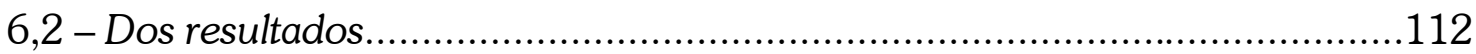

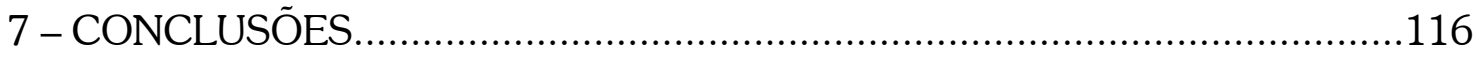

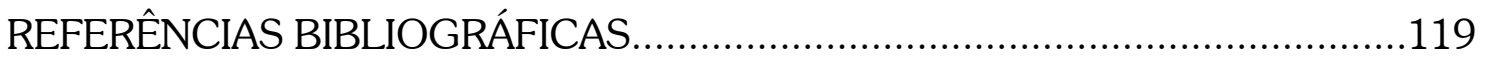

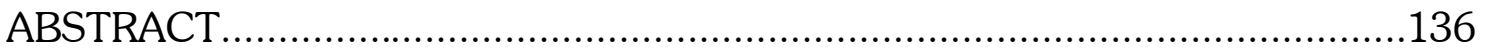

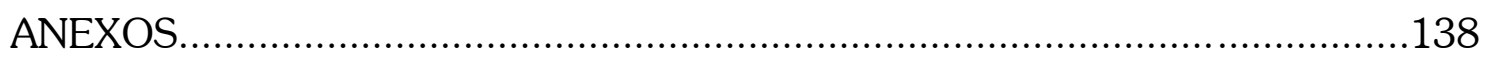




\section{RESUMO}

A finalidade deste trabalho foi verificar o grau de infiltração marginal em cavidades classe $\mathrm{V}$, vestibulares e linguais, em dentes pré-molares humanos extraídos por razões ortodônticas e restaurados com resina composta condensável, resina composta híbrida, resina composta modificada por poliácidos e ionômero de vidro modificado por resina.

Foram utilizados 50 dentes livres de cáries, que após a coleta foram limpos e fixados em formalina tamponada a $10 \%$ e, a seguir, armazenados em água destilada. Foram realizadas cavidades classe $\mathrm{V}$ por vestibular e lingual com $3 \mathrm{~mm}$ de diâmetro e 1,5 mm de profundidade, e em seguida restaurados e agrupados segundo o material restaurador escolhido em : Grupo I: dentes restaurados com resina composta condensável Alert; Grupo II: dentes restaurados com resina composta condensável Solitaire; Grupo III: dentes restaurados com resina composta híbrida Z- 250 ; Grupo IV: dentes restaurados com compômero Dyract AP e Grupo V: dentes restaurados com ionômero de vidro Vitremer (grupo controle).

Concluídas as restaurações os dentes foram imersos em água destilada a $37^{\circ} \mathrm{C}$ por 24 horas; polidos com discos Sof-Lex e impermeabilizados com Araldite e esmalte para unhas, preservando-se $2 \mathrm{~mm}$ ao redor da restauração, sem impermeabilização. Uma vez secos, os dentes foram

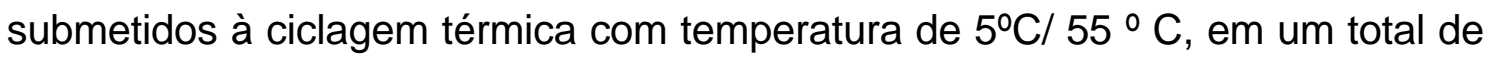
200 ciclos, com 30 segundos em cada banho. Os dentes foram imersos em uma solução aquosa de azul de metileno a $2 \%$ por um período de 24 horas. 
Concluídos os procedimentos acima, os espécimes foram lavados e cortados longitudinalmente com disco diamantado, no sentido vestíbulo-lingual. Os dentes foram examinados com lupa com aumento de $7 x$ e classificados segundo o grau de penetração máxima do corante, utilizando-se escores de 0 a 4, segundo o número de paredes infiltradas. A análise estatística aplicada aos resultados obtidos permitiu as seguintes conclusões: a resina composta Alert demonstrou menor infiltração marginal $(P<0,05)$, seguida do Dyract $A P$, sendo que ambas comportaram-se estatisticamente melhor que os demais grupos. Não houve diferença estatística significante entre a resina Z-250 e o Vitremer. A resina composta Solitaire teve o pior desempenho quanto à infiltração marginal. 
1 - INTRODUÇÃO 


\section{1 - INTRODUÇÃO}

As restaurações dentárias visam não só reproduzir a reconstituição morfológica do dente, como também restabelecer a estética e funções perdidas, quando da instalação de um processo carioso.

Atualmente, diversos materiais restauradores são empregados em cavidade de dentes anteriores e posteriores e, ao longo do tempo, tem sofrido modificações em sua composição com a finalidade promover uma adequada inter-relação do material com a superfície dentária da cavidade, de tal forma que a penetração de bactérias e a recidiva de cárie sejam impedidas. A adaptação marginal pode ser definida como o grau de proximidade e interrelação do material restaurador e a parede da cavidade ${ }^{44,92,93}$, sendo que este termo pode ser também utilizado como sinônimo da adaptação da margem do ângulo cavo-superficial. Entretanto em uma restauração não é somente a exposição da superfície na adaptação da mesma que é relevante, pois embora haja semelhanças entre as técnicas usadas para avaliar e mensurar a adaptação dos materiais restauradores existem importantes variáveis tais como o preparo cavitário, a forma do mesmo e a técnica da restauração empregada, que podem interferir nestes resultados ${ }^{49,67,94,98,105}$. Aliando-se ao material restaurador e as suas propriedades individuais, tais como a utilização de adesivos dentinários ${ }^{1,5}, 70,74,75,76,84,96,99$ ou materiais restauradores que absorvem água, considera-se também que as diferentes técnicas de acabamento e polimento podem ser fatores intervenientes na avaliação da microinfiltração marginal ${ }^{11,56,74}$. 
Entre os materiais restauradores, as resinas compostas atuais possuem propriedades físicas bastante satisfatórias, quando comparadas às resinas compostas convencionais, visto que o coeficiente de expansão térmica linear diferente do tecido dental, a baixa resistência à abrasão e a contração de polimerização destas últimas, limitam o seu uso indiscriminado e a sua longevidade $4,9,103$. A fenda marginal provocada principalmente pela contração de polimerização tem sido descrita como a principal causa da infiltração marginal em restaurações próximas à junção cemento-esmalte ${ }^{19,90}$.

A contração de polimerização é medida pelo fator de configuração (fator $\mathrm{C}$ ), que é proporcional à superfície aderida e inversamente proporcional à superfície livre, permitindo avaliar o estresse liberado nas forças de contração de polimerização das resinas compostas e, quanto maior o número de paredes que recebem o agente adesivo, maior é à força de contração e o estresse do fator $C^{15}$. Observa-se também que durante a contração de polimerização da resina composta podem ocorrer fraturas do agente adesivo com comprometimento do selamento periférico e aumento da infiltração marginal ${ }^{29}$, 75, permitindo a passagem de bactérias, fluidos, moléculas ou íons entre a parede cavitária e o material restaurador ${ }^{92}$, fator este que pode comprometer a longevidade da restauração ${ }^{45}$, com aparecimento de cárie secundária ${ }^{51,52}$, descoloração marginal e sensibilidade pós-operatória do elemento dentário ${ }^{13}$.

Para compensar as propriedades negativas das resinas compostas foram desenvolvidas algumas técnicas: uso de adesivos dentinários ${ }^{17,38,39,55}$; condicionamento ácido das paredes de esmalte e dentina da cavidade ${ }^{23,37,42,}$ 50, 88,104; uso de base forradora de (cimento de ionômero de vidro ou resina 
composta de baixa viscosidade) e sistema adesivo-resina composta ${ }^{40,41,61,89,}$ 95, 97,99; o biselamento das margens da cavidade; a introdução de novas técnicas de inserção e polimerização da resina composta na cavidade e retenções adicionais nas paredes cavitárias.

Os sistemas adesivos ajudam a manter o equilíbrio biológico, respeitando o complexo dentino-pulpar e os aspectos mecânicos relacionados à adesão, conseguindo-se estabilidade para a restauração, com resultados satisfatórios em longo prazo. O condicionamento ácido promove a formação da camada híbrida ${ }^{67,81}$ e impede a penetração de bactérias pela interface dente/ restauração levando à formação de barreira dentinária ${ }^{86}$. O "primer" normalmente remove ou modifica a "smear-layer" para promover um aumento da capacidade de molhamento, desidratação química e permitir a penetração em profundidade do monômero ${ }^{46}$. O adesivo, por sua vez, forma os "tags", com aumento da área de adesão ${ }^{16,18,86}$. Para se conseguir a formação destes "tags" se faz necessária à utilização da técnica úmida ${ }^{6,69,82,83,91}$ de secagem do substrato (dentina). O uso da mesma é importante no sentido de impedir a desidratação dentinária e conseqüentemente promover a formação da camada híbrida, as quais favorecem o selamento marginal| ${ }^{21,34,35}$ contribuindo para 0 sucesso da restauração. Além destes procedimentos, a aplicação de selantes de superfície, após o acabamento e polimento das restaurações, aumenta a resistência à abrasão, reduz a infiltração marginal e aumenta a vida útil das restaurações de resina composta por meio de sua penetração na interface dente/restauração possibilitando o vedamento ${ }^{60,66}$ A hidratação da resina 
composta pré e pós-acabamento e polimento, associada ao uso de selantes de superfície, também reduz a microinfiltração ${ }^{79}$.

Os materiais que liberam flúor podem ser divididos em quatro grupos distintos: cimento de ionômero de vidro, cimento de ionômero de vidro híbrido (modificado por resina), compômeros e resinas compostas fluoretadas.

O cimento de ionômero de vidro possui propriedades mecânicas e resistência ao desgaste menores que as resinas compostas que liberam flúor. Os materiais com maior conteúdo resinoso apresentam menor liberação de flúor, mas promovem uma melhor estética e durabilidade clínica ${ }^{26,31,72}$. Nas restaurações de lesões cariosas, os ionômeros modificados por resinas, compômeros e resinas compostas que liberam flúor, apresentam a melhor combinação entre remineralização efetiva e estética ${ }^{49,}{ }^{85}$. Pesquisas atuais sugerem que os materiais restauradores com maior flexibilidade (baixo módulo flexural) são os preferidos. As resinas fluidas e os ionômeros híbridos são mais flexíveis que a maioria das resinas compostas multiuso e compômeros. Todos estes materiais, com exceção dos ionômeros híbridos necessitam de um agente adesivo para retenção e minimização da microinfiltração ${ }^{77,}{ }^{80,102}$. Os íons metálicos liberados pelo ionômero de vidro podem ser parcialmente responsáveis pela inibição da cárie ${ }^{59}$.

Os compômeros são polimerizados através da luz e por uma reação ácido-básica com a água absorvida da estrutura dentária ${ }^{12}$. Contrariamente aos cimentos de ionômero de vidro convencionais e modificados por resina, estes são formulados sem água e liberam flúor por um mecanismo similar aqueles dos cimentos de ionômero convencionais e modificados por resina. Dado à 
pequena quantidade de ionômero de vidro presente neles a quantidade de flúor liberada e a sua duração são menores que as dos cimentos de íonômero de vidro. Além disso, a reincorporação de flúor dos compômeros, a partir de tratamentos ou escovação com dentifrícios fluoretados, não é alta como a dos cimentos de ionômero de vidro. Devido ao seu componente resinoso, os compômeros necessitam de um agente adesivo para fixar-se à estrutura dentária sendo que alguns deles utilizam agentes adesivos de um frasco, ou seja, contém "primers" acidificados, os quais se unem ao esmalte e dentina sem a necessidade de um condicionamento adicional com o ácido fosfórico ${ }^{43}$. Alguns fabricantes, entretanto, recomendam este condicionamento antes da aplicação do "primer" para aumentar a resistência adesiva dos compômeros ${ }^{7}$, 10, $20,22,36,54,71$

As resinas compostas condensáveis foram introduzidas recentemente como uma possível alternativa para o amálgama, diferindo das resinas compostas convencionais para dentes anteriores e posteriores pelo aumento na quantidade de partículas inorgânicas em sua composição. Estas partículas podem ser porosas, irregulares ou até fibras sendo que o contato entre elas permite que a resina seja condensável. As resinas compostas condensáveis produzem contatos interproximais aceitáveis em restaurações de classe II; a inserção em um só incremento, dado à alta profundidade de polimerização e baixa contração de presa; possuem uma resistência média; rigidez e radiopacidade alta e desgaste baixo e comparável a do amálgama. Ainda tem vantagem sobre as resinas compostas convencionais por apresentarem uma menor contração de polimerização, dado a seu alto 
conteúdo de carga inorgânica (> $80 \%$ por peso) e tendência de se apresentarem mais secas sem molharem as superfícies como as resinas viscosas $^{73}$

Segundo a American Dental Association, uma restauração de resina composta ideal deve cumprir cinco requisitos básicos: ter alta resistência ao desgaste; boa adaptação marginal; ser resistente à degradação pela água e outros solventes; ser radiopaca e de fácil execução. Estes requisitos confluem para um grande objetivo da odontologia atual: aumentar a longevidade clínica dos materiais restauradores ${ }^{3}$.

O trabalho proposto visou avaliar um destes itens, ou seja, a infiltraçâo marginal das resinas compostas condensáveis comparadas ao ionômero de vidro híbrido, compômero e resina composta avançada. 
2 - REVISÃO DA LITERATURA 


\section{2 - REVISÃO DA LITERATURA}

KIDD, E.A.M. ${ }^{51}$, em 1976, realizou uma revisão da literatura, enfocando a microinfiltração entre a interface dente restauração, quando esta era realizada com amálgama e/ou materiais estéticos (resina acrílica, cimento de silicato e resina composta). Estudou ainda as técnicas laboratoriais desenvolvidas para estudar a infiltração marginal (corantes isótopos radioativos, pressão com as bactérias, análise de ativação de nêutrons, técnicas de cáries artificiais, microscopia eletrônica de varredura e ciclagem térmica). As temperaturas usadas nos procedimentos de ciclagem térmica relatada variavam de $4^{\circ} \mathrm{C}$ a $60^{\circ} \mathrm{C}$ ou de $15^{\circ} \mathrm{C}-45^{\circ} \mathrm{C}$, assim como o tempo de imersão, variando desde alguns segundos até várias horas, sendo que a maior parte das pesquisas estudadas usava tempos de 30 a 60 segundos. O número de ciclos variava de 1 a 2.500. Concluiu que a técnica de cáries artificiais parece ser de particular relevância clínica, uma vez que relaciona a microinfiltração e suas conseqüências.

GOING, R. E. ${ }^{44}$ realizou em 1979 uma revisão da literatura sobre materiais e técnicas úteis para clínicos no sentido de minimizar a infiltração marginal e, portanto, conseguir a excelência clínica das restaurações. Concluiu que, embora um progresso significativo tenha ocorrido com as resinas compostas e técnicas associadas, o problema da infiltração marginal foi apenas reduzido. Afirmou ainda que o principal objetivo dos futuros trabalhos deve ser a prevenção da formação de espaços entre a restauração e o dente.

YEDID, S.E. e CHAN, K.C. ${ }^{104}$, em 1980, compararam a resistência 
de união de cilindros de resina composta (Cervident e Concise) e ionômero de vidro (ASPA) aplicados sobre superfícies tanto de esmalte como de dentina, sendo somente as superfícies dentinárias tratadas com ácido fosfórico a 37\%, ácido cítrico a 50\%. Após os testes de resistência à união verificaram que esta dependia da estrutura dentária, tipo de ácido e do material restaurador usado. Concluíram que houve mais efetividade para as resinas compostas quanto ao condicionamento ácido tanto em esmalte como em dentina, porém recomendam que este deve ser feito no primeiro somente com ácido fosfórico a 37\%, uma vez que o aumento de resistência à união nesta área demonstrou ser estatisticamente significante para o esmalte e não para a dentina.

Em um estudo para verificar a influência do condicionamento dentinário na adesão do cimento ionomérico, POWIS, D.R. et $\mathrm{al}^{71}$, em 1982 , submeteram superfícies dentinárias a vários tipos de substâncias condicionadoras antes da aplicação do cimento ionomérico. Realizados os testes de resistência à tração puderam verificar que existia diferença estatisticamente significante nos resultados obtidos, visto que quando era empregado o ácido poliacrílico, o ácido tânico ou o Dodicin, os mesmos eram mais elevados. A explicação aventada foi que essas substâncias seriam capazes de ligar-se com mais hidrogênio da estrutura dentária, o que asseguraria melhor limpeza e molhamento da superfície. Ao contrário do EDTA e ácido cítrico, os quais atacam o cálcio, destruindo a superfície dentária, essas substâncias criariam melhores condições de adesão.

CRIM, G. A.et $\mathrm{al}^{28}$, em 1985, prepararam cinqüenta pré-molares hígidos com cavidades tipo classe $\mathrm{V}$, vestibulares e linguais, sendo estas 
restauradas com a resina composta Concise $(3 \mathrm{M})$. Os dentes foram divididos em três grupos com 10 dentes/ 20 restaurações e submetidos a cinco métodos de avaliação da termociclagem, sendo estabelecidos dois subgrupos para os métodos 1 e 2, sendo o grupo 3 o grupo controle, perfazendo o total dos 50 dentes. $O$ método 1 ( $\mathrm{A}$ e $B$ ) utilizou $4 \mathrm{~s} / 60^{\circ} \mathrm{C}, 23 \mathrm{~s} / 37^{\circ} \mathrm{C}, 4 \mathrm{~s} / 12^{\circ} \mathrm{C}$ e $23 \mathrm{~s} / 37^{\circ} \mathrm{C}$, sendo que a ciclagem foi diretamente realizada com os espécimes imersos em solução de fucsina básica a $0,5 \%$, enquanto que no grupo B esta foi realizada primeiramente em água com posterior imersão na fucsina a 0,5\% por 24 horas. O método 2 ( $\mathrm{A}$ e $B$ ) utilizou técnica semelhante em água e cálcio radioativo a 0,1 $\mathrm{mCi} / \mathrm{mL}$ e $\mathrm{pH} 5,5(\mathrm{~A})$ e somente em cálcio radioativo, por 2 horas $(\mathrm{B})$. $\mathrm{O}$ método 3 empregou temperatura constante e imersão no corante por 24 horas. Os dentes foram seccionados e examinados por microscopia óptica com magnitude de 40 x. A análise estatística dos resultados não revelou diferença estatisticamente significante nos métodos de termociclagem, contudo, apesar do radioisótopo não propiciar melhor evidenciação da microinfiltração comparado com a fucsina básica, em ambos perceberam que houve melhor demonstração desta, quando os espécimes foram submetidos a ciclagens térmicas.

ASMUSSEN, E. e MUNKSGAARD, E.C. ${ }^{6}$, em 1985, realizaram um trabalho para verificar a possibilidade de união de um adesivo dentinário à parte orgânica da dentina, visto que a hidratação na superfície desfavorece esta união. Os autores concentraram esta pesquisa no desenvolvimento de adesivos ativos em ambientes aquosos, verificando que as misturas aquosas de aldeídos e certos compômeros ativos preencheram tais requisitos. A força 
de união entre uma resina restauradora e a dentina foi medida após o uso destas misturas como intermediárias. Para remover a camada de dentina agregada, esta foi pré-tratada com EDTA 0,5M. Entre os aldeídos alifáticos estudados, o propiônico e o glutaraldeído foram considerados os mais eficazes. Os aldeídos aromáticos resultaram em união de baixa intensidade. Dos monômeros investigados o HEMA (hidroximetil metacrilato) produziu forças de união mais elevadas. Esta última associação, denominada GLUMA, reduziu significativamente os espaços causados pela contração de polimerização da resina. Concluíram que uma união lisa das resinas restauradoras à dentina pode ser alcançada com misturas aquosas de aldeídos e monômeros, afirmando inclusive que as forças de união nestes casos se desenvolveram rapidamente atingindo um platô comparável com as forças de união obtidas entre uma resina e o esmalte condicionado por ácidos.

McLEAN, J.W. et al ${ }^{61}$, em 1985, propuseram uma técnica restauradora de lesões de classe III e V utilizando um cimento ionomérico para preenchimento das cavidades. Após o endurecimento do material removeram os excessos com uma pasta diamantada, deixando as margens de esmalte livres e biseladas. Segundo observações através de microscopia eletrônica de varredura, os autores verificaram a possibilidade do condicionamento ácido e as microporosidades na superfície dos cimentos ionoméricos. Desta forma realizaram o condicionamento ácido tanto na superfície de esmalte, quanto no cimento ionomérico. A seguir foi aplicada de uma resina composta de micropartícula. Atribuíram a esta técnica uma importância prática em dentística, uma vez que promovem união da resina composta à dentina por meio do 
cimento ionomérico intermediário, sem necessidade do uso de um agente de união dentinária específica.

LEINFELDER, K. F. et $\mathrm{al}^{55}$, estudaram em 1986 a eficácia dos adesivos dentinários na redução da microinfiltração nas restaurações de resina composta. Empregaram duas resinas compostas de micro-partícula (Durafill e Silux), uma resina composta para dentes posteriores $(P-10)$ e cinco adesivos dentinários (Bondlite, Dentin Adhesit, Dentin Adhesive, Scotchbond, Sinterfil), em cavidades padronizadas preparadas em dentes molares humanos extraídos, com as margens estabelecidas ao nível de esmalte, na junção cemento-esmalte e no cemento. Os dentes restaurados foram submetidos à ciclagem térmica a $5^{\circ} \mathrm{C}-55^{\circ} \mathrm{C}$, em uma solução de fucsina básica a $0,5 \%$ durante 30 minutos, perfazendo um total de 125 ciclos. Os dentes foram seccionados, fotografados com um aumento de 1,5 vez e submetidos a três avaliadores que classificaram o grau de microinfiltração. A análise estatística permitiu concluir que: os agentes adesivos dentinários não reduzem a microinfiltração em torno de restaurações de resina composta nas margens de cavidades situadas na junção cemento-esmalte, comparativamente àquelas situadas em esmalte e cemento. A microinfiltração foi efetivamente reduzida enquanto materiais com coeficientes de expansão térmica próxima ao do esmalte foram utilizados.

CRIM, G.A. e GARCIA-GODOY, G.F. ${ }^{27}$, em 1987, investigaram e compararam os efeitos do tempo de ciclagem térmica sobre a microinfiltração em restaurações com resina composta empregando agentes de união. Prémolares humanos extraídos foram usados para realizar preparos cavitários de 
classe $\mathrm{V}$ no terço cervical das faces vestibulares e linguais, ficando as margens em esmalte e com ângulo cavo-superficial em $90^{\circ}$, com os preparos submetidos ao condicionamento ácido por 1 minuto, lavados e restaurados com o sistema Prisma Bond e Prisma Fil. Cinco destes, contendo 10 restaurações, selecionados ao acaso para um dos testes dos seguintes métodos agruparamse em: (a) os dentes restaurados e imediatamente submetidos a 100 ciclos térmicos; (b) os dentes restaurados e imediatamente submetidos a 1.500 ciclos térmicos; (c e d) os dentes restaurados e armazenados em água/temperatura ambiente durante $24 \mathrm{~h}$ e então submetidos antes à ciclagem por 100 e 1.500 ciclos, respectivamente. Cada ciclo térmico consistia de $23 \mathrm{~s} / 37^{\circ} \mathrm{C}, 4 \mathrm{~s} / 54^{\circ} \mathrm{C}$, $23 \mathrm{~s} / 37^{\circ} \mathrm{C}$ e $4 \mathrm{~s} / 12^{\circ} \mathrm{C}$. Após a ciclagem os espécimes foram colocados em uma solução de fucsina básica por $24 \mathrm{~h}$. A análise dos resultados demonstrou que o tempo de armazenagem ou a duração de ciclagem não exerceram influência significativa sobre os padrões de microinfiltração. O tempo de ciclagem não revelou diferença estatisticamente significante a curto ou longo prazo.

RETIEF, D.H. ${ }^{74}$, em 1987, fez uma análise dos sistemas adesivos utilizados na época com a finalidade de verificar se efetivamente eram capazes de prevenir a microinfiltração. Para tanto recorreu a pesquisas por ele realizadas e aos dados disponíveis na literatura, donde concluiu que: (1) o ataque ácido do esmalte eliminou efetivamente a microinfiltração das restaurações com resina composta, desde que esmalte remanescente estivesse presente particularmente nos limites gengivais das restaurações; (2) as restaurações com cimento de ionômero de vidro poderiam apresentar infiltrações marginais tanto nas margens de esmalte como de cemento; (3) 
embora os mais recentes agentes de união à dentina tivessem potencial para prevenir a microinfiltração, outros estudos adicionais se fariam necessários para caracterizar isto.

VIEIRA, L.C.C. ${ }^{99}$, em 1988, avaliou a capacidade de vedamento marginal proporcionada por cinco sistemas adesivos utilizando 40 dentes recém-extraídos, os quais receberam cavidades classe II M.O.D., com paredes gengivais de uma das caixas proximais localizadas em esmalte e a outra em dentina e/ou cemento. Assim, cinco grupos de oito dentes foram restaurados seguindo as instruções dos fabricantes e submetidos a tratamentos térmicos durante uma semana, em um total de 105 ciclos, variando a temperatura de $5^{\circ}$ $-55^{\circ} \mathrm{C}$. Durante o último ciclo foram colocados em uma solução de RodaminaB a $0,1 \%$, sendo em seguida lavados e seccionados para verificar o grau de infiltração. As margens de esmalte revelaram um melhor comportamento no que diz respeito ao vedamento marginal para os sistemas adesivos Glass Ionomer Liner / Scotchbond / P-30 e Bondlite / Herculite, quando comparados com o sistema Gluma / Lumifor. Nas margens de cemento o melhor comportamento foi atribuído ao sistema adesivo. Glass lonomer Liner / Scotchbond / P-30, quando comparado com os sistemas ARM / Adaptic e Gluma-Lumifor.

CRIM, G.A. ${ }^{24}$, em 1989, avaliou o tempo de armazenamento de dentes em 3 e 18 meses e a sua influência sobre os adesivos dentinários, sobre a superfície de dentina e a infiltração marginal. Foram utilizados 10 molares humanos extraídos armazenados em água destilada por três meses. Cavidades tipo classe $V$ foram preparadas nas faces vestibulares e linguais, 
com as margens em esmalte e em cemento e submetidas a ataque ácido por 15s e lavagem por 30s seguido de aplicação dos adesivos dentinários Scotchbond 2 ou Gluma e restauração com a resina composta Silux Plus. Os dentes foram submetidos à ciclagem térmica de 100 ciclos, sendo que cada ciclo consistiu em $23 \mathrm{~s} / 37^{\circ} \mathrm{C}, 4 \mathrm{~s} / 12^{\circ}, 23 \mathrm{~s} / 37^{\circ} \mathrm{C}$ e $4 \mathrm{~s} / 54^{\circ} \mathrm{C}$. O corante utilizado foi a fucsina básica por $24 \mathrm{~h}$ e os dentes cortados longitudinalmente e avaliados em microscopia de 50X de magnitude. O autor concluiu que não houve diferença estatisticamente significante quanto ao período de armazenagem e o grau de microinfiltração.

FITCHIE, J.G.et al. ${ }^{38}$, em 1990, restauraram cavidades tipo classeV (em forma de "V") de abrasão e erosão com margens gengivais em cemento ou dentina em 40 dentes pré-molares humanos extraídos, simulando cavidades de abrasão e erosão restaurados com os seguintes materiais: Tenure Bond / Prisma-Fill, Gluma Bond / Pekalux, Ketac-Fil (controle negativo) e Prisma-Fil (controle positivo). Todas as restaurações foram polidas com discos Sof-Lex e os dentes armazenados em água destilada e submetidos a termociclagem a $4^{\circ}$ $\mathrm{C}$ e $58^{\circ} \mathrm{C} / 1$ minuto cada com total de 100 ciclos. Os quatro grupos testados em intervalos de uma semana, seis meses e 1 ano para determinação da microinfiltração foram imersos em solução de cálcio ${ }^{45}$ radioativo na concentração de $0,1 \mathrm{mCi} / \mathrm{mL}$ por 2 horas; seguidamente lavados com detergente, cortados longitudinalmente e colocados sobre um filme periapical ultra-rápido por 17 horas para produção de auto-radiografias. Concluíram que Tenure Bond / Prisma-Fil e Gluma Bond / Pekalux permitiram maior infiltração que os cimentos de ionômero de vidro Ketac-Fil. Os adesivos dentinários 
Tenure e Gluma mostraram infiltração marginal entre a resina composta e a interface cemento-dentina, nos três intervalos de tempo de uma semana, cinco meses e 1 ano.

KANCA, J. ${ }^{50}$, em 1991, teve o propósito de avaliar a microinfiltração e a força de adesão em 20 molares humanos extraídos, com cavidades circulares de $4 \mathrm{~mm}$ de diâmetro e $2 \mathrm{~mm}$ de profundidade, divididos em dois grupos: um grupo foi restaurado com Dual-Cure Scotchbond e Silux Plus, sendo o esmalte condicionado por 15 s e o segundo grupo, com o esmalte e a dentina condicionada por 20s, lavados por 30s e secos com ar comprimido, sendo as cavidades restauradas com Silux. As restaurações receberam polimento com discos Sof-Lex, sendo os dentes submetidos à ciclagem térmica de $5^{\circ} \mathrm{C}$ e $55^{\circ} \mathrm{C} / 30$ s cada, com total de 500 ciclos e imersão em solução aquosa de fucsina básica a 0,5\%, lavados, cortados e avaliados em um microscópio de $40 \mathrm{x}$ de magnitude. Em outros vinte dentes foram avaliadas as forças de adesão produzidas pelo adesivo Dual-Cure Scotchbond e resina composta P-50 em uma máquina de testes universal Instron com velocidade de $0,05 \mathrm{~cm} / \mathrm{min}$. O autor concluiu que os grupos experimentais tiveram menor infiltração marginal que o grupo controle (Scotchbond 2). Os grupos experimentais obtiveram maior força de adesão que o grupo controle.

MIXSON, J.M. et al ${ }^{64}$, em 1991, avaliaram a infiltração marginal em dentes seccionados em duas partes e em diversas partes e compararam também cavidades tipo classe V tipo caixa e em forma de "V". Para tanto utilizaram 20 dentes terceiros molares humanos extraídos, com cavidades abertas com broca carbide nำ169 nas faces mesial e distal de cada dente, em 
forma de "V", tendo $3 \mathrm{~mm}$ de altura, $5 \mathrm{~mm}$ de distância V-L e $3 \mathrm{~mm}$ de profundidade. As cavidades em forma de caixa tinham três $\mathrm{mm}$ de altura, 6 $7 \mathrm{~mm}$ de distância V-L e $3 \mathrm{~mm}$ de profundidade. A parede oclusal ficava em esmalte, onde foi feito um bisel de $0,5 \mathrm{~mm}$, com a parede gengival ficando em cemento. As cavidades receberam condicionamento ácido e adesivo Dual Cure Scotchbond (P30) ou Scotchbond $2(\mathrm{P}-50)$ e acabamento com pontas diamantadas e discos Sof-lex. Os espécimes receberam ciclagem térmica de $5^{\circ} \mathrm{C}$ a $55^{\circ} \mathrm{C} / \mathrm{com} 30$ s cada banho, por 100 ciclos, sendo imersos em solução de nitrato de prata e em seguida cortados no sentido V-L em duas partes e em 6 partes (central, lateral, final) e avaliados em microscopia com 30X de magnitude. A análise estatística demonstrou diferença significante na microinfiltração dos dentes cortados em 2 partes e em múltiplas partes (final) em cavidades em forma de "V" e Scotchbond 2 (P-50). A maior microinfiltração esteve presente no corte final das classes $\mathrm{V}$ tipo caixa e em "V".

NAKABAYASHI, N; NAKAMURA, M; YASUDA, N. ${ }^{67}$, em 1991, publicaram várias considerações sobre o sistema adesivo 4 META/MMA-TTB , a importância da hibridização dos tecidos dentais para alcançar alta resistência de união. Afirmaram que a camada híbrida é muito importante devendo sempre ser formada para minimizar a infiltração marginal, e que para a sua formação seria necessário que o colágeno não fosse desnaturado após o condicionamento ácido, fato este que produziria a diminuição da infiltração do adesivo na superfície da dentina descalcificada. Além disso, o ácido não deveria ser muito agressivo para que fibras colágenas não fiquem expostas abaixo da camada híbrida, determinando uma área dentinária enfraquecida e 
posterior degradação. Para a formação da camada híbrida ainda se faz necessário que o adesivo possua monômeros com ambos os grupos, hidrofílicos e hidrofóbicos, os quais penetrem a dentina e se combinem com a mesma; finalmente, o catalizador, como é o caso de TBB, deve propiciar continuidade da polimerização na presença de água e oxigênio, principalmente nas áreas dentinárias mais profundas, onde os túbulos são mais numerosos. Concluíram que a camada híbrida é uma zona ácida resistente, formada por um entrelaçamento de fibras colágenas e adesivo dentinário que sela a dentina reduzindo a microinfiltração, e assim previne problemas relacionados à hipersensibilidade e à cárie secundária.

TJAN, A.H.L. e TAN, D.E. ${ }^{95}$, em 1991, avaliaram as falhas da resina composta de baixa viscosidade no selamento marginal das restaurações e o resultado da contração de polimerização em 35 dentes terceiros molares humanos extraídos, onde realizaram cavidades classe $\mathrm{V}$ nas faces mesial e distal, com bisel na margem de esmalte de $45^{\circ}$ e $0,5 \mathrm{~mm}$. As cavidades foram condicionadas e restauradas com Bondlite e Herculite XR e o acabamento feito em discos Sof-Lex e os dentes divididos em sete grupos: grupo 1- sem resina composta intermediária; grupo 2- agente adesivo Visio Bond; grupo 3- agente adesivo Concise; grupo 4 agente adesivo Scotchbond Dual-Cure; grupo 5 Scotchbond 2; grupo 6- selante de fissura Concise e grupo 7- selante de fissura Concise ativada quimicamente. Os dentes, armazenados por sete dias e então submetidos a termociclagem a $5^{\circ} \mathrm{C}$ e $55^{\circ} \mathrm{C}$ 0,5 em solução aquosa de fucsina básica/ 30s em cada banho, foram lavados, cortados e analisados, demonstrando que as resinas compostas de baixa viscosidade, quando 
utilizadas como intermediária entre a dentina e a resina restauradora, reduzem o "gap" marginal e também, significantemente a microinfiltração marginal das margens gengivais das restaurações de resina composta.

ZYSKIND, D. et al. ${ }^{105}$, em 1991, avaliaram a infiltração marginal ao redor de cavidades em forma de "V" simulando aquelas formadas por abrasão ou erosão na vestibular e lingual de 20 dentes pré-molares. Estas, preparadas tinham uma margem em esmalte e outra em dentina/ cemento. Para restaurar foram usados três cimentos de ionômero de vidro e uma resina composta, sendo as superfícies condicionadas por ácido poliacrílico e restauradas com o cimento de ionômero de vidro segundo instruções dos fabricantes. Foram utilizados os cimento de ionômero de vidro: Ketac-Fil, Fuji II e Chemfil II e a resina composta Scotchbond / Silux. O acabamento e polimento das restaurações foram realizados com discos-abrasivos e os dentes armazenados em água destilada por 10 dias, sendo então submetidos a termociclagem, que consistiu em 250 ciclos a $4^{\circ} \mathrm{C}$ e $60^{\circ} \mathrm{C}$, seguido de imersão em solução de fucsina básica a $2 \%$ por $24 \mathrm{~h}$ e lavados. Os resultados demonstraram severa microinfiltração nas margens oclusal e de esmalte, pouca ou nenhuma infiltração na margem cervical. Ao redor das restaurações foi detectada infiltração marginal nos dentes testados, sendo esta maior no esmalte e nos cimentos de ionômero de vidro que na resina composta. Nenhum dos cimentos de ionômero de vidro mostrou superioridade quanto a prevenir a infiltração marginal.

AIROLDI, R.L., KREJCI, I e LUTZ, $\mathrm{F}^{1}$, em 1992, analisaram o efeito de dez agentes adesivos em restaurações de resina composta quanto a 
qualidade marginal antes e depois da termociclagem em 40 dentes pré-molares humanos extraídos onde foram realizadas 80 cavidades classe $\mathrm{V}$ por vestibular e lingual, em dimensões $3,0 \mathrm{~mm}$ mésio-distal, $2,5 \mathrm{~mm}$ vertical e $1,5 \mathrm{~mm}$ de profundidade e bisel de $12 \mathrm{~mm}$ na margem de esmalte. O acabamento foi feito com pontas diamantadas finas e, após 15 minutos, polimento com discos flexíveis e os dentes divididos em 10 grupos: grupo I-XR Bond + Herculite XR; grupo II-Tripton + Opalux; grupo III-Tenure + Marathon One; grupo IVRestabond 3 + Restalux; grupo V-Optec Pentra Bond II + Pentra-Fil; grupo VI Panavia Ex; grupo VII-Gluma + Pekalux; grupo VIII-Prisma Universal Bond 2 + Prisma APH; grupo IX: Kulzer Experimentell + Estilux e Grupo X-Syntac + Helioprogress. Restaurados e polidos os dentes foram submetidos a 2.500 ciclos a $5^{\circ} \mathrm{C}$ e $55^{\circ} \mathrm{C} / 2$ minutos cada banho. Foram feitas réplicas para análise em microscopia eletrônica de varredura e imersas em solução de 0,1 de fucsina básica por 20 horas. Concluíram que a adaptação marginal decresceu após a termociclagem nos grupos IV e V. Excelente margem foi observada nos grupos: X, VII, VIII, IX e III. A adaptação marginal inicial em dentina mostrou-se significantemente pior do que a do esmalte.

MIXSON, J. M. et $\mathrm{al}^{65}$, em 1992, estudaram a forma de cavidades e agentes adesivos que poderiam afetar a microinfiltração em dentes restaurados com resina composta em vinte dentes terceiros molares humanos extraídos com 20 cavidades tipo classe $\mathrm{V}$, preparadas em forma de caixa e em forma de "V". As cavidades foram restauradas com Dual Cure, Scotchbond e P30 ou Scotchbond 2 e resina composta P-50 e os dentes mantidos 7 dias em imersão para posterior acabamento com broca 884 e polimento com discos Sof-Lex. A 
seguir realizaram a termociclagem de 100 ciclos $/ 5^{\circ} \mathrm{C}$ e $55^{\circ} \mathrm{C} / 30$ s em cada banho, seguido de imersão dos espécimes em nitrato de prata a $50 \%$ por 2 horas, para posterior lavagem, corte e avaliação quanto à infiltração marginal. Não demonstrou diferença estatística significante entre o Dual Cure Scotchbond e Scotchbond 2, nas cavidades em forma de caixa. Nas cavidades em forma de "V" o Scotchbond 2 permitiu menor microinfiltração que o Dual Cure Scotchbond

SWIFT JR, E.J. e LE VALLEY, B. D. ${ }^{88}$ em 1992, avaliaram a "técnica de KANCA" com três adesivos dentinários utilizando o ataque ácido em esmalte e dentina para eliminar a infiltração marginal ao redor das margens da resina composta. Foram usados 60 molares humanos extraídos, com cavidades tipo classe $\mathrm{V}$ preparadas nas faces vestibulares dos molares com brocas $\mathrm{n}^{\circ} 56$, obtendo-se $2 \mathrm{~mm}$ de altura, $3 \mathrm{~mm}$ de largura e $1,5 \mathrm{~mm}$ de profundidade e bisel de $45^{\circ}$ no esmalte, realizado com uma ponta diamantada. Os dentes foram divididos em 6 grupos: grupo 1 (Scotchbond 2), as margens de esmalte foram condicionadas com ácido fosfórico gel a 37\% por 20s; grupo 2: (Tenure) o esmalte atacado por 20s; grupo 3: (Clearfil) esmalte e dentina condicionados por 15s; grupo 4: (Técnica Kanca) esmalte e dentina condicionados por 20s; grupo 5: (Técnica de Kanca sem o Scotchbond 2) esmalte e dentina condicionados por 20s; e grupo 6: (Técnica de Kanca sem o Tenure) esmalte e dentina condicionados por 20s. As cavidades restauradas com resina composta Silux foram polidas após 30 minutos, com brocas multilaminadas de 12 lâminas, sendo os espécimes armazenados por 24 horas em água destilada e submetidos à ciclagem térmica com 300 ciclos $/ 5^{\circ} \mathrm{C}$ e 
$55^{\circ} \mathrm{C} / 30$ s cada banho, sendo o corante usado o nitrato de prata a $50 \%$ por 2 horas. Os dentes foram cortados longitudinalmente e analisados não evidenciaram infiltração marginal no esmalte, embora a infiltração marginal estivesse presente nas margens gengivais dos grupos avaliados. A técnica de Kanca e o Tenure apresentaram maior efetividade entre os sistemas e grupos testados.

TAYLOR, M.J. e LYNCH, E92, em 1992, em uma revisão da literatura sobre vários métodos para demonstração da infiltração com materiais restauradores, analisaram dentre estes a pressão do ar, utilização de bactérias, radioisótopos, microscopia eletrônica de varredura, estudos eletroquímicos e análises de ativação de nêutrons, ciclagem térmica e mecânica, traçadores químicos e penetração de corantes na interface dente / restauração. Estes autores observaram que o uso de corantes para avaliar a microinfiltração constitui uma das técnicas mais utilizadas atualmente. Este método associado a secções do dente, permite analisar toda a extensão da interface do material restaurador e o dente, além de demonstrar a infiltração em cores contrastantes com as estruturas dentárias e o material restaurador sem a necessidade de reações químicas ou exposições a radiações maléficas.

TJAN, A. H. L94. em observação, em 1992, avaliaram os "microgap" nas paredes gengivais de restaurações classe II com diversas técnicas incrementais na colocação de resinas compostas. Foram usados 25 prémolares humanos extraídos com cavidades M.O. preparadas com a broca nำ245, bisel em esmalte de 0,5 a $1 \mathrm{~mm}$, realizado com uma ponta diamantada. Três técnicas incrementais foram testadas: primeira: colocação da resina em 
direção subgengival; segunda: camadas oblíquas e vestíbulo-lingual e duas técnicas de uma só vez, com a fotopolimerização em uma só camada por oclusal e terceira: uma camada só com fotopolimerização, por vestibular, lingual e oclusal. Para condicionamento o ácido gel foi por 30s e a lavagem das cavidades por 30 s, sendo as mesmas restauradas com a resina composta Visio-Molar. Concluíram que nenhuma das técnicas teve significante aumento na adaptação da margem gengival, comparando a técnica de uma só vez e fotopolimerizada por oclusal. A técnica de uma só vez, polimerizada por vestibular, lingual e oclusal permitiu aumento na margem (gap). A técnica de colocação da resina composta de uma só vez não é recomendada para restaurações de resina composta para classe II, especialmente em cavidades profundas.

WENDT, J.S.L. et $\mathrm{al}^{100}$, em 1992, fizeram estudos utilizando 50 dentes não cariados, onde foram preparadas cavidades M.O.D. restauradas com Scotchbond e resina composta P-50, com posterior acabamento e polimento realizados com brocas multilaminadas de 12 lâminas. Os dentes foram divididos em 5 grupos, sendo: o grupo A: sem termociclagem, armazenadas 24h em fucsina básica; grupo B: termociclagem de 250 ciclos/ 15 s cada banho em água/ $5^{\circ} \mathrm{C}$ e $50^{\circ} \mathrm{C}$ e armazenagem de 24 em fucsina básica; grupo C: termociclagem de 250 ciclos/ cada banho de 15 s em fucsina básica/ 5ํ e 50ํ․ grupo D: sem termociclagem, armazenagem de $4 \mathrm{~h}$ na fucsina básica e grupo E: termociclagem de 250 ciclos/ cada banho de $15 \mathrm{~s}$ em água destilada/ $5^{\circ} \mathrm{C}$ a $50^{\circ} \mathrm{C}$ e armazenagem de $4 \mathrm{~h}$ na fucsina básica. Concluíram que não houve aumento da microinfiltração quando as 
restaurações foram termocicladas em temperaturas extremas e armazenagem no corante ou em água. Nos grupo sem termociclagens o grau de infiltração foi menor, mas não estatisticamente significante. Todos os dentes dos grupos experimentais exibiram infiltração marginal.

CRIM, G. A. ${ }^{25}$ em 1993, avaliaram cinco resinas compostas e um ionômero de vidro quanto à infiltração marginal no período de 24h e 6 meses em dentes molares humanos extraídos com cavidades tipo classeV, preparadas com a broca carbide nำ170, com dimensões de $4 \mathrm{~mm}$ de distância mésio-distal, $2 \mathrm{~mm}$ ocluso-gengival e $1 \mathrm{~mm}$ de profundidade. $\mathrm{O}$ bisel curto de 0,5mm (com exceção dos dentes pertencentes ao grupo do ionômero de vidro) esteve presente no esmalte, mas não na margem gengival. Os dentes foram divididos em seis grupos de 10 espécimes, com as resinas compostas testadas: A.P.H., Z-100, Charisma e Bisfil M e o cimento de ionômeros de vidro foi o Fuji II LC, sendo a inserção dos restauradores realizada segundo as instruções dos fabricantes e o acabamento com discos e pastas polidora, após 15 minutos. Os dentes, armazenados por 24 horas em água destilada a $37^{\circ} \mathrm{C}$ receberam a ciclagem térmica de 100 ciclos de $23 \mathrm{~s} / 37^{\circ} \mathrm{C}, 4 \mathrm{~s} / 12^{\circ} \mathrm{C}, 23 \mathrm{~s} / 37^{\circ} \mathrm{C}$ e 4s/ 54ํㅡ. Após o que, metade dos grupos foram imersos em fucsina básica e cortadas longitudinalmente para avaliação. A outra metade dos espécimes permaneceu em água destilada a $37^{\circ} \mathrm{C}$ e a cada 30 dias recebeu uma ciclagem térmica de 100 ciclos e retornavam para o banho em água destilada, por um período de seis meses. Concluiu que não houve diferença estatística nas margens do esmalte em 24h e 6 meses; quanto às margens de dentina/cemento não demonstraram diferença em 24h, mas em 6 meses houve 
aumento da infiltração marginal para as resinas compostas $\mathrm{APH}$, Charisma e Bisfil M.

CRIM. G.A ${ }^{26}$ em 1993, analisou o selamento de dois ionômeros de vidro fotopolimerizáveis e convencional em cavidades tipo classe $\mathrm{V}$, preparadas nas faces vestibular e lingual de molares humanos extraídos, com a broca carbide $\mathrm{n}^{\circ} 170$, tendo $4 \mathrm{~mm}$ de comprimento, por $2 \mathrm{~mm}$ de altura, e $90^{\circ}$ com 0 ângulo cavo-superficial. Restaurados os dentes foram divididos em cinco grupos: grupo 1: cavidades restauradas com Fuji II LC; grupo 2: com cimentos de ionômeros de vidro Variglass; grupo 3: com o Fuji II; grupo 4: igual o grupo 2, excetuando pelo esmalte que não sofreu condicionamento ácido e grupo 5: pequeno bisel de $0,5 \mathrm{~mm}$ a $0,75 \mathrm{~mm}$. Os dentes sofreram termociclagem a $12^{\circ} \mathrm{C}$ e 54ํㅡ sendo imersos em fucsina básica por 24 horas e cortados longitudinalmente em sentido vestíbulo/lingual. Os resultados demonstraram manchas e fendas no esmalte adjacente ao Variglass. Em todos os casos houve infiltração marginal que penetrou nas fendas do esmalte e progrediu até a junção amelodentinária. A adição de um bisel no esmalte eliminou as fendas.

DAVIS, E.L. et $a^{31}$, em 1993, avaliaram a força de cisalhamento e a microinfiltração de três ionômeros de vidro ativados por luz visível e um ionômero de vidro ativado quimicamente em 24 terceiros molares humanos extraídos com cavidades tipo classe $\mathrm{V}$, nas faces vestibular e lingual, com uma broca $n^{0} 56$. Os restauradores utilizados foram os cimentos de ionômeros de vidro: Geristore, Vitrebond e Zionomer e Ketac-Bond e a resina composta posterior P50, de forma incremental com acabamento e polimento com discos Sof-Lex e, após 72 horas de armazenagem em água destilada, a ciclagem 
térmica, que consistiu de 1500 ciclos $/ 4^{\circ} \mathrm{C}, 37^{\circ} \mathrm{C}, 54^{\circ} \mathrm{C}$ e $37^{\circ} \mathrm{C} / 15$ segundos cada linha. Os dentes foram imersos em fucsina básica a 2\% por 24 horas, lavados, cortados e avaliados permitindo concluir que não houve significância estatística na força de adesão dos ionômeros de vidro e também não houve significância estatística quanto a microinfiltração entre os cimentos de ionômeros de vidro. Entretanto foi relatado que os espécimes tiveram mínima ou nenhuma microinfiltração.

HALLETT, K.B. e GARCIA-GODOY, F. ${ }^{49}$ em 1993, avaliaram dois ionômeros de vidro modificados por resina e compararam com dois outros convencionais quanto à sua infiltração marginal no esmalte e dentina/cemento. Os autores utilizaram 45 molares hígidos e com cavidades tipo classe $\mathrm{V}$, preparadas na vestibular e lingual, com a broca n 329 carbide. As cavidades tinham $5 \mathrm{~mm}$ de largura, $3 \mathrm{~mm}$ de altura e $2 \mathrm{~mm}$ de profundidade. Os preparos cavitários, restaurados com os cimentos de ionômeros de vidro convencionais Fuji II e Ketac-Fil e dois ionômeros de vidro modificados por resina Fuji II L.C. e Photac Fil, foram polidos e receberam a ciclagem térmica que consistia em $30 \mathrm{~s} / 6^{\circ} \mathrm{C}$ e $30 \mathrm{~s} / 60^{\circ} \mathrm{C} /$ por 1000 ciclos. Concluídos estes procedimentos, os dentes foram imersos em fucsina básica a $2 \%$ por 24 horas, sendo então lavados e cortados no sentido longitudinal vestíbulo-lingual. Concluíram que os cimentos de ionômeros de vidro modificados por resina infiltraram menos que os cimentos de ionômeros de vidro condicionais. A formação do "gap" para os cimentos de ionômeros de vidro foi limitada a parede axial das restaurações.

TAYLOR, M.J. e LYNCH, E. ${ }^{93}$, em 1993, fizeram uma revisão da literatura quanto à adaptação e grau de proximidade e inter-relação do material 
de preenchimento com a parede cavitária. Vários fatores influenciam na adaptação marginal com o preparo cavitário, tais como o seu tamanho e sua forma e também a influência da localização das margens da cavidade (esmalte, dentina ou cemento). A colocação do material vai determinar uma adaptação interna e externa. Pode ser usada uma forma incremental do material e esta pode ser paralela às paredes cavitárias ou oblíqua às mesmas. Também influenciam nos resultados a escolha do material e o método de ativação, bem como o forramento usado sob o material restaurador e os efeitos dos métodos de acabamento e polimento do material restaurador. Para tais experimentos podem ser usados métodos "in vivo" e "in vitro". "In vivo" aceita-se três graus de categorias como resultado: clinicamente ideal, clinicamente aceitável e clinicamente inaceitável. "In vitro" podem ser usados modelos, fotografias ou réplicas que podem ser examinados em microscopia eletrônica. Concluíram que os testes padrões usados em critérios qualitativos como a microscopia eletrônica de varredura, devem ser semelhantes aos testes padrões (critérios clínicos de Ryge) e da medida da abertura marginal.

BARNES et $\mathrm{al}^{8}$. em 1994, utilizaram 50 dentes, sendo 25 dentes anteriores e 25 dentes posteriores com cavidades convencionais tipo classe $\mathrm{V}$ na face vestibular e lingual. Os dentes foram condicionados por ácido fosfórico em gel a $40 \%$ por 60 s e depois de lavados por 20 s somente em esmalte, sendo aplicado o adesivo de esmalte e dentina Universal Bond 3 e restaurados com a resina composta APH Prisma, LD Caulk, de acordo com as instruções do fabricante. As restaurações foram polidas com discos Sof-Lex seqüenciais e pastas para polimento com taça de borracha e os espécimes submetidos à 
ciclagem térmica a $10^{\circ} \mathrm{C}$ a $50^{\circ} \mathrm{C} / 1$ minuto para cada ciclo/ 540 ciclos e imersão em solução de nitrato de prata. Os mesmos foram cortados com um disco diamantado em duas partes vestíbulo-lingual e examinados em um estereomicroscópio de poder de 25X. Não houve diferença estatisticamente significante entre a face vestibular e lingual de esmalte e cemento das superfícies dentárias, nem entre a metade mesial e distal, mas esta esteve presente entre a margem de esmalte e cemento, com menor infiltração marginal no esmalte e maior infiltração no cemento.

DAVIDSON, C.L. e ABDALLA, A.I. ${ }^{30}$, em 1994 fizeram um estudo para avaliar a infiltração marginal em cavidades classe $\mathrm{V}$ com restaurações de resina composta sem carga oclusal e com carga oclusal em primeiros e segundos molares inferiores com cavidades classe $\mathrm{V}$ na vestibular e lingual, com dimensão mésio-distal de 3,0mm, ocluso-gengival de $2,5 \mathrm{~mm}$ e profundidade de $2,5 \mathrm{~mm}$ realizados com a broca $\mathrm{n}^{\circ} 56$ e bisel de $45^{\circ}$ na margem de esmalte oclusal, com uma ponta diamantada. Os dentes foram divididos em oito grupos: grupo 1: Ketac-Fil; grupo 2: Fuji II LC; grupo 3: KetacBond / Pertac; grupo 4: Photac-Bond / Pertac; grupo 5: Scotchbond 2 / P50; grupo 6: Scotchbond Multi Purpose / P50; grupo 7: Clearfil Liner Bond / Clearfil Photo Posterior e grupo 8: Optibond / Herculite XR. As restaurações, polidas com disco Sof-Lex foram subdivididas em 3 grupos: A controle (sem carga), grupo B (carga de $125 \mathrm{~N}$ ) e grupo C (carga de $250 \mathrm{~N}$ ). Os dentes receberam ciclagem térmica de 5.000 ciclos, sendo imersos no corante azul de metileno a $2 \%$, após $24 \mathrm{~h}$. Os dentes lavados, cortados e analisados, permitiram concluir que no grupo controle só os grupos 2, 6, 7 e 8 mostraram perfeita integridade 
marginal. Após a carga de $125 \mathrm{~N}$ os grupos 1 , 3 e 5 mostraram significante aumento na microinfiltração. No grupo da carga de $250 \mathrm{~N}$ resultou em um significante aumento da infiltração marginal em todos grupos testados com exceção do grupo 6 e 7 e todos os grupos mostraram infiltração na parede gengival com escores de 0 a 4.

FERRARI, $M$ et $\mathrm{al}^{35}$, em 1994, investigaram a efetividade dos sistemas adesivos nas restaurações tipo classe $V$ na superfície do esmalte ou na superfície esmalte-cemento "in vivo" e "in vitro". Para os testes "in vivo" utilizaram 29 pacientes e os dentes: 20 incisivos, 14 caninos superiores e 6 caninos inferiores. Foram preparadas cavidades tipo classe $V$ com $3 \mathrm{~mm}$ de diâmetro e $2 \mathrm{~mm}$ de profundidade, restauradas com: Clearfil Liner Bond / Clearfil Ry, Gluma 200 / Pekafill, Gluma 2000 / Pekalux, Scotchbond MultiPurpose / Z 100. Os dentes foram polidos com discos Sof-Lex, e depois de três meses, extraídos, sendo armazenados, imersos em água destilada por sete dias e, logo a seguir, imersos na fucsina básica a $0,5 \%$ por $24 \mathrm{~h}$, para então serem lavados, cortados e avaliados. Nos testes "in vitro" foram usados 40 dentes incisivos com cavidades e restaurações seguindo os mesmos passos dos testes "in vivo". Após o acabamento das restaurações, os dentes receberam a ciclagem térmica de 250 ciclos $/ 5^{\circ} \mathrm{C}$ a $55^{\circ} \mathrm{C}$ em água/ cada banho de 15 s e imersão em fucsina básica a $0,5 \%$ por $24 \mathrm{~h}$, sendo posteriormente lavados, cortados e avaliados. Concluíram que não houve diferença estatística significante de infiltração marginal nos testes "in vivo" e "in vitro", nem entre os materiais testados. Os testes clínicos foram mais favoráveis aos materiais testados quanto a microinfiltração do que os testes laboratoriais. 
GILPATRICK, R.O. et al ${ }^{42}$, em 1994 avaliaram vários tempos de ataque ácido (fosfórico) e a infiltração marginal resultante nos períodos de 5s, 15s e 30s em 48 dentes pré-molares humanos extraídos e não cariados, nos quais foram realizadas cavidades tipo classe $\mathrm{V}$, circulares, com a broca $\mathrm{n}^{p 56}$, atingindo $3,0 \mathrm{~mm}$ de diâmetro e $1,5 \mathrm{~mm}$ de profundidade, com ângulo cavo superficial e bisel em esmalte realizados com brocas multilaminadas de 12 lâminas. Os dentes foram divididos em três grupos: grupo A: ataque ácido por 30s, grupo B: ataque ácido por 15s e grupo C: ataque ácido por 5s. Os dentes, lavados por 20s e secos por 20s, receberam aplicação do primer Scotchprep e o agente de união Scotchbond 2 em dentina e esmalte, sendo posteriormente restaurados com a resina composta Silux Plus. Os excessos foram retirados com brocas de acabamento e discos Sof-lex seqüenciais e os espécimes armazenados em água. Sofreram a ciclagem térmica em $4^{\circ} \mathrm{C}-58^{\circ} \mathrm{C} / 1$ minuto cada banho, sendo então os imersos em azul de metileno por 4 horas. Decorrido o tempo foram lavados e cortados longitudinalmente e analisados em microscopia de 20X de magnitude. Concluíram que a maior infiltração marginal ocorreu com o ataque ácido por 5 s e semelhante nos tempos de $15 \mathrm{~s}$ e 30 s. As paredes oclusal e gengival infiltraram mais que as sua homônimas mesial e distal, tendo-se por vantajosa a utilização do tempo de 15s para o ataque ácido no esmalte.

GWINNETT, A.J. e YU, S. ${ }^{47}$, em 1994, avaliaram o efeito da armazenagem em água nas restaurações com adesivo de dentina em 24h e 6 meses, quanto à força de adesão e a integridade marginal. Foram usados 40 dentes terceiros molares divididos em quatro grupos de 10 dentes e os 
adesivos All-Bond 2 e Amalgabond e a resina composta P-50 em uma matriz de PVC cilíndrica com uma área de $0,178 \mathrm{~cm}^{2}$. Em dois grupos os dentes estiveram imersos em água por 24 horas e os outros dois grupos por 6 meses, antes de medir a força de cisalhamento na máquina de testes Instron. Para avaliar a microinfiltração marginal, cavidades tipo classe $V$ com $3 \mathrm{~mm}$ de largura, $2 \mathrm{~mm}$ de profundidade e $2 \mathrm{~mm}$ de altura, com margens em esmalte (com bisel) e em cemento foram realizadas e restauradas com a resina composta P-50 e polidas com discos de Sof-Lex seqüencial. Os dentes foram armazenados por 24 h e 6 meses a $37^{\circ} \mathrm{C}$ em água destilada e então imersos em eosina a $37^{\circ} \mathrm{C}$ por 24 horas. Os espécimes foram moldados sendo as réplicas analisadas em microscopia eletrônica. Os dentes armazenados em 24h apresentaram maior força de adesão que aqueles armazenados por 6 meses, mas sem significância para a microinfiltração marginal no esmalte e no cemento Os maiores "gaps" estiveram presentes no assoalho das cavidades restauradas com o Amalgabond e menores com o All-Bond 2.

RETIEF, D.H. ${ }^{75}$, em 1994, relatou que todas a resinas compostas sofrem contração de polimerização resultando em forças de tensão e estresses na interface dente/restauração. A maior parte da contração de polimerização ocorreu nos primeiros 15 minutos após a iniciação da polimerização, porém com as resinas compostas ativadas por luz visível esta se deu segundos após a sua polimerização. $\mathrm{O}$ estresse dos adesivos da dentina ocorre nas paredes da cavidade resultando em microinfiltração na interface dente/restauração. As propriedades da resina composta, a contração de polimerização, diferentes coeficientes de expansão térmica entre o dente e a restauração, a absorção de 
água determinam a dimensão do "gap" e a microinfiltração. Nas paredes de esmalte o condicionamento ácido e o bisel puderam eliminar a microinfiltração na margem gengival estendida abaixo da junção cemento/esmalte. A microinfiltração pode ser reduzida pela técnica incremental, porém esteve aumentada quando os dentes receberam o estresse mastigatório ou a carga oclusal. O tamanho da cavidade em área e volume tem significante influência na dimensão do "gap" marginal. O acabamento e polimento das restaurações reduziram significantemente as dimensões das fendas marginais permitindo uma melhor adaptação marginal.

RETIEF, D.H. et al ${ }^{76}$, em 1994, tiveram o propósito de determinar a relação entre a força de cisalhamento dos sistemas adesivos à dentina e a quantidade de microinfiltração nas restaurações em 115 corpos de prova, utilizando os seguintes materiais: (A) All-Bond/Bisfil-P; (B) Syntac/Heliomolar; (C) XR-Bond/Herculite; (D) Scotchbond 2/Silux; (E) Denthesive/Charisma; (F) Prisma Universal Bond 2/Prisma APH e (G) Tenure/Perfection. Para os testes de cisalhamento foram usados primeiros e segundos molares humanos extraídos e uma máquina Instron Modelo 1011, com a velocidade de $0,5 \mathrm{~mm} /$ minuto, sendo a força de cisalhamento expressa em MPa. Para os testes de microinfiltração em caninos e pré-molares, com cavidades classe $\mathrm{V}$ sem bisel, realizadas na face vestibular dos dentes, com 3mm de diâmetro e $1,5 \mathrm{~mm}$ de profundidade, foram utilizados dois incrementos para realizar as restaurações, sendo o acabamento dado com broca de 12 lâminas e disco de Sof-lex, após $15 \mathrm{~min}$ a polimerização. Os dentes receberam a ciclagem térmica de 500 ciclos no azul de metileno a $2 \% / 8^{\circ} \mathrm{C}$ a $50^{\circ} \mathrm{C} /$ cada banho a $15 \mathrm{~s}$. A 
quantidade de infiltração marginal foi determinada pelo método de Douglas \& Zakariasen em $\mu \mathrm{g}$, sendo a força de cisalhamento capaz de reduzir a microinfiltração próxima de zero, $\pm 21 \mathrm{Mpa}$.

SIDHU, S. K ${ }^{85}$, em 1994 avaliou a capacidade de selamento marginal de um ionômero de vidro ativado quimicamente e dois ionômeros de vidro ativado por luz visível, utilizando 30 dentes humanos extraídos, com cavidades cilíndricas de $2 \mathrm{~mm}$ de diâmetro e $1,5 \mathrm{~mm}$ de profundidade e com todas as margens terminando em dentina, realizadas na face vestibular. Três grupos foram estabelecidos: grupo 1, cavidades restauradas com cemento de ionômero de vidro quimicamente ativado Fuji Cap II; grupo 2: restauradas com cimentos de ionômeros de vidro Fuji II L.C. e o grupo 3: restauradas com cimento de ionômero de vidro Variglass VLC. Nos grupos 2 e 3 os cimentos de ionômeros de vidro foram polimerizados por luz visível e as restaurações realizadas segundo as instruções dos fabricantes, sendo polidas com discos Sof-lex após 24 horas. Os dentes receberam, na seqüência, a ciclagem que consistiu em 1500 ciclos/ $5^{\circ} \mathrm{C}$ e $55^{\circ} \mathrm{C} / 30$ s cada banho, sendo imersos em fucsina básica por 24 horas. O grupo controle Fuji Cap. II teve um "gap" de $25 \mu \mathrm{m}$, enquanto que o Fuji II V.L.C. alcançou "gap" de $8 \mu$, e a Variglass $10 \mu \mathrm{m}$, mas não houve diferença estatística significante entre os grupos testados.

FITCHIE, J. G. et al ${ }^{39}$, em 1995, avaliaram "in vitro" a microinfiltração em cavidades classe V utilizando 20 dentes incisivos humanos extraídos e 20 incisivos bovinos extraídos e testado o adesivo Syntac. As cavidades tipo classe $\mathrm{V}$ preparadas possuíam $2 \mathrm{~mm}$ de profundidade, $3 \mathrm{~mm}$ mésio-distal e 2mm inciso-gengival, com margem incisal de esmalte com bisel 
de $1 \mathrm{~mm}$ com $45^{\circ}$ de inclinação. Os dentes foram armazenados em água destilada até o momento da restauração, sendo realizado o ataque ácido por 30s somente no esmalte, com lavagem por 30 s, aplicação do sistema adesivo Syntac (primer e adesivo) e a resina composta Heliomolar ou APH, preparadas de acordo com as orientações dos fabricantes. O polimento foi realizado com disco Sof-lex, com posterior armazenagem dos espécimes em água destilada por sete dias. Decorrido este tempo passaram pela ciclagem térmica com 100 ciclos $/ 4^{\circ} \mathrm{C}-58^{\circ} \mathrm{C} / 1$ minuto em cada banho foram imersos no $\mathrm{Ca}^{45}$ radioisópo por 2 horas, sendo então seccionados e analisados. Não houve diferença estatisticamente significante entre o substrato dos incisivos humanos $\mathrm{e}$ incisivos bovinos. O sistema adesivo Syntac /APH teve menor infiltração marginal do que o sistema Syntac / Heliomolar na margem gengival (dentina) dos dentes bovinos, mas esta diferença não é estatisticamente significante. A melhor adesão evidenciada foi no esmalte.

KÖPRÜLÜ, H. et al. ${ }^{53}$, em 1995, fizeram um trabalho de pesquisa utilizando 40 dentes pré-molares extraídos com cavidades tipo classe $\mathrm{V}$ de $3 \mathrm{~mm}$ de diâmetro e $1,5 \mathrm{~mm}$ de profundidade, nas faces vestibular e lingual. As cavidades foram realizadas com broca carbide em alta-rotação e o limite cemento e o ângulo cavo-superficial em 90ํㅡㄴ sendo quatro grupos de 10 preparos cavitários restaurados com cimento de ionômero de vidro Fuji II LC, de acordo com o fabricante, porém de duas maneiras: $1^{\mathrm{a}}$ com matriz cervical e $2^{\mathrm{a}}$ com instrumentos de mão. Na técnica de colocação das camadas as restaurações foram divididas em quatro grupos: a) imersão da resina composta de uma só vez; b) colocação vertical dos incrementos; c) a colocação da resina 
composta é de forma incremental, sendo primeiramente colocada à resina composta na face cervical e d) colocação da resina composta em camadas, sendo a primeira na parede oclusal, utilizando sempre duas camadas de resina composta. Após $24 \mathrm{~h}$ estas foram polidas com discos Sof-lex e submetidas a termociclagem a $5^{\circ} \mathrm{C}-55^{\circ} \mathrm{C} / 100$ ciclos e imersão em fucsina básica a $0,2 \%$ por 24 h. Decorrido este tempo os dentes foram lavados e cortados longitudinalmente no sentido vestíbulo-lingual. A análise estatística dos resultados permitiu observar que não houve diferença estatisticamente significante entre os grupos e as técnicas aplicadas, quanto à infiltração marginal.

PACHUTA, S.M. e MEIERS, J.C. ${ }^{69}$ em 1995, utilizaram 40 dentes molares humanos extraídos e não cariados, com cavidades classe $\mathrm{V}$ realizadas com a broca carbide $n^{\circ} 57$, foram divididos em 4 grupos com 10 dentes: grupo 1: a dentina não sofreu nenhum tratamento; grupo 2: dentina condicionada com GC Dentin Conditioner (ácido poliacrílico a 10\%) por 20s e lavagem com água/ 30s; grupo 3: ProBond primer 30s em dentina e secagem com ar comprimido e grupo 4: GC Dentin Conditioner e ProBond adesivo/ fotopolimerização/ 20s. As restaurações com Fuji II LC, ionômero de vidro modificado por resina composta foram realizadas com o auxílio de uma seringa Centrix e o polimento com discos Sof-lex, médio, fino e superfino. Os dentes, armazenados em água destilada por 24 horas e submetidos à ciclagem térmica por 1000 ciclos em água destilada por $5{ }^{\circ} \mathrm{C}-55^{\circ} \mathrm{C} / 30$ s cada banho foram imersos na fucsina básica a $0,5 \%$, por 24 horas, depois lavados, cortados em direção vestíbulo-lingual e avaliados em um estereomicroscópio com 
magnitude de 10X. Não houve diferença estatisticamente significante entre os diversos tratamentos da dentina, tanto na margem de esmalte ou de dentina, quanto à infiltração marginal. Houve excelente adaptação entre o ionômero de vidro e dentina nos diversos tratamentos dos grupos executados.

ROSSOMANDO, K.J. e WENDT, S. L ${ }^{78}$, em 1995, usaram 90 dentes terceiros molares humanos extraídos com preparo cavitário tipo classe $\mathrm{V}$, com $2 \mathrm{~mm}$ de diâmetro cemento/esmalte e $2 \mathrm{~mm}$ de profundidade, preparado com a broca 245 e condicionamento com ácido fosfórico a 37\% / 15s e lavagem por 20s. Os materiais utilizados foram Tytin / Liner F, APH / Universal Bond 3 e Heliomolar / Syntac, sendo os dentes restaurados divididos em grupos: A) imersos em fucsina básica a 0,5\% por 168 h (sete dias); B) termocicladas com 5.000 ciclos na fucsina básica a $0,5 \% / 5^{\circ} \mathrm{C}-55^{\circ} \mathrm{C} / 10$ s cada banho; grupo $\mathrm{C}$ : termociclagem igual ao grupo B com o tempo de banho de 60s. Não houve diferença estatisticamente significativa entre os grupos que sofreram a termociclagem ou não, porém constataram que foi significante a extensão da infiltração marginal na interface dente/restauração nos dentes não termociclados e termociclados, respectivamente. $O$ tempo de 10 s de permanência nos banhos colaborou para que houvesse condução térmica na restauração.

SALAMA, F.S. et a ${ }^{80}$, em 1995, realizaram um estudo "in vitro" com 30 pré-molares humanos hígidos com cavidades tipo classe $\mathrm{V}$, preparadas nas faces vestibulares, tendo dividido-os em três grupos de 10 dentes, segundo os materiais restauradores: grupo 1: ionômero de vidro Photac-Fil; grupo 2: Vitremer e o grupo 3: Variglass VLC. Todos foram aplicados segundo as 
instruções dos fabricantes. Os dentes foram imersos em azul de metileno $5 \%$ por 4 horas, lavados, cortados longitudinalmente em direção vestíbulo-lingual com um disco diamantado e avaliados em um estereomicroscópio de magnitude de 32x. A ausência da termociclagem "in vitro" não preveniu a microinfiltração e que não houve diferença significante de infiltração marginal entre as paredes oclusal e gengival. O ionômero de vidro ativado por luz visível Variglass apresentou menor microinfiltração.

SANO, H. et al ${ }^{81}$, em 1995 , estudaram a microinfiltração no que tange à quantidade da magnitude do movimento da molécula corada através de fendas entre os materiais restauradores e a parede da cavidade preparada. $\mathrm{O}$ presente estudo examinou a migração do nitrato de prata na interface dentina e cinco diferentes adesivos dentinários com análise por microscopia eletrônica de varredura. Para tanto foram selecionados terceiros molares humanos com preparos cavitários tipo classe $V$ com 2,5mm de altura, 2,5mm de largura e 1,5$2 \mathrm{~mm}$ de profundidade. O esmalte e a dentina foram condicionados simultaneamente, lavados e submetidos a sucessiva aplicação de primer e dos adesivos dentinários: All-Bond 2, Superbond C \& B, Scotchbond Multi-Purpose, Clearfil Liner e KB 200 e a resina composta Silux, cada um compondo um grupo experimental. Os espécimes foram imersos em nitrato de prata por 24 horas, após a impermeabilização dos mesmos, com posterior lavagem, corte longitudinal com um disco diamantado em baixa velocidade e então exame por microscopia eletrônica de varredura. Por ordem decrescente a microinfiltação demonstrada foi: All-Bond 2, Superbond, Scotchbond, Clearfil Liner, Bond System e KB-200. O termo nanoinfitração ficou designado para distinguir este 
tipo especial de microinfiltração dentro da camada basal na região porosa da camada híbrida com formações de fendas.

TAY, F.R. et al ${ }^{90}$, em 1995, avaliaram um método para averiguação da microinfiltração ao longo da dentina e a interface da restauração em terceiros molares não cariados com preparos cavitários tipo classe $\mathrm{V}$, na vestibular e lingual, com $4 \mathrm{~mm}$ de diâmetro e bisel de $45^{\circ}$ no esmalte e sem bisel na margem dentina/cemento. As cavidades foram restauradas com All Bond 2 / P-50 e Scotchbond 2 / Silux, de acordo com as instruções dos fabricantes. Os espécimes permaneceram sete dias armazenados em água destilada a $37 \%$ sendo então submetidos à ciclagem térmica com 300 ciclos / $5^{\circ} \mathrm{C}+$ ou $-55^{\circ} \mathrm{C} /$ cada banho de 1 minuto de duração seguido de imersão em solução de nitrato de prata por 2 horas. Lavados por 10 minutos foram reimersos em uma solução de metil salicilato e expostos à luz fluorescente por 6 horas para completar a redução dos íons prata. A microinfiltração não foi uniforme na circunferência da restauração marginal e a analise estatística não foi significante, nem antes nem depois da desmineralização

YAP, A.U.J. et $\mathrm{al}^{103}$, em 1995, realizaram um trabalho utilizando 36 dentes pré-molares extraídos por motivos ortodônticos, com cavidades tipo classe $\mathrm{V}$ preparadas na vestibular, com $3 \mathrm{~mm}$ de distância vestibulo-lingual e $2 \mathrm{~mm}$ de profundidade. Os mesmos foram divididos em três grupos de 12 dentes: o grupo 1: restaurados com o compômero Dyract; o grupo 2: com resina composta TPH e adesivo Probond e o grupo 3: com o cimento de íonômero de vidro modificado por resina Fuji II LC. Os materiais foram manipulados de acordo com o fabricante e polimento realizado com brocas 
multilaminadas (de 12 lâminas) e discos Sof-Lex, com posterior imersão dos espécimes em uma solução salina isotônica. Ciclagem térmica a $5^{\circ} \mathrm{C}-65^{\circ} \mathrm{C}$ e imersão em fucsina básica a $0,5 \%$ por 24 horas a $37^{\circ} \mathrm{C}$ foram os procedimentos subseqüentes. Os dentes foram seccionados na direção vestíbulo-lingual e avaliados em um estereomicroscópio com 40X de magnitude. Os três materiais não revelaram significância estatística em relação aos selamentos sobre a dentina. A resina composta permitiu menor infiltração marginal que o compômero e o cimento de ionômero de vidro, em relação à margem de esmalte. $O$ selamento marginal dos três materiais foram significantemente piores na dentina que no esmalte.

APPLEQUIST, E.A. e MEIERS, J. C. ${ }^{4}$, em 1996, avaliaram a contração de polimerização nas margens de restaurações, levando em conta uma diminuição de sua longevidade. Para tanto selecionaram 30 dentes molares humanos extraídos com cavidades preparadas de $2 \mathrm{~mm}$ de profundidade, $3 \mathrm{~mm}$ de altura e $4 \mathrm{~mm}$ de largura; o preparo foi realizado com a broca carbide n 330 nas faces mesial e distal de cada dente. Cada grupo consistiu de 20 preparos sendo o grupo 1 restaurado com resina composta em camadas; o grupo 2 com resina composta e "beta-quartz insert" e o grupo 3 com resina composta e bolas prepolimerizados "insert". O adesivo de dentina Syntac e a resina composta Heliomolar também foram usados e o acabamento desta última foi obtido com pontas diamantadas microfinas e discos Sof-lex médio, fino e superfino. Os dentes passaram pela ciclagem térmica de $5^{\circ} \mathrm{C}$ $55^{\circ} \mathrm{C} / 30$ s cada banho/ 1.000 ciclos e então imersos em fucsina básica a 0,5\% por 24 horas, sendo lavados, cortados e examinados em microscopia de 20x 
de aumento. As restaurações com bolas de resina composta prepolimerizada exibiram maior microinfiltração do que as restaurações com "beta-quartz insert" ou técnica incremental.

ATTIN, T. et $\mathrm{al}^{7}$, em 1996, avaliaram a força de adesão em três ionômeros de vidro modificados com resina composta (Fuji II LC, Vitremer, Photac-Fil), três resinas compostas modificadas por poliácidos (Variglass VLC, Dyract, lonosit Fil), a resina composta híbrida (Blend-a-lux) e o ionômero de vidro Chemfil Superior.Os testes incluíram as forças de adesão em dentes não condicionados e em dentes condicionados com ataque ácido. Foram usados 80 dentes bovinos, armazenados por uma semana antes dos testes em 0,9 de cloreto de sódio, porém nos grupos de ionômero de vidro modificado com resina, resina composta modificada por poliácidos, resina composta híbrida e o ionômero de vidro ativado quimicamente, o esmalte foi condicionado com ácido fosfórico a $37 \%$, enquanto que o ácido poliacrílico foi o condicionador estabelecido para o ionômero de vidro modificado por resina e o ionômero de vidro Chemfil Superior. A força de adesão foi mensurada através de uma máquina universal de testes. Com exceção do Chemfil Superior, todos os materiais obtiveram força de adesão maior no esmalte condicionado que no esmalte não condicionado bem como com as resinas compostas modificadas por poliácidos e condicionadas com ácido fosfórico a 37\%.

BOUSCHLICHER, M.R. et $\mathrm{al}^{10}$, em 1996, utilizaram 50 terceiros molares humanos extraídos com preparos cavitários tipo classe $\mathrm{V}$, na face vestibular e lingual, de $3 \mathrm{~mm}$ de diâmetro, $2 \mathrm{~mm}$ de altura e $2 \mathrm{~mm}$ de profundidade, divididos em cinco grupos, segundo o material restaurador, a 
saber: grupo 1: Fuji II LC; grupo 2: Vitremer; grupo 3: Photac-Fil Aplicap; grupo 4: Ketac-Fil e grupo 5: foi restaurado com o Silux Plus. Estabeleceram três ionômeros de vidro híbridos, um cimento de ionômero de vidro e uma resina composta. Restaurados os dentes foram armazenados por 24 horas, polidos com discos Sof-lex e submetidos à ciclagem térmica de 300 ciclos $/ 5^{\circ} \mathrm{C}-55^{\circ} \mathrm{C} /$ 30s cada banho, sendo dez restaurações de cada grupo selecionadas para serem secas com ar comprimido simulando o tempo de espera que a restauração permanece seca pelo uso do isolamento absoluto. Após o dessecamento os espécimes foram imersos em água destilada a $37^{\circ} \mathrm{C}$ por 24 horas e a seguir no corante de nitrato de prata por $2 \mathrm{~h}$. Houve um aumento da microinfiltração no grupo dos dentes que sofreram a dessecação. O Fuji II LC não mostrou diferença significativa entre o grupo controle e o grupo dessecado. Os dentes restaurados com o Vitremer, Photac-Fil, Silux Plus e Ketac-Fil tiveram um aumento de microinfiltração nos dentes dessecados, mas não estatisticamente significante.

CAMPS, J. et al. ${ }^{14}$, em 1996, compararam a microinfiltração de agentes adesivos em dentes recém-extraídos, dentes preservados e dentes armazenados em água a $4^{\circ} \mathrm{C}$ contendo cloramina. Foram usados 80 dentes terceiros molares humanos extraídos divididos em três grupos: grupo 1: dentes extraídos e coletados há 2 horas; grupo 2: dentes preservados em solução salina a $4^{\circ} \mathrm{C}$ por 4 horas e grupo 3: dentes refrigerados e armazenados a $4^{\circ} \mathrm{C}$, após 12, 48 , 127 e 138 dias. As cavidades tipo classe $\mathrm{V}$ de forma retangular, nas faces vestibular e lingual, foram obtidas com a broca carbide $\mathrm{n}^{\circ} 56$, adquirindo a dimensão de $4 \mathrm{~mm}$ de mesial para distal, $3 \mathrm{~mm}$ da coroa para 
apical e 1,5mm de profundidade e os restauradores testados: o Scotchbond Multi-Purpose, a resina composta Z 100 e Gluma 2.000 e a resina composta Pekafill. Após o acabamento obtido com discos Sof-lex, os dentes foram submetidos a termociclagem de 100 ciclos $/ 4^{\circ} \mathrm{C}-55^{\circ} \mathrm{C} / 30$ s cada banho, posteriormente imersos na solução de nitrato de prata a $50 \mathrm{WT} \%$, cortados longitudinalmente com um disco diamantado e examinados em microscopia de $50 \mathrm{X}$ de magnitude. Os dentes armazenados e refrigerados a $4^{\circ} \mathrm{C}$ por 12 dias não revelaram alterações na microinfiltração, entretanto os dentes armazenados e refrigerados por 48 dias ou mais apresentaram aumento da infiltração marginal.

CARVALHO, R.M. et $\mathrm{al}^{15}$, em 1996, relataram que as resinas compostas apresentavam forças de contrações de polimerização e forças de adesão à estrutura dentária. Assim, o grau de stress deverá ser controlado pela forma da cavidade (fator $\mathrm{C}$ ), uso de bases, tamanho, posição e incrementos de resina composta colocadas na cavidade e a resina quimicamente ativada e ativada por luz visível. Nas resinas compostas quimicamente ativadas o fator $\mathrm{C}$ tende a ser menor, pois tem um tempo maior de absorção de água causando uma expansão volumétrica que compensa a contração de polimerização. 0 fator $\mathrm{C}$ foi definido como sendo diretamente proporcional às superfícies aderidas e inversamente proporcional às superfícies livres. Em uma cavidade de duas ou mais paredes a resina "flow" fica limitada aumentando o stress geral da superfície aderida. Durante a polimerização poderá ocorrer ruptura da adesão do cemento (mais comum que a de esmalte) permitindo a entrada de bactérias na superfície dentinária e produtos que possam irritar a polpa 
dentária. O fator $\mathrm{C}$, em geral em classe II e classe III utilizando resina composta, mensurado foi aproximadamente 1,0 a 2,0, em classe $V$ foi menor que 1,0, e em classe I foi aproximadamente 5,0. Para termos uma boa adesão de dentina, as forças de contração de polimerização devem ser minimizadas e as forças de adesão dentinária devem ser maximizadas. Os autores recomendam um adesivo com forças de adesão semelhantes ao esmalte e cemento, uso de uma base antes da resina composta e a utilização da resina composta na técnica incremental.

CASTELNUOVO, J. et $\mathrm{al}^{16}$., em 1996, avaliaram a microinfiltração em cavidades tipo classe V em forma de "V" comparando materiais adesivos de vários frascos, com materiais adesivos de um só frasco em 30 dentes molares inferiores humanos extraídos, com preparos cavitários na mesial e distal. As cavidades possuíam dimensões $4 \mathrm{~mm}$ de largura, $3 \mathrm{~mm}$ de altura e 2,5mm de profundidade, com uma margem em esmalte e outra em cemento, preparadas com uma broca carbide $\mathrm{n}^{\circ} 169$. Os adesivos testados foram: Optibond $\mathrm{X}$ Optibond FL; Albond 2 X One-Step e Tenure X Tenure Quik, preparados segundo as instruções dos fabricantes. As cavidades foram restauradas com a resina composta Pertac-Hybrid, o acabamento dado com a ponta diamantada $n^{\circ} 8884$ e polimento com discos Sof-lex. Os dentes, armazenados por sete dias a $37^{\circ} \mathrm{C}$ em água destilada, passaram pela termociclagem a $5^{\circ} \mathrm{C}-55^{\circ} \mathrm{C} / 30 \mathrm{~s}$ cada banho/ 300 ciclos. A seguir foram imersos em 0,5\% de fucsina básica por 24 horas, ao que foram lavados, cortados longitudinalmente por mesial e distal e analisados em microscopia a $100 \mathrm{X}$ de magnitude. $\mathrm{O}$ adesivo Optibond FL e o One-Step mostraram menor infiltração nas margens de cemento comparados 
com outras versões "multi-step". Nas margens de esmalte o Tenure Quik mostrou menor infiltração que o Tenure, e nenhum outro adesivo testado mostrou significante penetração nesta interface. Todos os adesivos mostraram menor infiltração nas margens de esmalte comparada com as margens de cemento, exceto o Optibond FL e One-Step.

DEJOU, J., SINDRES, V. e CAMPS, J. ${ }^{32}$, em 1996, compararam cinco métodos estatísticos para avaliar a eficiência dos selantes de restaurações de resina composta com seus sistemas adesivos em 260 dentes pré-molares e molares humanos extraídos, que foram divididos em 13 grupos de 20 dentes. Foram realizadas cavidades tipo classe $V$ na face vestibular dos dentes com $4 \mathrm{~mm}$ de altura, $3 \mathrm{~mm}$ de largura e $1,5 \mathrm{~mm}$ de profundidade, com bisel de $2 \mathrm{~mm}$ na margem de esmalte e restauradas com os sistemas adesivos da resina composta Pekalux, Helio Progress, Silux, Silux Plus, Prisma Fil, Pekalux, Bis Fil e Z 100. O contorno final foi dado com pontas diamantadas e o polimento com discos Sof-lex. Submetidos os dentes à ciclagem térmica de 100 ciclos/ $5^{\circ} \mathrm{C}-55^{\circ} \mathrm{C} /$ cada banho de $30 \mathrm{~s}$, foram imersos em fucsina básica a 0,5\% por 24 horas, cortados, analisados em microscopia de 100X de magnitude e submetidos a cinco métodos estatísticos: média de penetração do corante em cada dente, mediana de penetração do corante, modo de penetração do corante, máximo de penetração do corante e percentual de dentes sem penetração do corante nas seis faces. A máxima penetração do corante medida em cada dente pode ser o melhor critério de avaliação.

DOERR, C.L. et $\mathrm{aP}^{33}$, em 1996, utilizaram 30 dentes terceiros molares humanos extraídos e fizeram cavidades tipo classe $\mathrm{V}$ na vestibular e 
lingual no limite amelocementário, abertas com uma broca carbide rp330 e tinham $1,5 \mathrm{~mm}$ de profundidade, $4 \mathrm{~mm}$ de largura e $3 \mathrm{~mm}$ de distância oclusogengival. Foram restauradas com o ionômero de vidro convencional Ketac-Fil Aplicap e protegidas com Ketac-Glaze, sendo as demais restauradas com ionômero de vidro modificado com resina Photac-Fil Aplicap e protegido com Ketac-Glaze. Polidas com discos Sof-Lex e protegidas novamente as restaurações com Ketac-Glaze, os dentes foram armazenados em água destilada por sete dias e então submetidos à ciclagem térmica de 2.500 ciclos/ $5^{\circ} \mathrm{C}-55^{\circ} \mathrm{C} / 5 \mathrm{~s}$. Imersos no corante azul de metileno a $5 \%$ por 5 horas, depois lavados e armazenados em água destilada por 24 horas, os espécimes foram cortados no sentido vestibulo-lingual e analisados em microscopia com 64X de magnitude. Dois grupos foram termociclados e dois não. A análise estatística não verificou diferença significante na infiltração marginal entre os grupos que sofreram ciclagem térmica ou não e entre o ionômero de vidro convencional e o íonômero de vidro modificado por resina.

FERRARI, M. e DAVIDSON, C.L. ${ }^{34}$ em 1996, realizaram um estudo "in vivo" utilizando 17 pacientes de 57 anos e vinte dentes, sendo todos anteriores (incisivos e caninos), superiores e inferiores, indicados para extração, com cavidades tipo classe $V$ de $3 \mathrm{~mm}$ de tamanho e $2 \mathrm{~mm}$ de profundidade, com um total de 10 para cada grupo. O primeiro grupo foi restaurado com ionômero de vidro Fuji II LC e o segundo grupo com o adesivo Scotchbond Multi-Purpose e resina composta Z 100 com acabamento imediato das restaurações com discos Sof-Lex. Decorridos 75 a 90 dias os mesmos foram extraídos e imersos em solução de cloramina a 1\% por sete dias, 
posteriormente sendo imersos em azul de metileno a $2 \%$ por 24 horas, cortados em direção incisivo-apical e inspecionados em um estereomicroscópio com 20X de magnitude. Houve infiltração marginal tanto no esmalte como em cemento, porém a análise estatística não mostrou diferença entre o ionômero de vidro e a resina composta, nem entre a margem incisal e cervical dos dentes anteriores. Embora nenhum dos sistemas eliminou completamente a infiltração, não mais que $30 \%$ das restaurações apresentaram infiltração marginal.

GORACCI, G. et $\mathrm{al}^{45}$, em 1996, avaliaram a polimerização de resina composta de forma normal e de forma gradual, com objetivo de diminuir a infiltração marginal para evitar a passagem de bactérias e toxinas, hipersensibilidade, inflamação pulpar, cáries secundárias e necrose pulpar. Foram utilizados 12 pré-molares não cariados e extraídos por razão ortodôntica com cavidades retangulares com $2,5 \mathrm{~mm}$ de profundidade, submetidos a ataque ácido por 15s. Após a lavagem foi utilizado primer, adesivo e restaurador com resina composta Z-100. Os espécimes foram divididos em dois grupos, um sendo polimerizado com a luz visível (Visilux 2) por 40 s e $250 \mathrm{~mW} / \mathrm{cm} 2$ e o outro grupo com mesma lâmpada com aumento gradual de 30 a $250 \mathrm{~mW} / \mathrm{cm} 2$ por 4 minutos. Os espécimes foram cortados e examinados em microscopia eletrônica. Houve redução dos "gaps" marginais, na polimerização gradual, de forma lenta, melhorando a adesão da resina composta às paredes das cavidades, e esta técnica pode representar a solução definitiva para o problema da adesão das restauraçãos estéticas.

MAY JR, K.N. et al. ${ }^{60}$, em 1996, avaliaram o efeito da penetração do selante de superfície ao redor de restaurações classe $\mathrm{V}$, em relação a 
microinfiltração em 50 dentes com cavidades tipo classe $V$ na vestibular e lingual, com tamanho de $3 \mathrm{~mm}$ de diâmetro, $3 \mathrm{~mm}$ de altura e $1,5 \mathrm{~mm}$ de profundidade. Os dentes foram divididos em cinco grupos: grupo 1: Dentin Condicioner e Fuji II LC; grupo 2: Probond e Variglass; grupo 3: Optibond e Herculite XRV, grupo 4: Scotchbond Multi-Purpose e Sílex Plus e grupo 5: Scotchbond Multi-Purpose e Z-100. Os restauradores foram aplicados segundo as instruções dos fabricantes e o acabamento realizado com brocas multilaminadas de 12 lâminas e pontas para polimento Enhance, compondo grupos com aplicação de ácido fosfórico a 35\% e depois o selante de superfície Fortify. Os dentes permaneceram armazenados em água destilada até a realização da ciclagem térmica de 500 ciclos $/ 5^{\circ} \mathrm{C}-55^{\circ} \mathrm{C} / 30$ s em cada banho, seguido do que foram imersos em uma solução de nitrato de prata a $50 \%$ por 2 horas. A infiltração marginal nas margens de esmalte foi mínima para todos os sistemas usados, independente de ter sido usado o selante de superfície ou não. Para a margem de dentina o resultado foi semelhante com exceção do Variglass, visto que a superfície selada com o selante de superfície foi estatisticamente significante em relação à superfície não selada.

MEIERS, J.C. e KRESIN, J. C. ${ }^{62}$, em 1996, examinaram o uso de dois desinfetantes, um a base de clorexidine (Bisco Cavity Cleanser) e outro a base de iodo/potássio e solução de sulfato de cobre (ORA 5) para a lavagem das cavidades e a sua relação com a infiltração marginal. Foram utilizados 40 dentes terceiros molares humanos extraídos, não cariados, com cavidades classe $V$ na vestibular e lingual, realizadas com broca carbide $n \div 35$ e acabamento das paredes com broca carbide ํㅡㄴ. As cavidades tinham 
aproximadamente $2 \mathrm{~mm}$ de altura, $1,5 \mathrm{~mm}$ de profundidade e $6 \mathrm{~mm}$ de distância mésio-distal sendo metade da cavidade acima do limite amelodentinário e metade abaixo do mesmo. Lavadas com Cavity Cleanser e ORA-5, foram aplicados os adesivos dentinários Syntac e Tenure, com a resina composta Tetric, sendo o acabamento realizado com broca multilaminada e discos Soflex. Os espécimes receberam ciclagem térmica a $5^{\circ} \mathrm{C}-55^{\circ} \mathrm{C} / 30$ s cada banho/ 1000 ciclos sendo então imersos em 0,5\% de fucsina básica por 24 horas. Após a lavagem foram cortados e avaliados. Os resultados permitiram concluir que a clorexidina não afetou os adesivos dentinários, mas as soluções de $0,11 \%$ de iodo/potássio e sulfato de cobre produziram infiltração marginal significantemente maior na parede gengival quando foi utilizado o adesivo dentinário Syntac.

MUNRO, G.A. et al ${ }^{66}$, em 1996, utilizaram em sua pesquisa 42 dentes molares humanos extraídos com cavidades tipo classe $\mathrm{V}$ preparadas na superfície mesial e distal, utilizando a broca carbide $n^{\circ} 330$, com dimensões de 1,5mm acima e 1,5mm abaixo da junção esmalte-cemento, 4mm vestíbulolingual e $2 \mathrm{~mm}$ de profundidade. As restaurações foram realizadas com a resina composta Prisma TPH, perfazendo um total de oitenta e duas restaurações, divididas em 7 grupos: grupo 1: somente primer e adesivo; grupo 2: margens com duas camadas do primer Universal Bond; grupo 3: margens condicionadas com 10s de ácido fosfórico à 37\% com duas camadas de UB3 primer; grupo 4: margens com duas camadas com adesivo UB3; grupo 5: margens condicionadas com ataque ácido e duas camadas de UB3 adesivo; grupo 6: margens com duas camadas de Fortify e grupo 7: margens condicionadas com 
ácido fosfórico e duas camadas de Fortify. Os dentes, após armazenagem por uma semana em água, passaram por ciclagem térmica de 800 ciclos $/ 5^{\circ} \mathrm{C}$ $55^{\circ} \mathrm{C}$ e imersão em azul de metileno a $2 \%$ por 4 horas. Lavados e cortados, revelaram na análise estatística redução na microinfiltração quando usadas duas camadas de adesivo UB3 na margem gengival; que margem gengival condicionada com ácido e duas camadas de UB3 adesivo ou Fortify não revelou melhora no selamento marginal. As margens de esmalte com duas camadas de adesivo, com ataque ácido ou não, não revelaram significância quanto ao selamento quando comparado com o grupo sem ataque ácido.

SAUNDERS, W.P. e SAUNDERSE.M. ${ }^{83}$, em 1996, utilizaram 80 dentes pré-molares hígidos com preparos cavitários tipo classe $\mathrm{V}$ na vestibular e lingual, de $3 \mathrm{~mm}$ de largura, $1,5 \mathrm{~mm}$ de profundidade e $2 \mathrm{~mm}$ de altura, margem coronária em esmalte e a parte gengival em cemento. Os mesmos foram restaurados com os agentes adesivos Prime \& Bond, Scotchbond MultiPurpose e Dentastic, pela técnica "úmida" que consistia em aplicar ácido fosfórico por 20 s e secar a cavidade com seringa ar/ água por 2 s e pela técnica "seca" que consistia da aplicação do ácido fosfórico por 20s e secagem por 15s. A resina composta utilizada foi a Z-100, aplicada de forma incremental em três camadas, sendo a primeira camada na parede, a segunda na gengival e a terceira para completar o contorno dos dentes e o polimento realizado com discos Sof-lex imediatamente após, permanecendo os dentes armazenados em água por duas semanas, seguido de termociclagem a $5^{\circ} \mathrm{C}-37^{\circ} \mathrm{C}-55^{\circ} \mathrm{C} / 10 \mathrm{~s}$ cada banho/ 1500 ciclos. Os dentes foram imersos no corante azul de metileno a $2 \%$ por 48 horas, lavados com água e cortados com disco diamantado em 
direção vestíbulo-lingual. A análise estatística mostrou que não existe significância estatística entre a parede gengival entre os grupos e nem entre a parede de esmalte entre os grupos. Comparando a técnica "úmida" com a técnica "seca", a técnica úmida reduziu significantemente a infiltração marginal com materiais Prime \& Bond e Dentastic. Não houve diferença estatística nas técnicas executadas para o material Scotchbond Multi-Purpose Plus.

SWIFT JR, E.J. et ap9, em 1996, avaliaram a redução da microinfiltração dos sistemas adesivos com resina de baixa viscosidade, em 132 terceiros molares com cavidades preparadas tipo classe $\mathrm{V}$ na vestibular $\mathrm{e}$ lingual, com $5 \mathrm{~mm}$ de distância mésio-lingual, 3mm ocluso-gengival e $3 \mathrm{~mm}$ de profundidade. Cinco sistemas adesivos foram testados: All Bond 2, Clearfil Liner Bond 2, Optibond, Prime \& Bond e Scotchbond Multi-Purpose, aplicados segundo às instruções dos fabricantes, bem como a resina intermediária LVR ( OptiBond FL Adhesive ou o Protect Liner F ). Todas as cavidades foram restauradas com resina composta Z-100 e o acabamento e polimento realizados 10 minutos após o término das restaurações, com broca carbide de 12 lâminas. Armazenados por $24 \mathrm{~h}$ foram os dentes submetidos à ciclagem térmica a $5^{\circ} \mathrm{C}-55^{\circ} \mathrm{C} / 30$ s em cada banho/ 800 ciclos e imersos em uma solução aquosa de nitrato de prata a $50 \%$ por 2 horas, tendo sido cortados longitudinalmente e examinados em microscopia a 10X de magnitude. Houve diminuição de infiltração do OptiBond e Clearfil Liner Bond 2. A infiltração marginal no Scotchbond Multi-Purpose foi significantemente reduzida quando o Protect Liner F foi usado.

TAY, F.R. et al ${ }^{91}$, em 1996, utilizaram 24 dentes terceiros molares 
humanos extraídos, cortados na altura do esmalte e cemento com um disco diamantado paralelo ao plano oclusal dos dentes, obtendo discos de dentina com espessura de $1,5 \mathrm{~mm}$, sendo os mesmos submetidos a tratamentos com dentina "úmida" e dentina "seca". Os discos de dentina foram condicionados com ácido fosfórico a $10 \%$ por 20 s e lavados com água destilada por 20 s, distribuindo-os em quatro grupos: DSDM e fórmula experimental usando a dentina úmida e DSDM e fórmula experimental usando a dentina seca. $\mathrm{Na}$ técnica da dentina úmida, após o condicionamento ácido, esta foi lavada com água e seca com pequenos pedaços de papel absorvente. Posteriormente foram aplicadas duas camadas de primer e polimerizadas por 20s. Na técnica da dentina seca, após o condicionamento ácido e lavagem com água, os discos de dentina foram secos por 30s e aplicação de duas camadas do primer e usados os adesivos Aelitebond (livre de água) e All-Bond 2 (contendo água), onde o primeiro, com a técnica da dentina seca, potencializa a dessecação da dentina formando espaços interfibrilares na área da colagem e produzindo na matriz intertubular uma região "hibridóide". Nos grupos da dentina úmida, observou-se a formação da camada híbrida. Os resultados foram obtidos por microscopia eletrônica de varredura (SEM) e de transmissão (TEM).

TRUSHKOWSKY, R.D. e GWINNETT, A. J. ${ }^{97}$, em 1996, avaliaram "in vitro" a extensão da microinfiltração em cavidades tipo classe V com resina composta e ionômero de vidro modificado por resina composta em 35 dentes humanos extraídos com cavidades na vestibular e lingual, com dimensões de $3 \mathrm{~mm}$ de diâmetro, $2 \mathrm{~mm}$ de altura e $2 \mathrm{~mm}$ de profundidade, com os ângulos cavo-superficial em bisel de $45^{\circ}$ de $0,5 \mathrm{~mm}$ de tamanho na margem da parede 
oclusal com uma ponta diamantada. Os preparos cavitários foram preparados com broca "carbide" nํ330 que, a cada cinco preparos, era trocada. Os 35 dentes foram divididos em 7 grupos de 10 preparos cavitários, a saber: grupo 1: (controle) Scotchbond Multi-Purpose/Z-100; grupo 2: Fuji Lining /SBM/ Z100; grupo 3: Fuji II LC/Z-100; grupo 4: Vitrebond/Z-100; grupo 5: Vitremer/Z100; grupo 6: Fuji II LC e o grupo 7: Vitremer. As restaurações foram realizadas segundo as instruções dos fabricantes seguidas de polimento com discos Soflex, para em seguida sofreram ciclagem térmica de à $5^{\circ} \mathrm{C}-50^{\circ} \mathrm{C} / 30$ s cada banho/1500 ciclos, seguido de imersão no nitrato de prata, corte e análise, demonstrando mínima ou nenhuma infiltração em todos os grupos, tanto em dentina como em esmalte.

FRIEDL K.H. et a ${ }^{40}$, em 1997, realizaram um estudo "in vitro" para avaliar a qualidade marginal entre restaurações de resina composta e restauração de ionômero de vidro híbrido e resina composta (técnica do sanduíche).Utilizaram 48 dentes terceiros molares humanos extraídos, livres de cárie, onde foram feitas cavidades tipo classe II, restauradas com o sistema adesivo: Scotchbond MP/Z-100 ou Probond/ Prisma TPH e na técnica do sanduíche o Vitremer/Z-100 ou Dyract/Prisma TPH. As margens das restaurações, avaliadas por microscopia eletrônica antes e depois da termociclagem com carga (TCML) à $5^{\circ} \mathrm{C} / 55^{\circ} \mathrm{C}$ e 5000 ciclos com carga de $72,5 \mathrm{~N}(1,7 \mathrm{~Hz})$, revelaram que após a termociclagem (TCML) mostraram "gaps" na interface material/dentina com o Vitremer/Z-100 (2,2\%), Dyract/Prisma TPH (7,3\%), Probond/Prisma TPH (6,0\%) e Scotchbond/Z-100 (29,6\%). O Probond/Prisma TPH, mostrou alto "gaps" marginal antes da termociclagem, 
seguido do Vitremer/Z-100, que demonstrou pequenos "gaps" comparado ao Dyract/Primer TPH. Após a termociclagem com carga (TCML) não houve diferença estatisticamente significante entre os grupos testados, o que permitiu concluir que a técnica sanduíche ionômero híbrido/resina composta tem um bom vedamento marginal e pode ser uma alternativa para as restaurações de resina composta.

BRACKETT, W.W. et $\mathrm{al}^{11}$, em 1997, fizeram um estudo utilizando incisivos bovinos nos quais realizaram cavidades tipo classe $V$ na vestibular $e$ lingual, na junção esmalte-cemento, com 1,5m de profundidade, $2 \mathrm{~mm}$ de altura e 3mm de largura. Os dentes foram restaurados com resina composta Z-100 e Prodigy e testados três métodos de polimento: brocas carbide multilaminadas de (8, 16 e 30 lâminas), polimento com pontas diamantadas de 45, 20 e 10 micrometros e discos Sof-lex seqüenciais. Os dentes, armazenados por uma semana em água destilada, foram submetidos a ciclagem térmica com $5^{\circ} \mathrm{C}$ 55으 200 ciclos, imersos em azul de metileno a 10\% por quatro horas, lavados, seccionados e examinados em microscopia de 20X. Após a análise estatística, foi constatado que não houve diferenças estatísticas entre os três métodos testados e as duas resinas compostas utilizadas, no que diz respeito à infiltração marginal.

CHERSONI, S. et $\mathrm{al}^{18}$, em 1997, fizeram um estudo usando terceiros molares humanos extraídos com cavidades tipo classe $\mathrm{V}$, na vestibular e lingual, de 2,2mm de diâmetro e $1,8 \mathrm{~mm}$ de profundidade e divididas em quatro grupos: A) Dyract-PSA/Dyract; B) Prime \& Bond 2.0/Dyract; C) Probond/Prisma TPH e D)Universal Bond 3/Prisma TPH. Após 15 minutos as restaurações 
foram polidas com discos de Sof-lex e obtidas réplicas com resina epóxica que foram analisadas em microscopia eletrônica de varredura (SEM). Os dentes foram imersos em eritrosina a $2 \%$ por 24 horas, depois lavados, secos e analisados em microscopia óptica (40X), enquanto que a avaliação dos "tags" foi feita em microscopia eletrônica. O percentual de margens mais perfeitas, tanto em dentina como em esmalte, foi melhor com o Probond/P. TPH e Prime \& Bond 2.0/Dyract e pior com a Dyract-PSA/Dyract e Universal Bond 3/P. TPH: A infiltração marginal ocorreu mais em dentina do que em esmalte. A formação de "gap" foi menor em esmalte do que em dentina enquanto o comprimento dos "tags" em dentina foi maior na porção mais profunda do que na porção superficial. O material que melhor selou as margens, tanto em dentina como em esmalte, foi Prime \& bond 2.0/Dyract.

PRATI, C. et $\mathrm{al}^{72}$, em 1997, realizaram um estudo para avaliar a morfologia das margens de dentina e esmalte em cavidades tipo classe V, utilizando resina composta e ionômero de vidro, analisados em réplicas por microscopia eletrônica de varredura. Foram realizadas cavidades tipo classe V em terceiros molares na vestibular e lingual, com profundidade de $1,8 \mathrm{~mm}$ e 2,5mm de diâmetro com os restauradores: Bis-Fil Molar, Ray Posterior, Fuji GC Light Curing, Herculite XRV, Silux Plus, Vitremer e Z 100, todos manipulados segundo as instruções dos fabricantes. Deu-se o acabamento e o polimento com discos Sof-lex. Depois de 15 minutos os espécimes foram moldados com silicona de adição (President), obtendo-se réplicas em resina epóxica. Seguidos outros trinta minutos, as restaurações foram imersas em eritrosina B por 24 horas, sendo então lavados, cortados no sentido vestíbulo-lingual e 
analisados em um estereomicroscópio com 40X de magnitude. O percentual de margem perfeita foi maior no esmalte do que em dentina. Não houve diferença estatística na infiltração marginal no esmalte longitudinal entre os materiais. A camada híbrida das restaurações de resina composta mostrou infiltração em áreas profundas da dentina, enquanto que os cimentos de ionômeros de vidro mostraram menor infiltração do que os outros materiais. Não houve relação entre morfologia da margem e microinfiltração, nem significância estatística entre esmalte e dentina ou entre os diversos grupos.

SETTEMBRINI, L. et $\mathrm{al}^{84}$, em 1997, fizeram um estudo "in vitro" para avaliar a microinfiltração utilizando adesivos dentinários "one-step" e um adesivo de dentina convencional de vários frascos. Foram utilizados 36 dentes humanos extraídos, separados em três grupos: grupo I: sem adesivo de dentina/esmalte (controle) e resina composta TPH; grupo II: Prime \& Bond e resina composta TPH e grupo III: ProBond e resina TPH. Cavidades tipo classe V na vestibular dos dentes, com $3 \mathrm{~mm}$ de altura, $4 \mathrm{~mm}$ de diâmetro mésio-distal e $2 \mathrm{~mm}$ de profundidade, realizadas com a broca $\mathrm{n}^{\circ} 556$ em alta rotação e água/ar na face, foram restauradas com resina composta TPH e polidas com o sistema de acabamento e polimento Enhance. Os espécimes impermeabilizados receberam ciclagem térmica em fucsina básica a 0,5\% nas temperaturas de $5^{\circ} \mathrm{C}-55^{\circ} \mathrm{C} / 1$ minuto em cada temperatura/ 500 ciclos. Foram lavados, cortados e examinados em microscopia de 20X de magnitude. Não houve significância entre os grupos quanto às margens de esmalte, mas nas margens de dentina/cemento o adesivo Prime \& Bond obteve menor infiltração marginal que o adesivo ProBond. $O$ adesivo dentinário one-step foi mais efetivo 
para prevenir a microinfiltração na interface de esmalte-resina composta e dentina-resina composta.

UNO, S., FINGER, W.J. e FRITZ, U, B. ${ }^{98}$, em 1997, investigaram a capacidade seladora do cimento de ionômero de vidro e compômero quanto à forma de cavidades do tipo classe V. Foram utilizados molares humanos extraídos com cavidades tipo classe $\mathrm{V}$, de $6 \mathrm{~mm}$ de comprimento, $3 \mathrm{~mm}$ de altura e 1,5mm de profundidade, com três formas idealizadas: tipo 1: semicircular em direção ocluso-cervical com o ângulo cavo-superficial em $90^{\circ}$; tipo 2: semicircular, com bisel de $45^{\circ}$ na margem de esmalte e tipo 3: cavidade em "V" com a parede pulpar arredondada e ângulo cavo-superficial de $135^{\circ}$. Os materiais utilizados foram três ionômeros de vidro: Fuji II LC (FUJ), Photac-Fil Aplicap (PHF), Vitremer (VIT) e um compômero Dyract (DYR). Restauradas as cavidades o polimento foi realizado com discos Sof-lex fino e superfino. Logo a seguir os dentes receberam a ciclagem térmica de $5^{\circ} \mathrm{C}-55^{\circ} \mathrm{C} / 15 \mathrm{~s}$ cada banho/1.500 ciclos e então imersos em fucsina básica a 0,1\% por 1 hora, lavados, cortados e levados à microscopia com um aumento de 60X. A termociclagem não teve efeito na penetração do corante em FUJ e PHF, enquanto que a microinfiltração no esmalte foi observada em DYR e VIT, e apicalmente no DYR e GLP. A cavidade tipo I teve maior infiltração que a tipo 2 e 3 para FUJ, VIT e GLP (Gluma/Pekafill). O selamento adequado foi obtido com o cimento de ionômero de vidro Fuji II LC.

YAP, A. U. J. e MOK, B. Y. Y. ${ }^{102}$, em 1997, avaliaram "in vitro" a influência do condicionamento do esmalte e dentina no selamento de três diferentes ionômeros de vidro reforçados com prata em cavidades prepradas 
em 36 molares humanos extraídos, tipo classe $\mathrm{V}$, com altura de $2 \mathrm{~mm}$, largura mésio-distal $3 \mathrm{~mm}$ e profundidade $2 \mathrm{~mm}$, nas faces $\mathrm{V}$ e $\mathrm{L}$. Os dentes foram divididos em três grupos de 12 dentes restaurados com Ketac Silver, Hi-Dense ou Miracle-Mix, com ou sem condicionamento com o ácido poliacrílico.Os ácidos recomendados pelos fabricantes foram Ketac conditioner - 10s, Hi-tooth cleanser - 10s e GC Conditioner - 20s e lavados por 30s e secos com ar comprimido. Na última camada foi aplicado o Hi-Glaze e polimerizado por 20s e o polimento com discos Sof-Lex. A ciclagem térmica de 500 ciclos de $5^{\circ} \mathrm{C} / 20 \mathrm{~s}$, $65^{\circ} \mathrm{C} / 2 \mathrm{~s}$ e $34^{\circ} \mathrm{C} / 10 \mathrm{~s}$, realizada depois de uma semana permitiu que os espécimes fossem imersos em fucsina básica a $0,5 \%$ por 24 horas a $37^{\circ} \mathrm{C}$; cortados e examinados em um estereomicroscópio de 40X de magnitude. A superfície condicionada reduziu a infiltração marginal no esmalte do H.D; não teve influência no selamento do esmalte do K.S. e M.M. e a superfície de dentina e cemento mostrou melhor selamento com o condicionamento ácido para o H.D. Entretanto o K.S. no selamento dentina-cemento obteve melhor desempenho sem o condicionamento. Para o M.M. o condicionamento ácido na dentina/cemento não teve influência significativa.

ARBABZADEH, F. et al ${ }^{5}$, em 1998, tiveram como propósito comparar a força de adesão e a discrepância marginal de cinco sistemas adesivos, utilizando 25 molares humanos extraídos com cavidades tipo classe $\mathrm{V}$ na vestibular e lingual, com $1,5 \mathrm{~mm}$ a $2 \mathrm{~mm}$ de profundidade, $2,5 \mathrm{~mm}$ oclusogengival, com um bisel de $0,5 \mathrm{~mm}$ no ângulo cavo-superficial do esmalte. Os sistemas adesivos usados foram: All-Bond 2, Clearfil Liner Bond, KB 200, Pro Bond e Aelite Bond e restaurados com a resina composta Pertac Hybrid ou 
Prisma Total Performance Hybrid. As restaurações foram polidas com discos Sof-Lex. Em seguida os espécimes receberam a ciclagem térmica de $5^{\circ} \mathrm{C}$ $55^{\circ} \mathrm{C}$ em saliva artificial, por 500 ciclos e imersão em solução aquosa de $1,5 \%$ de reação laranja 14 por 60s, depois cortados e analisados. O sistema adesivo All Bond 2 obteve maior força de adesão ao cisalhamento e o menor "gap" na margem de cemento e dentina.

BRACKETT, W. W. et al ${ }^{12}$, em 1998, avaliaram a integridade marginal de dois ionômeros de vidro e um compômero em cavidades tipo classe $\mathrm{V}$ em incisivos bovinos. Foram preparadas 32 cavidades em 15 dentes, utilizando a face vestibular e lingual. As cavidades tinham $1,5 \mathrm{~mm}$ de profundidade, $2 \mathrm{~mm}$ de altura e $3 \mathrm{~mm}$ de largura, com bisel de $45^{\circ}$ na margem com o esmalte, sendo as mesmas restauradas com o cimento de ionômero de vidro Fuji II LC, Vitremer e o compômero Dyract e polidas com discos Sof-lex. Os dentes foram armazenados por uma semana em água destilada e depois receberam a ciclagem térmica de 200 ciclos entre $5^{\circ} \mathrm{C}-55^{\circ} \mathrm{C}$ em água destilada/cada banho de 1 minuto /10s de tempo livre, entre um e outro banho, sendo imersos em azul de metileno a $10 \%$ por 4 horas, cortados e analisados em um microscópio de 20X de magnitude. Não houve significância estatística nos três materiais testados quanto à infiltração.

CORTES, O. et al ${ }^{22}$, em 1998, utilizaram 20 pré-molares humanos extraídos e armazenados em água destilada, divididos em quatro grupos, com cinco dentes cada e com 10 cavidades na face vestibular e lingual dos dentes: grupo (1) cavidades classe V restauradas com Dyract; grupo (2) restaurações de Dyract com condicionamento com ácido fosfórico a $37 \%$ por 20s; grupo (3) 
restaurações com compômero Compoglass; grupo (4) condicionamento com ácido fosfórico a $37 \%$ por 20 s. As restaurações realizadas foram polidas com discos Sof-lex seqüencial e os dentes imersos em água destilada por 24 horas, e depois em fucsina básica a $2 \%$ por 24 horas, quando foram lavados, seccionados em direção vestíbulo-lingual e avaliados em microscopia óptica. A análise estatística demonstrou infiltração marginal mais significante no cemento que no esmalte. Em relação à superfície condicionada ou não, não houve diferença significante entre os dois compômeros, Dyract e Compoglass.

FERRARI, $M$. et $\mathrm{al}^{36}$, em 1998, teve o propósito de analisar o selamento marginal de dois compômeros "in vivo" em 25 pacientes com cavidades tipo classe $\mathrm{V}$, realizadas com diâmetro de $3 \mathrm{~mm}$, circular e $2 \mathrm{~mm}$ de profundidade. Os espécimes foram divididos em quatro grupos: grupo1: Dyract/ Dyract-PSA; grupo 2: Dyract/Prime \& Bond 2.0; grupo 3: Compoglass/ SCA e grupo 4: Compoglass/ Syntac Single. Os dentes, polidos após o termino das restaurações, permaneceram na cavidade bucal por um período de 60 dias a 90 dias. Decorrido esse tempo, foram extraídos e imersos em solução de azul de metileno a $2 \%$ por 24 horas, depois lavados e cortados no sentido vestíbulolingual. O Dyract e o Compoglass quando aplicados com Prime \& Bond 2, e Syntac Single com sistema P.S.A. e S.CA. e aplicação do ácido fosfórico, aumenta o selamento marginal. Nenhum dos sistemas puderam prevenir a microinfiltração.

GLADYS, S. et af ${ }^{43}$, em 1998, avaliaram "in vivo" lesões de classe V, em cavidades preparadas em 86 pacientes, com idade de 23 a 76 anos, em dentes molares com lesões de abrasão, erosão ou profundidade pela cárie, 
totalizando 187 restaurações, restauradas com um ionômero de vidro convencional (Hifi Master Palette), três ionômeros de vidro modificados por resinas (Fuji II LC, Vitremer, 3M Exp. 155) e uma resina composta modificada por poliácidos (Dyract). As restaurações foram avaliadas imediatamente, após seis, 12 e 18 meses. E o exame clínico avaliou a integridade marginal, a retenção do material restaurador, microinfiltração clinicamente, cáries recorrentes e vitalidade pulpar. A perda de material e defeitos foram analisados por meio de réplicas em microscopia eletrônica de varredura. A retenção dos materiais testados foi boa. As discrepâncias marginais foram localizadas na incisal de esmalte ou cervical de dentina, com exceção do Dyract que mostrou mais defeitos na margem de esmalte. Este problema poderia ter sido amenizado com a aplicação da técnica do ataque ácido total. Todos os materiais apresentaram microinfiltração ao longo do tempo.

GORDAN, V. V. et al. ${ }^{46}$, em 1998 , avaliaram a microinfiltração de primers acidificados no selamento marginal em cavidades tipo classe $\mathrm{V}$ em 60 dentes molares humanos extraídos, não cariados. Foram realizadas cavidades tipo classe $V$ preparadas com broca carbide $n^{\circ} 57$ em alta rotação, que mediam $3 \mathrm{~mm}$ de largura, $2 \mathrm{~mm}$ de altura e $1,5 \mathrm{~mm}$ de profundidade e os primers acidificados: Clearfil Liner Bond 2, Denthesive II, Scotchbond Multi-Purpose (controle), com e sem ataque ácido. Os dentes foram restaurados com a resina composta Silux Plus $\mathrm{XL}$, segundo as instruções dos fabricantes e 0 acabamento foi dado com discos Sof-lex, seguido de imersão dos espécimes em água destilada por 48 horas e ciclagem térmica de 500 ciclos $/ 5^{\circ} \mathrm{C}-55^{\circ} \mathrm{C} /$ 26s, com 13s de tempo de transferência entre os banhos. Após 48 horas 
passaram pela eritrosina $B$, solução a $2 \%$ de tetra-iodofluorescente por 24 horas, depois lavados e cortados para avaliação. O Clearfil Liner Bond 2 e Denthesive II sem ataque ácido produziram selamento marginal comparável ao Scotchbond Multi- Purpose no esmalte e dentina. O Clearfil Liner Bond 2 e Denthesive II com ataque ácido produziram selamento marginal comparável ao Clearfil Liner Bond e Denthesive II sem ataque ácido no esmalte e na dentina.

KUGEL, G. et al ${ }^{54}$, em 1998, avaliaram a microinfiltração do compômero Dyract AP usando a técnica do ataque ácido total comparado com a técnica sem ataque ácido em 20 dentes molares humanos extraídos, livres de cárie. Foram realizados preparos cavitários vestibular e lingual, tipo classe $\mathrm{V}$ preparados com broca carbide $\mathrm{n}^{057}$, nas seguintes dimensões: $2 \mathrm{~mm}$ de profundidade, $3 \mathrm{~mm}$ mésio-distal, $2 \mathrm{~mm}$ no sentido inciso-gengival e bisel de $45^{\circ}$ de 0,5mm na margem de esmalte, e então divididos em 2 grupos: grupo I: aplicação ácido fosfórico a 34\% por 15s, lavados e secos com ar comprimido por poucos segundos deixando a dentina "úmida"; aplicação do adesivo Prime \& Bond 2.1 e colocação do Dyract AP na forma incremental; cada camada foi polimerizada com 40s e acabamento com brocas multilaminadas, acompanhadas com ponta Enhance e polimento com tiras de lixa e PrismaGloss. O grupo II, realizado da mesma maneira, só sem o ataque ácido. Os dentes foram impermeabilizados e receberam a ciclagem térmica com 600 ciclos a $5^{\circ} \mathrm{C}-55^{\circ} \mathrm{C} / 30$ s em cada banho, ao que permaneceram imersos na fucsina básica a 0,5\%. Passaram por lavagem, corte e avaliação e microscopia com 30X de magnitude. $\mathrm{O}$ ataque ácido total reduziu a microinfiltração usando o compômero Dyract AP. 
OWENS, B.M. et al ${ }^{68}$, em 1998, avaliaram a infiltração marginal em dentes com cavidade em forma de "V", utilizando a resina composta Z-100 e dois compômeros: Dyract e Geristore. Em dentes anteriores bovinos foram realizadas cavidades na vestibular e lingual, bisel no esmalte e grupos com bisel na margem gengival do cemento. As cavidades tinham $1,5 \mathrm{~mm}$ de profundidade, sendo restauradas com a resina composta Z-100 com e sem condicionamento com ácido fosfórico por 15s. Foram utilizados também o Dyract e o Geristone com e sem condicionamento ácido. Os dentes permaneceram armazenados em água destilada por uma semana e então submetidos a ciclagem térmica de $4^{\circ} \mathrm{C}-58^{\circ} \mathrm{C} / 1$ minuto cada banho; foram imersos no azul de metileno a $5 \%$ por 4 horas, lavados, cortados no sentido longitudinal e avaliados. A resina composta Z-100 sem o bisel gengival exibiu menor infiltração marginal.O compômero Dyract sem o bisel gengival e sem o condicionamento ácido aumentou a microinfiltração. Em todos os materiais restauradores houve aumento da microinfiltração marginal nas cavidades classe $\mathrm{V}$ com bisel gengival.

SANTINI, A. e MITCHELL, S. ${ }^{82}$, em 1998, avaliaram o efeito na dentina úmida ou seca de três agentes adesivos em cavidades tipo classe $\mathrm{V}$, quanto a microinfiltração marginal. Foram utilizados 60 dentes pré-molares e molares humanos extraídos, onde foram realizados preparos cavitários tipo classe $V$ na vestibular e lingual com $3 \mathrm{~mm}$ de tamanho, $1,5 \mathrm{~mm}$ de profundidade e $2 \mathrm{~mm}$ de altura. Os espécimes foram divididos em três grupos: grupo 1: com o adesivo Gluma CPS; grupo 2: adesivo EBS e grupo 3: adesivo Prime \& Bond 2.1. As resinas compostas foram Pekafill NF, Pertac \| e Spectrum TPH, 
respectivamente. Após o acabamento e polimento, obtidos com discos finos Sof-lex, os dentes foram impermeabilizados e receberam a ciclagem térmica de 500 ciclos a $5^{\circ} \mathrm{C}-55^{\circ} \mathrm{C} /$ banho de 30 s, com posterior imersão em solução Procion Brilliant Red a 5\%, por 24h. Lavados, foram cortados para avaliação em microscopia eletrônica de varredura. Todos os grupos mostraram microinfiltração nas margens de esmalte e dentina, sendo que nas margens gengivais houve diferença estatística com a técnica "úmida" (menor infiltração marginal) que com a técnica "seca". Nas margens de esmalte não houve diferença estatística entre a técnica "úmida" e "seca".

YAP, A.U.J. ${ }^{101}$, em 1998, estudou a influência da armazenagem, da ciclagem térmica e da ciclagem com carga na microinfiltração marginal dos ionômeros de vidro reforçados com prata Shofu Hi-Dense. Foram feitas 50 cavidades tipo classe II em dentes molares humanos extraídos, não cariados. A cavidade classe II possuía as caixas proximais com $1 \mathrm{~mm}$ abaixo da junção amelocementária. Os preparos cavitários foram condicionados com ácido poliacrílico a $25 \%$ por 10 s, lavados por 15 s e secos com ar comprimido e restaurados com ionômero de vidro Shofu Hi-Dense, sendo os excessos removidos com brocas de 12 lâminas e passados Shofu Hi-Glaze. Após uma semana os espécimes foram imersos em saliva artificial, quando o acabamento e polimento foram realizados com brocas de 12 lâminas e discos Sof-lex. Os dentes foram divididos em 5 grupos: grupo 1: controle (não-cicladas); grupo 2: termocicladas; grupo 3: cicladas com carga; grupo 4: três meses de armazenagem/ não- cicladas e grupo 5: três meses de armazenagem/termocicladas e cicladas com carga. $\mathrm{O}$ selamento marginal do 
Shofu Hi-Dense demonstrou maior efetividade em esmalte que em dentina. A termociclagem, a ciclagem com carga e os três meses de armazenagem com ou sem termociclagem não influenciaram na microinfiltração da interface esmalte e cemento. O aumento da microinfiltração na interface dentinacemento foi significante em todos tratamentos.

FITCHIE, J.G. et al $^{37}$, em 1999, avaliaram a infiltração marginal em 40 dentes incisivos bovinos, com 40 cavidades tipo classe $\mathrm{V}$, com $2 \mathrm{~mm}$ de profundidade, $3 \mathrm{~mm}$ no sentido mésio-distal e $2 \mathrm{~mm}$ inciso-gengival. Os dentes foram divididos em 4 grupos de 10 dentes: grupo A: Prime \& Bond (ataque ácido total); grupo B: Prime \& Bond (ataque ácido em esmalte); grupo C: Optibond FL (ataque ácido total) e grupo D: Bisco One-Step (ataque ácido total). O condicionamento foi com ácido fosfórico a 37\% por 15s e lavagem com água por $15 \mathrm{~s}$ e os dentes restaurados com resina composta TPH híbrida. Os espécimes receberam ciclagem térmica entre $4^{\circ} \mathrm{C}-58^{\circ} \mathrm{C} / 100$ ciclos/ cada ciclo de 1 minuto, com 10s de transferência de uma temperatura para outra, colocados no isótopo de $\mathrm{Ca}$ por 2 horas, cortados longitudinalmente e colocados sobre um filme de raios-X por 12 horas, para produzir autoradiografias.Embora o Primer \& Bond nos grupos A e B mostraram microinfiltração menos significante na margem gengival, não houve diferença significante de infiltração na margem de esmalte.

LIM, C.C. et $\mathrm{al}^{56}$, em 1999, compararam os efeitos do acabamento e polimento imediatamente à restauração e após uma semana, utilizando ionômero de vidro modificado por resina (Fuji II LC) e resina composta modificada por poliácidos (Dyract). Foram utilizados 24 dentes humanos pré- 
molares extraídos, com cavidades tipo classe $\mathrm{V}$ na vestibular e lingual dos espécimes. As cavidades tinham $3 \mathrm{~mm}$ mésio-distal, $2 \mathrm{~mm}$ ocluso-gengival e $2 \mathrm{~mm}$ de profundidade. Os dentes foram restaurados com Fuji II LC e Dyract segundo as recomendações dos seus fabricantes. As restaurações tiveram acabamento imediato (dois grupos) e os outros (dois) grupo de 6 espécimes cada teve acabamento após 1 semana, sendo os dentes imersos em uma solução salina a $37^{\circ} \mathrm{C}$. A ciclagem térmica foi feita em fucsina básica a $0,5 \%$ por 24h; os dentes lavados, cortados e avaliados em um estereomicroscópio a 40X de magnitude. Não houve diferença estatística no esmalte com acabamento imediato e após uma semana para o Dyract e dentina. Na Fuji II LC, não houve diferença estatística no acabamento imediato ou após uma semana na dentina, mas para o esmalte o acabamento após uma semana teve menor microinfiltração do que o acabamento imediato.

MANDARINO, F. et $\mathrm{al}^{58}$, em 1999, realizaram em estudos utilizando 20 molares humanos hígidos onde foram cofeccionadas 40 cavidades tipo classe V, sendo 20 na face vestibular e 20 na face lingual, com a parede cervical localizada $1 \mathrm{~mm}$ abaixo da junção esmalte-cemento. As cavidades, padronizadas com 1,6mm de profundidade, extensão ocluso-cervical 3,0mm e extensão mésio-distal $2,0 \mathrm{~mm}$ receberam restaurações com o sistema restaurador inlay/onlay Charisma (Kulzer). Os preparos cavitários foram moldados com polisulfeto Coeflex e vazados com gesso Velmix especial (tipo IV), para obtenção dos modelos que anteriormente receberam as restaurações com resina Charisma. Antes da cimentação o condicionamento com ácido fosfórico a 35\% / 30s foi realizado no esmalte e 15s na dentina e lavados 
abundantemente com água. Foi aplicado o sistema adesivo Scotchbond MultiUso Plus (3M) e as restaurações cimentadas com cimento Dual (Vigodent) . Depois de $48 \mathrm{~h}$ foi realizado o acabamento e polimento com discos Sof-lex e taça de borracha com pastas para polimento e os dentes impermeabilizados com duas camadas de Araldite de presa rápida e duas camadas de esmalte comum colorido. A ciclagem térmica posterior alcançou $10^{\circ} \mathrm{C}-5^{\circ} \mathrm{C} /$ de $15 \mathrm{~s}$ em cada temperatura/ 200 ciclos. Em seguida os espécimes foram colocados em solução com azul de metileno a $2 \%$ por 24 horas e seccionados no meio para avaliar a infiltração nas seguintes condições: C1-ácido hidrofluorídrico + silano, C2-ácido fosfórico + silano, C3-sem ácido+silano, C4-sem silanização. Houve diferença significante entre a parede cervical que propicia maiores níveis de infiltração que a parede oclusal. Houve maior infiltração marginal nas condições experimentais C2 e C4.

PILO, R. e BEM-AMAR, A. ${ }^{70}$, em 1999, fizeram um estudo "in vitro" comparando adesivo de dentina de um frasco com adesivo dentinário de vários frascos e sua influência na infiltração marginal. Foram utilizados 48 dentes molares humanos extraídos onde foram realizadas cavidades tipo classe $\mathrm{V}$ na vestibular e lingual com a broca carbide $\mathrm{n}$ 우잉. As cavidades tinham $2 \mathrm{~mm}$ de altura, $4 \mathrm{~mm}$ mésio-distal e $2 \mathrm{~mm}$ de profundidade. Os preparos cavitários tinham a margem oclusal em esmalte e a margem gengival em cemento. Os dentes foram divididos em 6 grupos com oito espécimes cada grupo, com os adesivos Optibond FL e Solobond (Kerr), All Bond 2 e One-Step (Bisco) e Scotchbond Multi-Purpose e Single Bond (3M), estes usados segundo a recomendação dos seus fabricantes. Restauradas as cavidades com a resina 
composta Z-100 realizou-se o acabamento com discos Sof-lex. Todos os espécimes foram armazenados por sete dias a $37^{\circ} \mathrm{C}$ e depois receberam carga oclusal de $10 \mathrm{Kg}$ por 0,5 s por 500 vezes e termociclagem de 1400 ciclos com temperatura de $5^{\circ} \mathrm{C}$ e $5^{\circ} \mathrm{C}$ com cada banho de $10 \mathrm{~s}$, sendo imersos em fucsina básica a $0,5 \%$ por 48 horas a $37^{\circ} \mathrm{C}$. Os dentes foram lavados, cortados $\mathrm{e}$ examinados em um estereomicroscópio. Os adesivos de um frasco tiveram igual performace que os adesivos de vários frascos quanto a microinfiltração marginal. Os adesivos SBMP e Single Bond foram melhores seladores nas margens de esmalte, enquanto que os adesivos One-Step e Optibond FL foram melhores seladores nas margens de cemento. A escolha do adesivo mais eficiente vai depender do caso específico.

RODRIGUES, J.A. et al ${ }^{77}$, em 1999, avaliaram a microinfiltração de três ionômeros de vidro híbridos, três resinas compostas modificada por poliácidos (compômeros), um ionômero de vidro e uma resina composta híbrida. Foram utilizados 240 dentes humanos extraídos, fazendo-se cavidades tipo classe $V$ com $1,5 \mathrm{~mm}$ de diâmetro e $1,5 \mathrm{~mm}$ de profundidade feitas com uma ponta diamantada n-15. As cavidades, realizadas em dentes uniradiculares (incisivos, caninos e pré-molares) ocupavam a face vestibular da raiz, $4 \mathrm{~mm}$ abaixo do limite amelocementário. Cada grupo de dentes possuía 24 espécimes: grupo I: Vitremer; grupo II: Campoglass; grupo III: Photac-Fil Aplicap; grupo IV: Variglass; grupo V: Dyract, grupo VI: Fuji II LC; grupo VII: Ketac-Fil Aplicap e grupo VIII: Z-100. Os espécimes sofreram ciclagem térmica em água a $5^{\circ} \mathrm{C}-55^{\circ} \mathrm{C} / 500$ ciclos/ 1 minuto cada banho/ com 15 segundos de transferência entre os banhos, seguidos de imersão em azul de metileno a $2 \%$ 
por 24 horas, foram lavados, seccionados e examinados por três examinadores com estereomicroscópio de 16X de magnitude. Os ionômeros de vidro híbrido e as resinas compostas modificadas por poliácidos não produziram diferença estatística comparado com a resina composta, mas quando comparadas com o ionômero de vidro convencional tiveram menor microinfiltração marginal.

HAKIMEH, S. et $a^{48}$, em 2000 , relataram que a microinfiltração marginal é um problema importante relacionado com o material de preenchimento e outros fatores. Neste estudo foi avaliado o efeito da ciclagem com carga, a ciclagem térmica e o tipo de preparo cavitário em forma de "V" não retentivo (com paredes divergentes) e em forma de "U" (com paredes paralelas) em 32 dentes molares e pré-molares, com cavidades tipo classe $\mathrm{V}$ na vestibular e lingual, com dimensões de $3 \mathrm{~mm}$ de largura, $2,5 \mathrm{~mm}$ de profundidade e $4 \mathrm{~mm}$ de distância ocluso-cervical. As cavidades foram preparadas com a broca ํㅜㅇㅣ e os dentes divididos em 4 grupos de oito: grupo I: termociclagem somente; grupo II: ciclagem com carga; grupo III: termociclagem e carga, grupo IV: sem tratamento. As cavidades foram restauradas com compômero Dyract, segundo as instruções dos fabricantes. A termociclagem consistia em $4^{\circ} \mathrm{C}-60^{\circ} \mathrm{C} /$ cada banho de 1 minuto/transição de 15s, por um período de 5 dias (2.880 ciclos). A ciclagem com carga foi realizada em uma máquina de testes (MTS modelo 810), por 7 horas com carga de $100 \mathrm{~N}$, sendo os dentes imersos por 24 horas em fucsina básica a $2 \%$. Os resultados refletem que termociclagem afetou a microinfiltração da restauração de compômero. A alternativa de compressão com carga usada na ciclagem não afetaram significantemente a microinfiltração. A cavidade classe 
V em "U" foi superior a cavidade em "V" para reduzir a microinfiltração, enquanto que a microinfiltração nas margens de esmalte revelourse maior do que nas margens de cemento.

TORRES, C. R. G. ARAUJO, M. A. M. ${ }^{96}$, em 2000, compararam a microinfiltração marginal de quatro sistemas adesivos dentinários de quinta geração em 20 terceiros molares humanos extraídos e selecionados onde foram realizados preparos cavitários classe II, "slot" vertical nas faces mesial e distal dos elementos dentais. As cavidades apresentaram $3 \mathrm{~mm}$ de largura vestibulo-lingual e $2 \mathrm{~mm}$ de profundidade, ao nível da parede gengival e os dentes divididos em quatro grupos de cinco. Os grupos I e II receberam os sistemas de frasco único One-Step (Bisco, Inc) e Single Bond (3M Dental Products), respectivamente. Os grupos III e IV foram os sistemas autocondicionantes Clearfil Liner Bond 2 (Kuraray) e Etch \& Prime 3.0 (Degussa), respectivamente. A técnica incremental foi de inserção oblíqua, e a resina composta utilizada foi a prisma TPH (Dentsply Detrey). Ao término das restaurações, os espécimes permaneceram armazenados em água destilada por 24 horas, sendo então procedidos o acabamento e polimento. As amostras foram submetidas a termociclagem, a $5^{\circ} \mathrm{C}-55^{\circ} \mathrm{C} / 30$ s em cada banho/500 ciclos, imersão em uma solução aquosa de fluoresceína sódica a $2 \%$ durante 15 horas e então lavados em água corrente por 10 minutos e cortados no sentido mésio-distal com um disco de carborundum. Os sistemas adesivos Single Bond, One Step e Clearfill Liner Bond 2 não mostraram diferença estatisticamente melhor quanto ao selamento marginal. $O$ Single Bond apresentou menor infiltração marginal, porém com significância estatística 
apenas para o Etch \& Prime 3.0. 
3 - PROPOSIÇÃO 


\section{3 - PROPOSIÇÃO}

O propósito desta pesquisa foi verificar o grau de infiltração marginal em cavidades classe $V$, após ciclagem térmica, em função dos seguintes aspectos:

tipo de material restaurador (resina composta condensável, resina composta híbrida, resina composta modificada por poliácidos e ionômero de vidro modificado );

localização da parede cavitária (parede gengival em cemento e parede oclusal em esmalte). 
4-MATERIAIS E MÉTODOS 


\section{4 - MATERIAIS E MÉTODOS}

Dentes pré-molares humanos extraídos por razões ortodônticas foram coletados na clínica de Cirurgia da Faculdade de Odontologia de Lins e mantidos em solução de formalina. Após a coleta, que se processava semanalmente, estes dentes foram limpos por raspagem e fixados por mais 72 horas na mesma solução, evitando assim possível decomposição do tecido pulpar, passando-se então a uma armazenagem posterior em água destilada até o momento de uso.

Todos os dentes foram examinados com lupa com aumento de $7 x$ descartando-se aqueles que apresentavam pequenas trincas, anomalias de esmalte dentário, abrasão, dentes de coloração amarelada intensa e com hipercementose. Ao todo foram selecionados 50 pré molares livres de cáries.

Os dentes foram limpos com pedra pomes e água com taça de borracha e lavados abundantemente com água para então serem realizadas cavidades padronizadas tipo Classe $\mathrm{V}$, na vestibular e lingual de cada dente, segundo BARNES et $\mathrm{al}^{8}$, totalizando 100 cavidades. Elas foram iniciadas com uma ponta diamantada número $1015^{\star}$ até alcançar um diâmetro de $3 \mathrm{~mm}$. A seguir, com uma broca carbide número $245^{\star \star}$ aprofundava-se a cavidade até atingir $1,5 \mathrm{~mm}$ (figura 1). Ambas, ponta diamantada e broca carbide, foram utilizadas em alta rotação e refrigeradas com spray ar-água e com um cursor para

\footnotetext{
* KG Sorensen, São Paulo, Brasil.

** SS White, Rio de Janeiro, Brasil.
} 
mensuração da profundidade, sendo que a cada 5 preparos cavitários elas foram substituidas. $\mathrm{O}$ acabamento das paredes foi executado com a mesma broca carbide em baixa rotação e recortadores de margem gengival. As cavidades tipo Classe $\mathrm{V}$ foram preparadas com a parede oclusal em esmalte dentário e a parede gengival em cemento dentário. As características finais das cavidades foram: parede axial convexa em todos os sentidos; paredes circundantes ligeiramente expulsivas formando ângulo reto com a superfície externa do dente; ângulos internos arredondados; ângulo cavo-superficial nítido e sem bisel e ausência de retenções adicionais.

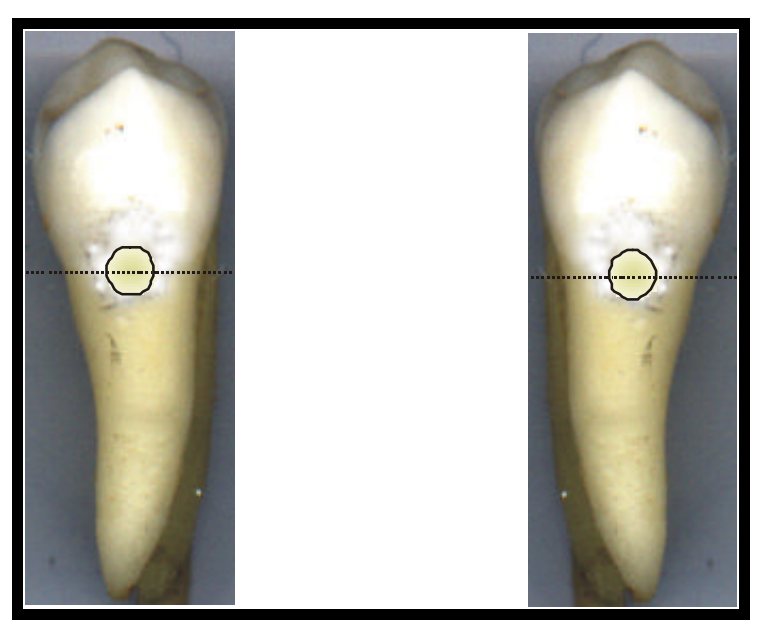

Figura 1 - Preparo cavitário realizado na face vestibular e lingual de pré-molares (esmalte/cemento)

Dimensões: $3 \mathrm{~mm}$ de diâmetro e 1,5mm de profundidade

Os 50 dentes com as cavidades preparadas foram divididos em 5 grupos para serem restaurados (figura 2) com os materiais a serem testados:

Grupo I: restaurações com o sistema da resina composta condensável Alert* . Após o preparo cavitário o esmalte foi condicionado por 30 segundos com ácido fosfórico a $37 \%$ e a dentina por 15 segundos e lavados,

* Jeneric/ Pentron, Wallingford, USA. 
abundantemente, por 30 segundos com água. Foi removido o excesso de água com jatos de ar no esmalte, enquanto que na dentina utilizou- se papel absorvente, deixando a dentina úmida. Foram aplicadas duas camadas de primer/ adesivo Bond-1, com o aplicador* recomendado, por 10 segundos, obtendo-se uma superfície espessa e brilhante. Foram aplicados, delicadamente, jatos de ar por 10 segundos para remover completamente o solvente, a fim de conseguir máxima resistência. O primer/adesivo foi fotopolimerizado com o aparelho Optilight $600^{* *}$ por 10 segundos.

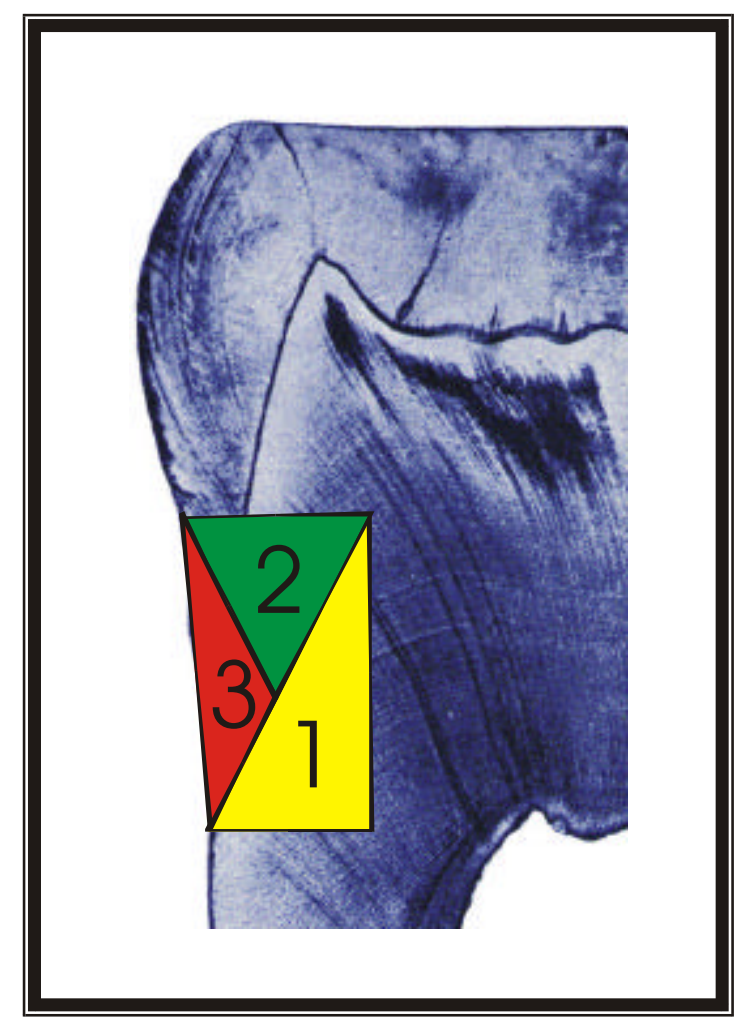

Figura 2 - Representação esquemática da técnica incremental da resina composta, em três camadas: 1 - primeira camada; 2 - segunda camada; 3 - terceira camada.

* Microbrush, Grafton, USA

** Gnatus, Ribeirão Preto, São Paulo, Brasil. 
Foi aplicada a resina composta fluída Flow-It nas paredes laterais e assoalho da cavidade com uma espátula de titânio* e fotopolimerizada por 40 segundos.Foi inserida a resina composta condensável Alert em camadas, sendo utilizado o condensador próprio do kit e cada camada foi fotopolimerizada por 40 segundos. Completada a restauração, o acabamento e polimento, foi feita a impermeabilização da superfície condicionando-a com ácido fosfórico por 20 segundos até $2 \mathrm{~mm}$ além dos limites da restauração, seguido de lavagem com água e secagem com jatos de ar. Aplicando-se o selante resinoso de superfície Protect-It, empregando-se 0 aplicador recomendado, seguido de secagem com ar e fotopolimerização por 20 segundos.

Grupo II- Sistema da resina composta condensável Solitaire**. Após o preparo cavitário foi aplicado o ácido fosfórico Esticid por 30 segundos em esmalte e 15 segundos em dentina, tendo sido removido por lavagem com água durante 30 segundos. $\mathrm{O}$ excesso de água foi removido conforme o grupo I. Tendo-se aplicado o primer Solid Bond P por 30 segundos e secado com ar procedeu-se com aplicação do Solid Bond S, secando-se novamente com ar e fotopolimerizando-o por 40 segundos. Foram aplicadas várias camadas de resina composta com o condensador, sendo que a cada uma delas procedeuse à fotopolimerização por 40 segundos, em várias direções.

Grupo III- Sistema da resina composta híbrida Filtek Z 250***.

\footnotetext{
* American Eagle Composite ํㅜ 7, USA.

** Kulzer, Werheim/ Ts, Germany.

*** $3 \mathrm{M}$, St. Paul, MN. USA.
} 
Após o preparo cavitário e condicionamento padrões utilizados nos grupos anteriores, foram aplicadas duas camadas consecutivas do adesivo 3M Single Bond no esmalte e dentina, seguido de secagem rápida por 2 a 5 segundos com ar, e fotopolimerizado por 10 segundos. A resina composta 3M Filtek Z 250 foi colocada em incrementos inferiores a 2,5 mm, com espátula de titânio, sendo cada camada incrementall fotopolimerizada por 20 segundos, até completar a restauração.

Grupo IV- Sistema do compômero Dyract AP*. Preparadas as cavidades foram condicionadas com o. mesmo ácido utilizado nos grupos anteriores e tendo-se mantido a dentina úmida foi aplicado o Prime \& Bond 2.1 na cavidade, com um aplicador próprio, por 30 segundos. Os excessos foram removidos com jatos de ar (3 a 5 segundos) e fotopolimerizado por 10 segundos. Foi aplicada uma segunda camada do mesmo material obedecendo-se o mesmo procedimento. O Compule foi adaptado na extremidade da pistola e aplicado em incrementos inferiores a $3 \mathrm{~mm}$ sendo cada camada fotopolimerizada por 40 segundos, até preenchimento total da cavidade.

Grupo V- lonômero de vidro híbrido Vitremer** - Grupo controle. Após o preparo cavitário foi aplicado o primer por 30 segundos, com o aplicador, seguido de secagem com jatos de ar e fotopolimerização por 20 segundos. A proporção pó/ líquido foi a recomendada pelo fabricante e o tempo de espatulação inferior a 45 segundos. $O$ ionômero de vidro foi colocado no interior da cavidade com uma seringa Centrix ${ }^{\star \star \star}$ e então polimerizado por 40 segundos. Após completar o preenchimento da cavidade foi

\footnotetext{
* Dentsply, Konstanz, Germany.

** 3M, St. Paul, MN. USA.

${ }^{* * \star}$ Centix Incorporeted, USA.
} 
aplicado o protetor de superfície Gloss, que foi fotopolimerizado por 20 segundos.Concluídas as restaurações de todos os grupos, o acabamento das mesmas consistiu na remoção dos excessos grosseiros com lâmina de bisturi número 15. Os dentes, assim preparados, foram imersos em água destilada por 24 horas, em estufa por $37^{\circ} \mathrm{C}$. Decorrido este tempo, foram realizados o acabamento e polimento das restaurações com discos Sof-lex* seqüenciais. Os dentes foram então impermeabilizados com duas camadas de Araldite ${ }^{\star *}$ de presa rápida e duas de esmalte para unhas $^{\star * *}$, em cores diferentes para cada grupo, preservando-se 2 $\mathrm{mm}$ ao redor das restaurações sem a impermeabilização. Após o período de secagem (aproximadamente 1 hora), os dentes foram submetidos à ciclagem térmica.

A ciclagem térmica utilizou temperaturas de $5^{\circ}$ e $55^{\circ} \mathrm{C}$ com um total de 200 ciclos, de 30 segundos para cada um dos extremos de temperatura. Para que fosse realizada a ciclagem os dentes foram colocados no corante azul de metileno a $2 \%$ e assim mantidos durante a seqüência de ciclos realizados. Para o controle das temperaturas necessárias foram utilizados termômetros próprios ${ }^{\star * \star *}$. Completados os ciclos os dentes foram mantidos em azul de metileno a $2 \%$ por 24 horas, a $37^{\circ} \mathrm{C}$.

Concluída a ciclagem térmica, os espécimes foram lavados, escovados e mantidos em água corrente por 6 horas e por igual tempo em condição ambiente para secagem natural. Uma vez secos os dentes, a película

\footnotetext{
* 3M do Brasil Ltda, São Paulo, Brasil.

** Brascola S.A, São Paulo, Brasil.

*** Risqué, São Paulo, Brasil.

**** Termômetro Incoterm, São Paulo, Brasil.
} 
impermeabilizante foi removida deles por raspagem e estes foram fixados em uma placa de madeira por meio de godiva de baixa fusão. Os dentes foram então seccionados ao meio no sentido vestíbulo lingual, longitudinalmente, com um disco diamantado fixado em um micrótomo próprio*, sob refrigeração a água. O excesso de água foi removido colocando-se os dentes seccionados em papel absorvente por 30 minutos.

A avaliação da infiltração marginal foi realizada por dois examinadores calibrados entre si, com uma lupa com aumento de $7 x$ e classificadas segundo o grau de penetração do corante. Em consenso, os examinadores por análise prévia, escolheram somente uma das secções, ou seja, a que obteve maior grau de penetração do corante.

O grau de infiltração foi atribuído segundo o critério de escores modificados por CRIM e GARCIA-GODOY27 (figuras 3,4,5,6,7):

0- Nenhuma infiltração

1- Infiltração até metade da parede circundante

2- Infiltração em toda a parede circundante

3- Infiltração na parede circundante e axial

4- Infiltração na parede circundante, axial e em direção à polpa

Os dados obtidos foram organizados e submetidos à análise estatística através do teste não paramétrico de Mack- Skillings ${ }^{57}$, combinado com 0 de Kruskal-Wallis ${ }^{63}$, complementados pelos respectivos testes de contrastes entre variáveis, duas a duas.

${ }^{*}$ Bronwill- Motor Apliance WRP- USA 


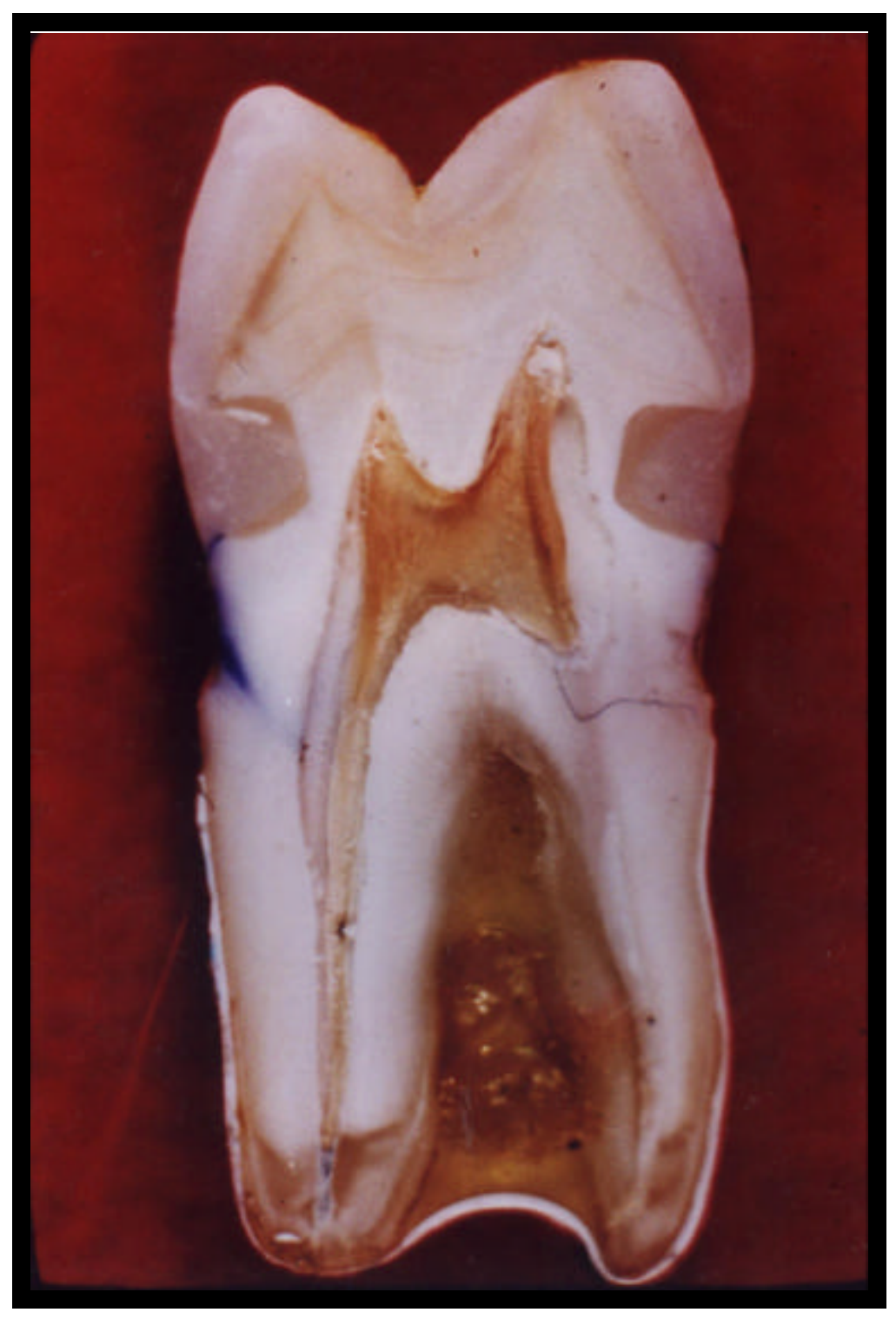

Figura 3 - Grau 0 


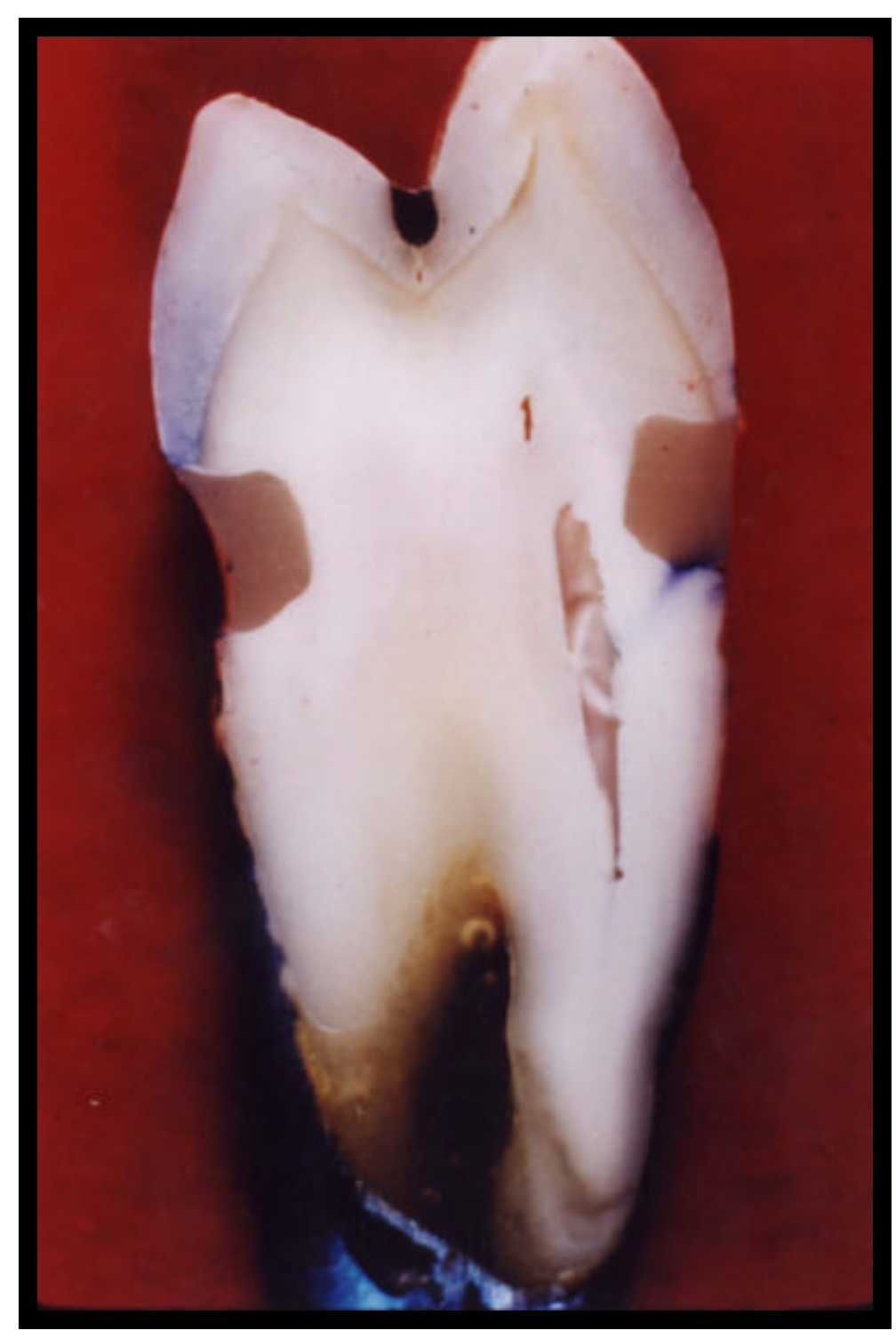

Figura 4 - Grau 1 


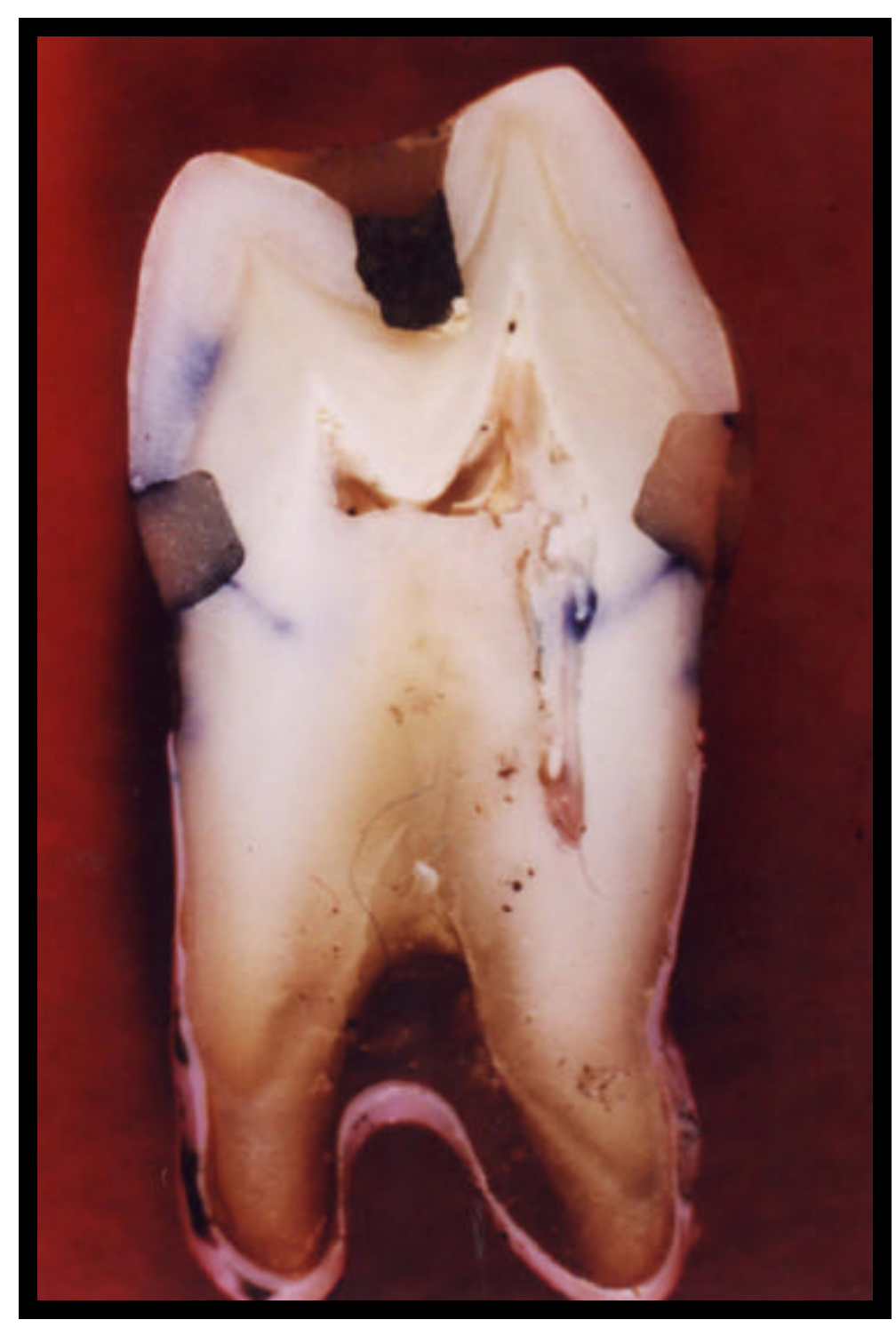

Figura 5 - Grau 2 


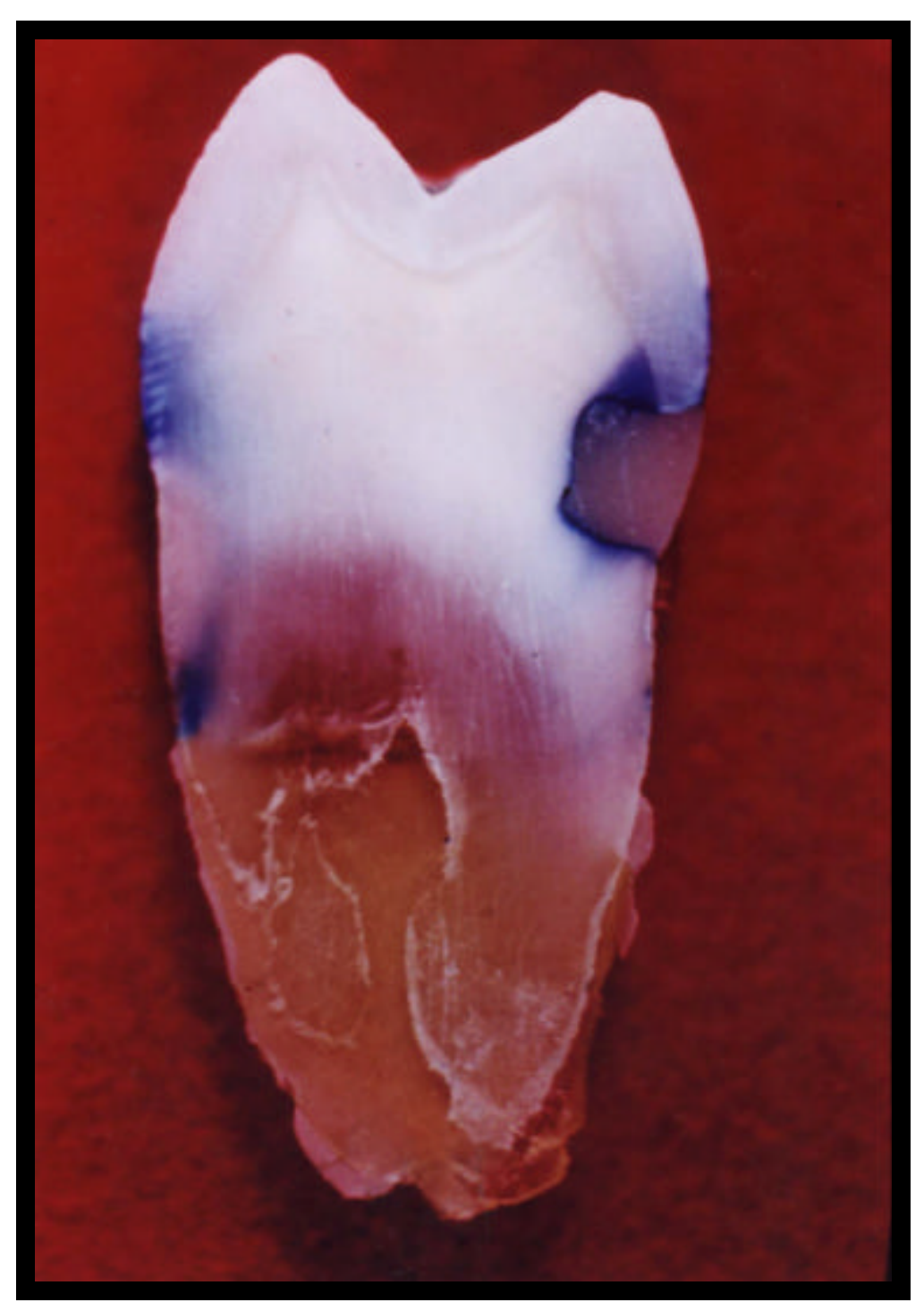

Figura 6 - Grau 3 


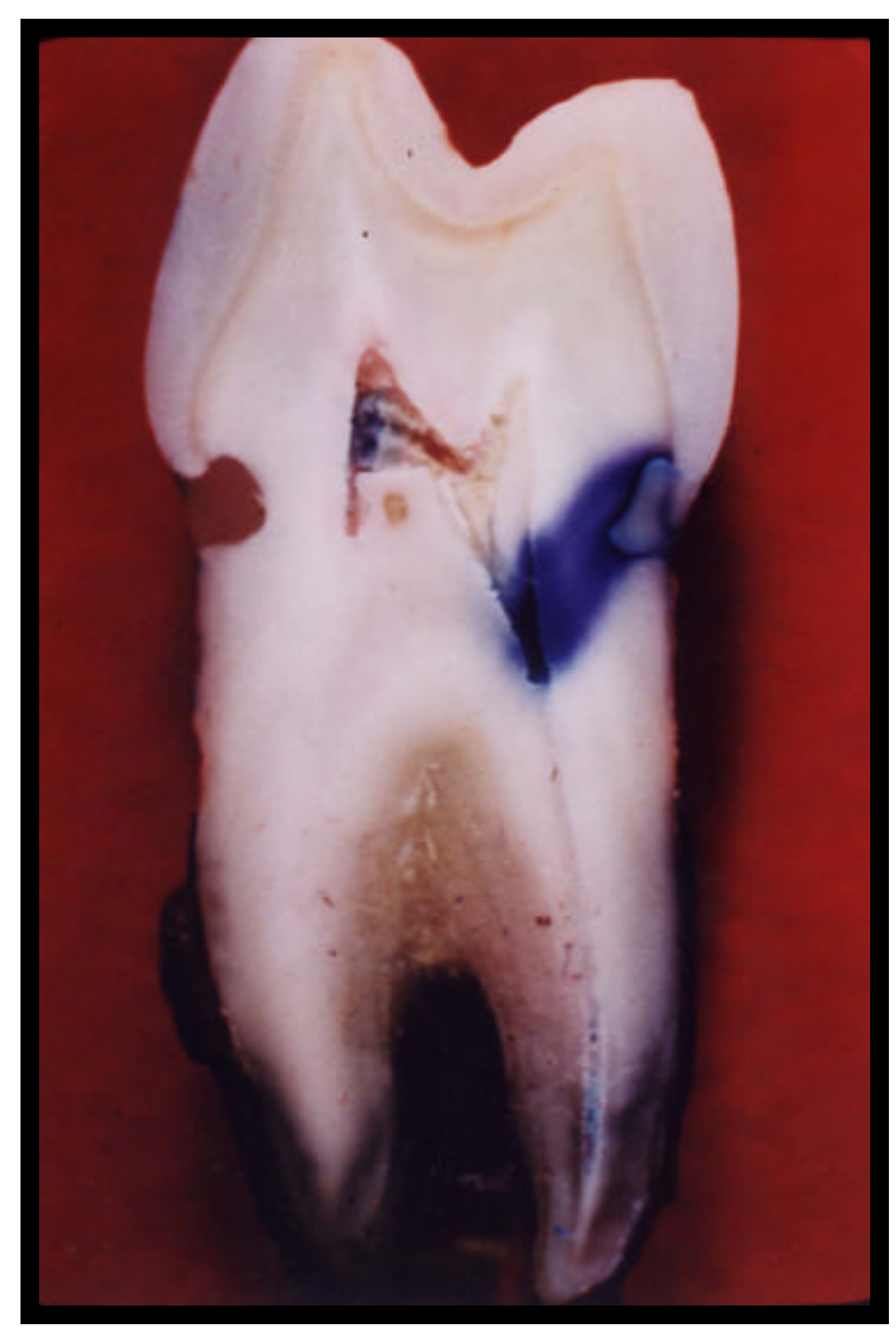

Figura 7 - Grau 4 
5 - RESULTADOS 


\section{5 - RESULTADOS}

Quadro 1. Escores (de 0 a 4) quantificando a infiltração marginal observada nos dentes (linhas) distribuídos em função dos materiais restauradores e das paredes cavitárias, de cada dente em cada linha.

\begin{tabular}{|c|c|c|c|c|}
\hline \multirow{3}{*}{$\begin{array}{c}\text { Materiais } \\
\text { Restauradores }\end{array}$} & \multicolumn{4}{|c|}{ Parede Cavitária } \\
\hline & \multicolumn{2}{|c|}{ ESMALTE (Oclusal) } & \multicolumn{2}{|c|}{ CEMENTO (Gengival) } \\
\hline & Vestibular & Lingual & Vestibular & Lingual \\
\hline ALERT & $\begin{array}{l}0 \\
0 \\
1 \\
0 \\
0 \\
1 \\
0 \\
0 \\
0 \\
1\end{array}$ & $\begin{array}{l}1 \\
0 \\
0 \\
0 \\
2 \\
0 \\
0 \\
0 \\
0 \\
0\end{array}$ & $\begin{array}{l}1 \\
0 \\
0 \\
0 \\
1 \\
1 \\
0 \\
0 \\
1 \\
0\end{array}$ & $\begin{array}{l}1 \\
0 \\
0 \\
0 \\
1 \\
0 \\
0 \\
0 \\
1 \\
0\end{array}$ \\
\hline SOLITAIRE & $\begin{array}{l}0 \\
3 \\
4 \\
4 \\
2 \\
0 \\
0 \\
4 \\
4 \\
4\end{array}$ & $\begin{array}{l}0 \\
3 \\
4 \\
1 \\
0 \\
4 \\
4 \\
4 \\
4 \\
0\end{array}$ & $\begin{array}{l}0 \\
4 \\
4 \\
4 \\
0 \\
0 \\
0 \\
4 \\
4 \\
4\end{array}$ & $\begin{array}{l}0 \\
4 \\
4 \\
0 \\
4 \\
4 \\
4 \\
4 \\
4 \\
1\end{array}$ \\
\hline Z-250 & $\begin{array}{l}1 \\
4 \\
1 \\
1 \\
1 \\
0 \\
0 \\
0 \\
1 \\
1\end{array}$ & $\begin{array}{l}4 \\
1 \\
0 \\
4 \\
1 \\
1 \\
0 \\
3 \\
1 \\
1\end{array}$ & $\begin{array}{l}2 \\
4 \\
0 \\
2 \\
1 \\
0 \\
4 \\
0 \\
4 \\
0\end{array}$ & $\begin{array}{l}4 \\
1 \\
1 \\
2 \\
1 \\
1 \\
1 \\
0 \\
0 \\
0\end{array}$ \\
\hline DYRACT AP & $\begin{array}{l}1 \\
2 \\
1 \\
0 \\
0 \\
0 \\
3 \\
0 \\
0 \\
0\end{array}$ & $\begin{array}{l}0 \\
0 \\
0 \\
4 \\
0 \\
0 \\
0 \\
4 \\
0 \\
3\end{array}$ & $\begin{array}{l}0 \\
0 \\
0 \\
0 \\
4 \\
0 \\
0 \\
1 \\
0 \\
4\end{array}$ & $\begin{array}{l}0 \\
0 \\
0 \\
4 \\
0 \\
0 \\
0 \\
3 \\
0 \\
0\end{array}$ \\
\hline $\begin{array}{l}\text { VITREMER } \\
\text { (CONTROLE) }\end{array}$ & $\begin{array}{l}1 \\
2 \\
2 \\
1 \\
3 \\
0 \\
1 \\
1 \\
1 \\
2\end{array}$ & $\begin{array}{l}2 \\
1 \\
1 \\
1 \\
1 \\
0 \\
1 \\
1 \\
2 \\
1\end{array}$ & $\begin{array}{l}4 \\
1 \\
4 \\
1 \\
2 \\
0 \\
2 \\
3 \\
1 \\
1\end{array}$ & $\begin{array}{l}4 \\
2 \\
0 \\
1 \\
1 \\
2 \\
1 \\
1 \\
4 \\
4\end{array}$ \\
\hline
\end{tabular}


O quadro 1 acolhe os escores atribuídos e representados das magnitudes das infiltrações marginais observadas nas paredes cavitárias dos dentes, distribuídos em função dos materiais restauradores e das paredes cavitárias de cada dente em cada linha.

O quadro 2 dispõe a soma dos postos consignados aos escores do quadro 1, calculadas para o teste de Kruskal-Wallis (Miller), distribuídas em função dos materiais restauradores e das paredes cavitárias, incluindo suas somas gerais.

Quadro 2. Somas de postos calculadas para o teste de Kruskal-Wallis sobre os escores do quadro 1, distribuídas em função dos materiais restauradores e das paredes cavitárias.

\begin{tabular}{|c|c|c|c|c|c|}
\hline \multirow{3}{*}{ MATERIAIS } & \multicolumn{4}{|c|}{ PAREDE CAVITARIA } & \multirow{3}{*}{$\begin{array}{c}\text { Somas } \\
\text { Gerais dos } \\
\text { Postos } \\
\text { Gerais dos } \\
\text { Materiais } \\
\end{array}$} \\
\hline & \multicolumn{2}{|c|}{ Esmalte (Oclusal) } & \multicolumn{2}{|c|}{ Cemento (Gengival) } & \\
\hline & Vestibular & Lingual & Vestibular & Lingual & \\
\hline Alert & 630,50 & 596 & 699 & 630,50 & 2556 \\
\hline Solitaire & 1331,50 & 1297,50 & 1253 & 1459,50 & 5341,50 \\
\hline Z-250 & 974 & 1157,50 & 1112,50 & 1008 & 4252 \\
\hline Dyract AP & 778,50 & 815 & 769,50 & 677 & 30,40 \\
\hline Vitremer & 1189 & 11095 & 1294 & 1318 & 4910,50 \\
\hline $\begin{array}{l}\text { Somas } \\
\text { Gerais dos } \\
\text { Postos das } \\
\text { Paredes } \\
\text { Cavitárias } \\
\end{array}$ & 4903,50 & 4975,50 & 5128 & 5093 & 20100 \\
\hline
\end{tabular}


Quadro 3. Postos Médios distribuídos em função dos materiais restauradores e das paredes cavitárias.

\begin{tabular}{|c|c|c|c|c|c|}
\hline \multirow{3}{*}{ MATERIAIS } & \multicolumn{4}{|c|}{ PAREDE CAVITARIA } & \multirow{3}{*}{$\begin{array}{l}\text { Postos } \\
\text { Médios } \\
\text { Gerais dos } \\
\text { Materiais }\end{array}$} \\
\hline & \multicolumn{2}{|c|}{ Esmalte (Oclusal) } & \multicolumn{2}{|c|}{ Cemento (Gengival) } & \\
\hline & Vestibular & Lingual & Vestibular & Lingual & \\
\hline Alert & 63,05 & 59,60 & 69,90 & 63,05 & 63,90 \\
\hline Solitaire & 133,15 & 129,75 & 125,30 & 145,95 & 133,5375 \\
\hline Z-250 & 97,40 & 115,75 & 111,25 & 100,80 & 106,30 \\
\hline Dyract AP & 77,85 & 81,50 & 76,95 & 67,70 & 76 \\
\hline Vitremer & 118,90 & 110,95 & 129,40 & 131,80 & 122,7625 \\
\hline $\begin{array}{l}\text { Postos } \\
\text { Médios } \\
\text { Gerais das } \\
\text { Paredes } \\
\text { Cavitária } \\
\end{array}$ & 98,07 & 99,51 & 102,56 & 101,86 & 100,50 \\
\hline
\end{tabular}

O quadro 3 adota os postos médios calculados sobre as somas dos postos contidos no quadro 2, incluindo os postos médios gerais dos materiais e das paredes cavitárias, fundamentais para a aplicação do teste de MackSkillings (Miller). Este teste, comparando o maior posto médio geral das paredes cavitárias (a de cemento vestibular $=102,56$ ) com o menor (de esmalte vestibular $=98,07)$, resultando diferença $=4,49$ que contra 0 valor crítico a n.s. $5 \%=30,04$, demonstra não existir qualquer diferença geral significante entre paredes $(p>0,05)$. Já entre materiais, aparecem diversas diferenças entre postos médios gerais estatisticamente significantes, ou seja, maiores do que o valor crítico a n.s. $5 \%=35,57$ e até maiores do que a n.s. $1 \%=42,44$, ensejando comparações, sistemáticas, duas a duas, buscando as diferenças entre tais postos gerais do quadro 3 (gráfico 1), relacionadas assim: 


$$
\begin{aligned}
& \text { Alert X Solitaire - 69,6375 ** } \\
& \text { Alert X Vitremer - 58,8625 ** } \\
& \text { Alert X Z-250 - 42,4000* } \\
& \text { Alert X Dyract AP - 12,1000 ns } \\
& \text { Dyract AP X Solitaire - 57,5375 ** } \\
& \text { Dyract AP X Vitremer - 46,7625 ** } \\
& \text { Dyract AP X Z-250 - 30,3000 ns } \\
& \text { Z-250 X Solitaire - 27,2375 ns } \\
& \text { Z-250 X Vitremer - 16,4625 ns } \\
& \text { Vitremer X Solitaire- 10,7750 ns }
\end{aligned}
$$

\begin{tabular}{|c|c|c|c|}
\hline Classificação & $\begin{array}{c}\text { Material } \\
\text { Restaurador }\end{array}$ & Posto Médio & Diferenciação \\
\hline $1^{0}$ & Alert & 63,90 & a \\
\hline $2^{\circ}$ & Dyract AP & 76 & $a b$ \\
\hline $3^{\circ}$ & Z-250 & 106,30 & $\mathrm{bc}$ \\
\hline $4^{\circ}$ & Vitremer & 122,76 & $C$ \\
\hline $4^{\circ}$ & Solitaire & 133,53 & c \\
\hline
\end{tabular}

\footnotetext{
** diferença significante $(\mathrm{P}<0,01)$

* diferença significante $(P<0,05)$

ns-diferença não significante $(P>0,05)$
}

Assim, conseguiu-se a seguinte sinopse classificatória sobre os materiais restauradores:

significante $(P>0,05)$ 
Gráfico 1 :Representação dos postos médios gerais da microinfiltração dos materiais restauradores considerando as paredes cavitárias $(\mathrm{n}=200$ )

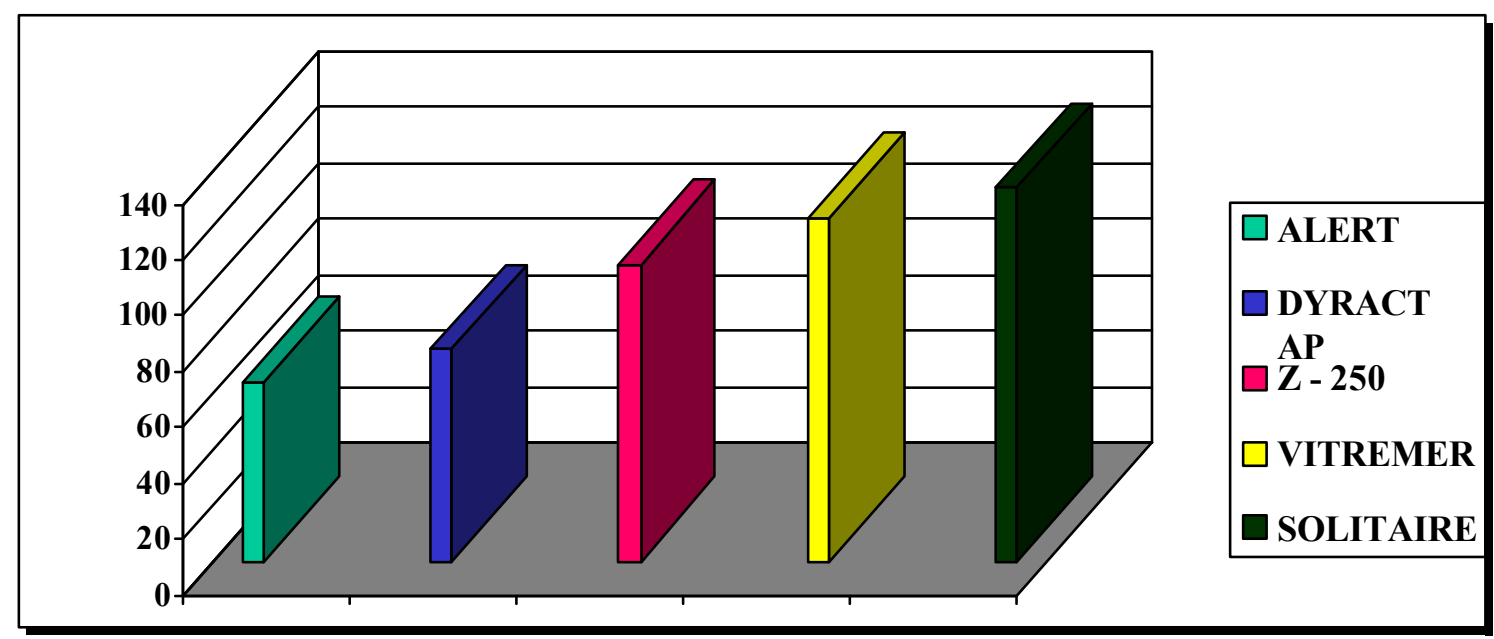

A constatação de que as paredes cavitárias não constituem fonte de variação significante permite destacar os materiais restauradores, autorizando a se aplicar o teste de Kruskal-Wallis, que é a um critério, sobre as somas de postos gerais (quadro 2), e o conseqüente teste de Miller (Miller) sobre os postos médios gerais (quadro 3) referentes a eles, os materiais restauradores. Em outras palavras, estes testes substituem o de Mack-Skillings, aumentando o poder de diferenciação da metodologia estatística.

O valor do $\mathrm{H}$ calculado de Kruskal-Wallis (Miller) é 45,15 , altamente significante quando comparado ao Qui Quadrado para 4 graus de liberdade e a nível de significância de $1 \%=13,28$. Os valores críticos de Miller (já corrigidos pelo z) e que substituem os de Mack-Skillings, são: 25,72 a 5\% e 30,16 a 1\%. As comparações entre postos médios dos materiais restauradores passam a ser estatisticamente diferenciadas assim: 
Alert X Solitaire $-69,6375$ **

Alert X Vitremer - 58,8625 **

Alert X Z-250 - 42,4000 **

Alert X Dyract AP - 12,1000 ns

Dyract AP X Solitaire $-57,5375^{* *}$

Dyract AP X Vitremer - 46,7625 **

Dyract AP X Z-250 - 30,3000 **

Z-250 X Solitaire $-27,2375$ *

Z-250 X Vitremer - 16,4625 ns

Vitremer X Solitaire - 10,7750 ns

** diferença significante $(P<0,01)$

* diferença significante $(P<0,05)$

ns-diferença não significante $(P>0,05)$

Destarte, a sinopse classificatória sobre os materiais restauradores, passa a ser:

\begin{tabular}{c|c|c|c}
\hline Classificação & $\begin{array}{c}\text { Material } \\
\text { Restaurador }\end{array}$ & Posto Médio & Diferenciação \\
\hline $1^{\circ}$ & Alert & 63,90 & a \\
$1^{\circ}$ & Dyract AP & 76 & a \\
$2^{0}$ & Z-250 & 106,30 & b \\
$3^{0}$ & Vitremer & 122,76 & bc \\
$4^{0}$ & Solitaire & 133,53 & c \\
\hline
\end{tabular}


Diferenciação: letras iguais representam diferenciação estatisticamente não significante $(P>0,05)$

Até aqui foram tratados os escores como independentes dos dentes. Assim, compete considerá-los dependentes, isto é, que os 4 escores em linha representativos de cada dente (quadro1) passem por tratamento conciliatório unificando-os através da média. Assim procedendo, obteve-se o quadro 4, que acolhe os escores médios de cada dente, distribuídos em função dos materiais restauradores.

Quadro 4. Escores médios representativos das infiltrações marginais calculados para os dentes, distribuídos sobre o fatorial materiais restauradores.

\begin{tabular}{||c|c|c|c|c||}
\hline Alert & Solitaire & Z-250 & Dyract AP & Vitremer \\
\hline 0,75 & 0,00 & 2,75 & 0,25 & 2,75 \\
0,00 & 3,50 & 2,50 & 0,50 & 1,50 \\
0,25 & 4,00 & 0,50 & 0,25 & 1,75 \\
0,00 & 2,25 & 2,25 & 2,00 & 1,00 \\
1,00 & 1,50 & 1,00 & 1,00 & 1,75 \\
0,50 & 2,00 & 0,50 & 0,00 & 0,50 \\
0,00 & 2,00 & 1,25 & 0,75 & 1,25 \\
0,00 & 4,00 & 0,75 & 2,00 & 1,50 \\
0,50 & 4,00 & 1,50 & 0,00 & 2,00 \\
0,25 & 2,25 & 0,50 & 1,75 & 2,00 \\
\hline \hline
\end{tabular}


Gráfico 2: Representação do posto médio da microinfiltração dos materiais restauradores,considerando os dentes e independentes das paredes cavitárias $(\mathrm{n}=50)$

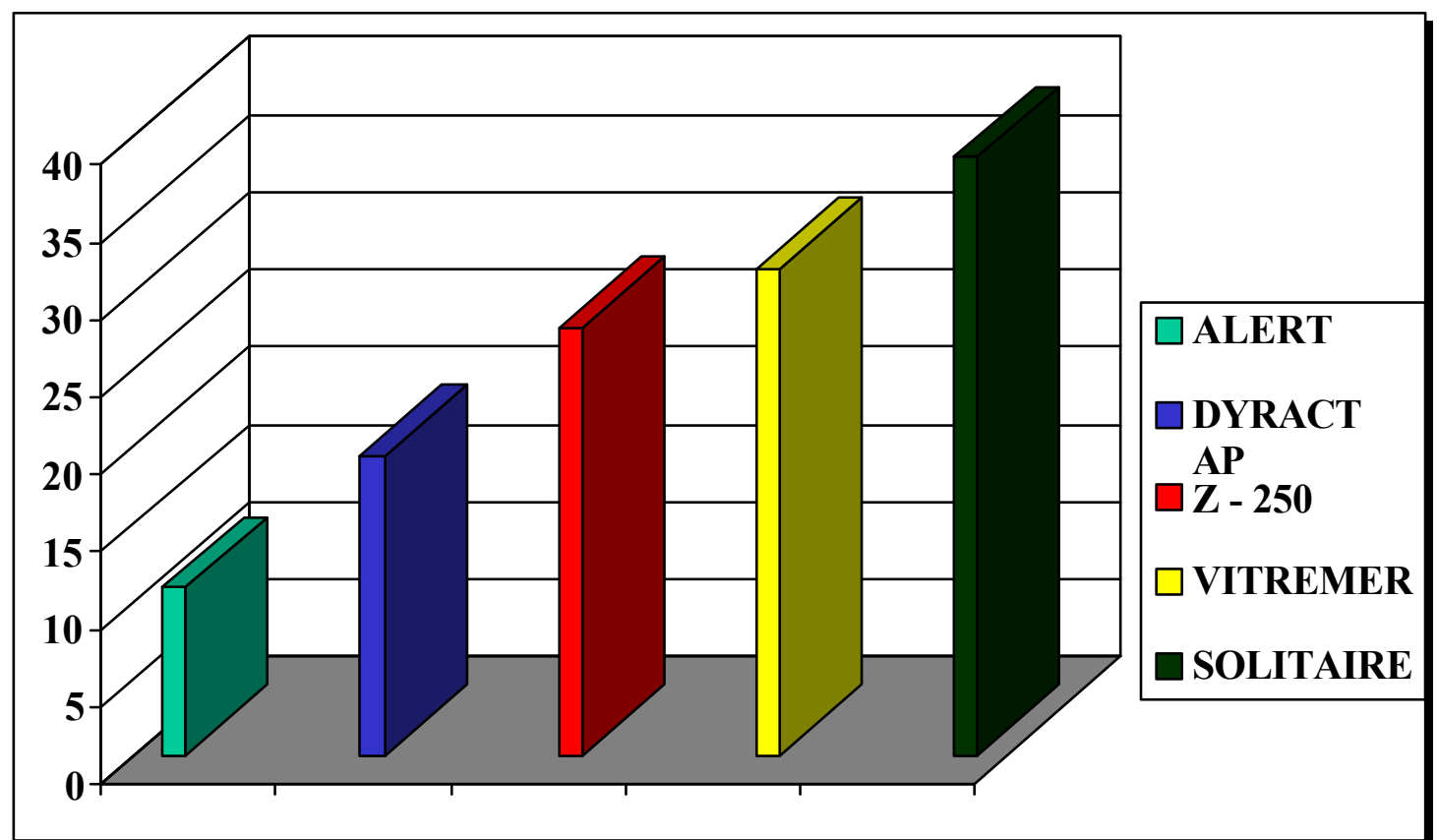

Sobre os escores médios do quadro 4 calculou-se os postos, suas somas e médias destas, respectivamente para cada material restaurador. Os postos médios constam na sinopse classificatória que segue após as diferenças para discernimentos entre eles (gráfico 2).

Sobre tais dados aplicou-se o teste de Kruskal-Wallis (Miller) seguido do contraste de Miller (Miller), tendo os valores críticos destes: 12,96 para ns $5 \%$ e 15,19 para ns $1 \%$ corrigidos por " $z$ " nesta alternativa estatística, as diferenças entre posto médios constam a seguir com os discernimentos estatísticos: 


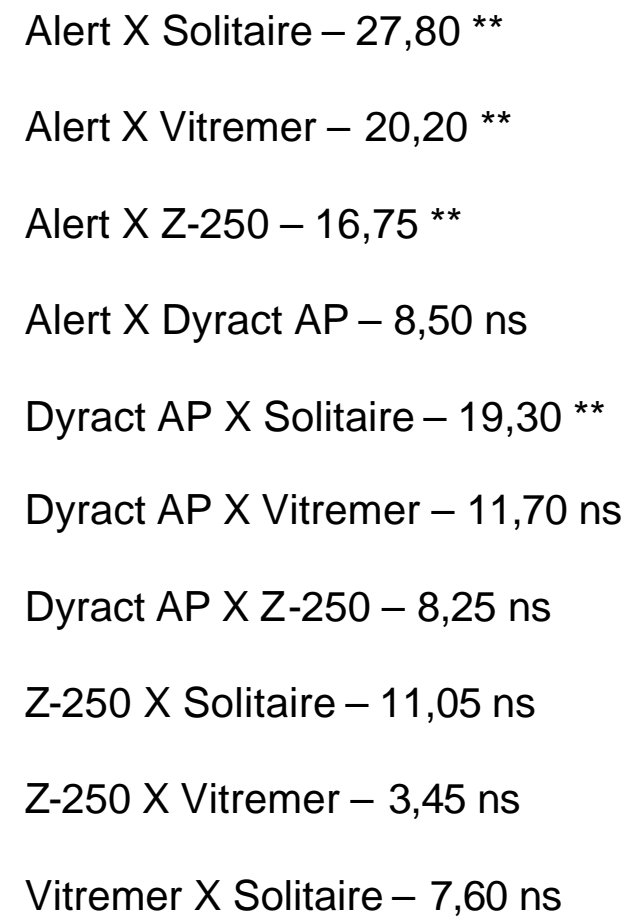

** diferença significante $(\mathrm{P}<0,01)$

* diferença significante $(P<0,05)$

ns-diferença não significante $(P>0,05)$

Da circunstância em pauta resulta a seguinte sinopse classificatória:

\begin{tabular}{c|c|c|c}
\hline Classificação & $\begin{array}{c}\text { Material } \\
\text { Restaurador }\end{array}$ & Posto Médio & Diferenciação \\
\hline $1^{\circ}$ & Alert & 10,85 & $\mathrm{a}$ \\
$2^{\circ}$ & Dyract AP & 19,35 & $\mathrm{ab}$ \\
$3^{\circ}$ & Z-250 & 27,60 & $\mathrm{bc}$ \\
$4^{\circ}$ & Vitremer & 31,05 & $\mathrm{bc}$ \\
$4^{\circ}$ & Solitaire & 38,65 & $\mathrm{c}$ \\
\hline
\end{tabular}

Diferenciação: letras iguais representam diferenciação estatisticamente não significante $(P>0,05)$ 
Tomando por base as três análises estatísticas feitas, tem-se a seguinte sinopse ordenativa dos materiais restauradores, partindo do que permitiu a menor infiltração marginal para a maior (quadro 5):

Quadro 5. Sinopse diferenciadora dos materiais restauradores, ordenados do que permitiu menor infiltração marginal para a maior.

\begin{tabular}{||c|c|c|c|c|c||}
\hline \multirow{2}{*}{ Classificação } & Material & \multicolumn{3}{|c||}{ Diferenciações } & \multirow{2}{*}{ Consenso } \\
\cline { 3 - 6 } & Restaurador & MS & KW1 & KW2 & \\
\cline { 3 - 5 } $1^{\circ}$ & Alert & $\mathrm{a}$ & $\mathrm{a}$ & $\mathrm{a}$ & $3 \mathrm{a}$ \\
$2^{\circ}$ & Dyract AP & $\mathrm{ab}$ & $\mathrm{a}$ & $\mathrm{ab}$ & $3 \mathrm{a} 2 \mathrm{~b}$ \\
$3^{\circ}$ & Z-250 & $\mathrm{bc}$ & $\mathrm{b}$ & $\mathrm{bc}$ & $3 \mathrm{~b} 2 \mathrm{c}$ \\
$4^{\circ}$ & Vitremer & $\mathrm{c}$ & $\mathrm{bc}$ & $\mathrm{bc}$ & $2 \mathrm{~b} 3 \mathrm{c}$ \\
$5^{\circ}$ & Solitaire & $\mathrm{c}$ & $\mathrm{c}$ & $\mathrm{c}$ & $3 \mathrm{c}$ \\
\hline
\end{tabular}

Diferenciações: letras iguais representam diferenças estatisticamente não significante $(P>0,05)$

MS = pelo teste de Mack-Skillings (Paredes Cavitárias \& Materiais restauradores)

$\mathrm{KW} 1=$ Kruskal-Wallis (só materiais restauradores de paredes cavitárias e independentes delas)

$\mathrm{KW} 2=$ Kruskal-Wallis (só materiais restauradores sobre escores médios dos dentes, independentes das paredes cavitárias).

Consenso = síntese das diferenciações 
Decodificação: Entre $01^{0}$ e $\circ 2^{\circ}$ colocado não há diferença estatisticamente significante: entre $\circ 2^{\circ}$ e $3^{\circ}$ e $4^{\circ}$ e entre o $3^{\circ}$ e $4^{\circ}$ e o ultimo $\left(5^{\circ}\right)$ também não $(P>0,05)$. Entre $\circ 1^{\circ}$ e $\circ 3^{\circ} / 4^{\circ}$ e $5^{\circ}$ as diferenças são significantes $(P<0,005)$, assim como entre o $2^{\circ}$ e o último (5ํ).

Destas análises estatísticas infere-se que o Alert sempre se destacou como o que menos infiltração marginal concedeu, seguido imediatamente e sem diferenciação consensual significante pelo Dyract AP. Noutro extremo, permitindo as maiores infiltrações marginais, posicionou-se o Solitaire, imediatamente antecedido pelo Vitremer e, antes dele, pelo Z-250. Entre estes três não houve destaque consensual significante, formando um bloco destacado em relação ao Alert e o Dyract AP. Todavia, houve tendência do Dyract igualar-se estatisticamente ao Z250 e até ao Vitremer. Resumindo, o Alert foi destacadamente o melhor e o Solitaire o pior selador marginal. O Dyract AP, o Z-250 e o Vitremer, no mesmo critério de ordenação foram intermediários, com destaque a centuado do Dyract AP.

Para verificar possíveis interferências dos fatores dentes (linhas) e paredes cavitárias (colunas), para cada material foi aplicada a análise não paramétrica de Friedman, cruzando-os a partir do Quadro 1. Em nenhum dos cruzamentos entre tais fatores dentro de qualquer dos materiais, foi constatada significância estatística $(p>0,05)$. Todavia, merece citação a probabilidade igual a 0,057 registrada entre os dentes amostrados no Solitaire, quando aplicado o KruskalWallis sobre eles, observando-se também $\mathrm{H}=16,49$ contra ० Qui- Quadrado a 5\% = 16,92. Julgamos que com a amostragem maior do que os 10 dentes utilizados neste experimento, alcançar-se-ia diferenciação estatística com inferência de $5 \%$. Os 
gráficos 3 e 4 representam os postos médios encontrados para os referidos cruzamentos.

Gráfico 3: Representação dos postos médios da microinfiltração dos materiais restauradores no esmalte

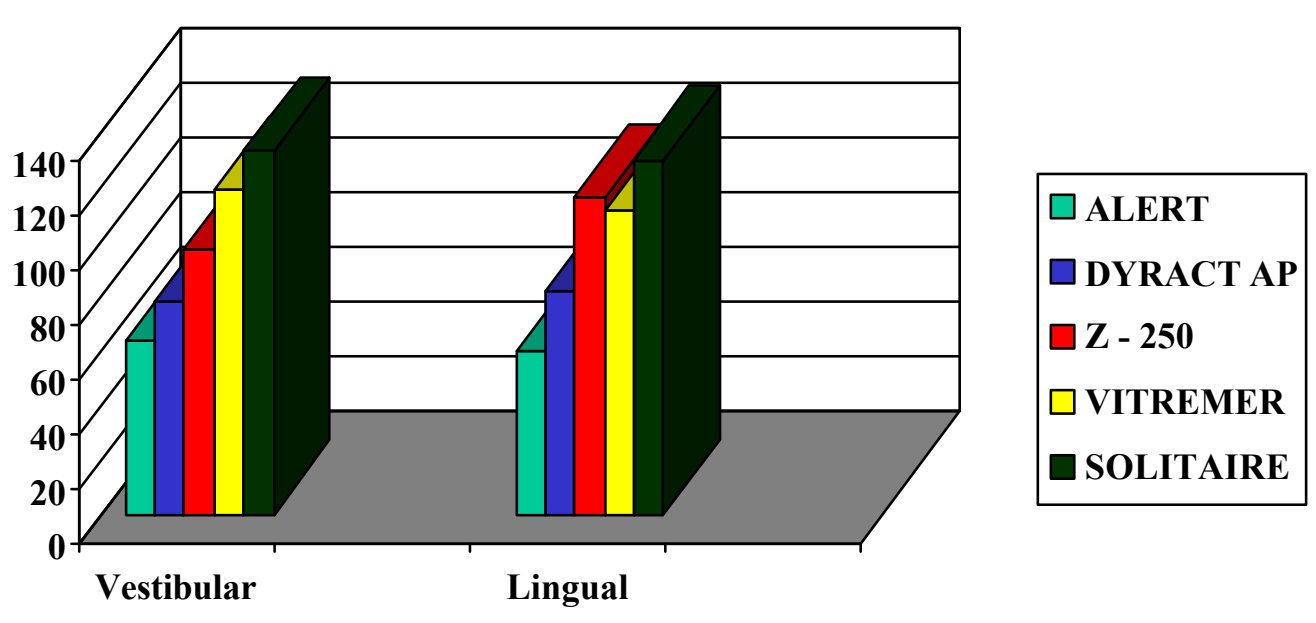

Gráfico 4: Representação dos postos médios da microinfiltração dos materiais restauradores no cemento

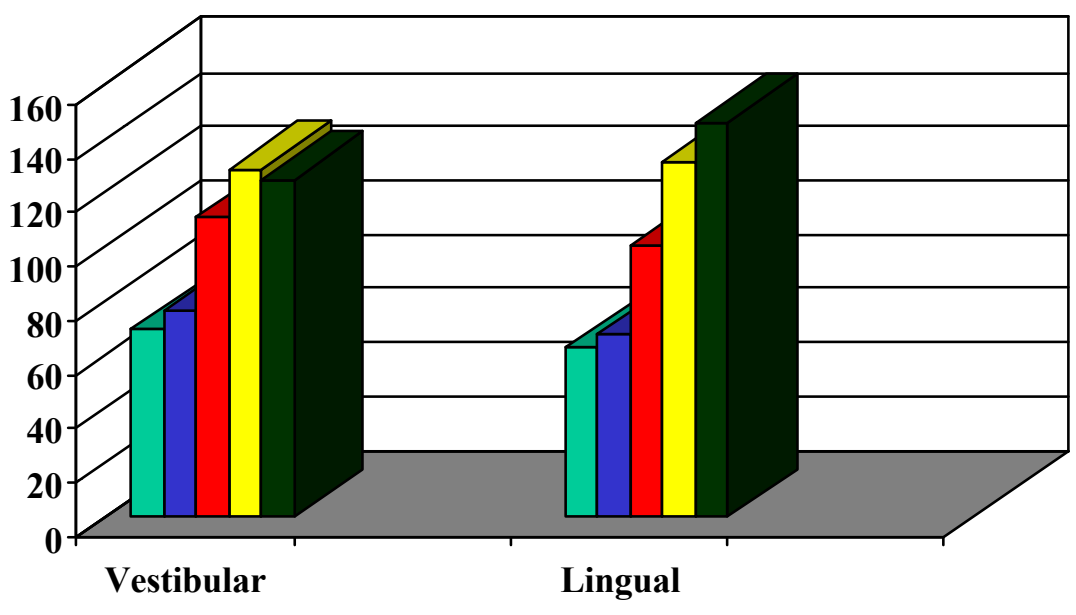

$\square$ ALERT

$\square$ DYRACT AP

$\square \mathrm{Z}-250$

VITREMER

DSOLITAIRE

Vestibular

Lingual 
6 - DISCUSSÃO 


\section{6 - DISCUSSÃO}

\section{1 - Da metodologia}

Nesse trabalho foram utilizados dentes pré-molares superiores e inferiores humanos e livres de cáries, onde foram avaliadas as infiltrações marginais em restaurações tipo classe $V$ com resina composta ${ }^{73}$, compômero ${ }^{20}$ e ionômero de vidro ${ }^{59}$.

RETIEF et $\mathrm{al}^{76}$ observaram que, a respeito do efeito dos meios de armazenagem e do tempo de duração da estocagem dos dentes extraídos, em relação à resistência de união do adesivo de dentina a dentina, os espécimes armazenados em soro fisiológico, cloramina a $1 \%$ ou formalina tamponada apresentaram melhores resultados de resistência de união, sem diferença estatisticamente significante entre os espécimes armazenados em períodos de 2 dias e seis meses. Contudo, nesse trabalho o meio de armazenagem foi a formalina tamponada a 10\% e os dentes foram estocados após a extração, por um período de até 90 dias, antes da realização das cavidades e restaurações. Portanto, quanto à armazenagem e estocagem dos espécimes utilizados, não diferimos da citação de RETIEF et $\mathrm{al}^{76}$. Outrossim, CAMPS et $\mathrm{al}^{14}$ compararam a microinfiltração de agentes adesivos em solução salina em 80 terceiros molares humanos recém extraídos, dividindo-os em 3 grupos: grupo 1: dentes extraídos e coletados em duas horas; grupo 2: dentes preservados em solução salina por 4 horas e grupo 3: dentes refrigerados e armazenados a 4ํㅡㄴ Celsius por períodos de 12/48/72/ 138 dias, concluindo que os dentes armazenados e refrigerados a $4^{\circ}$ C por 12 dias, não sofreram alteração com relação a 
microinfiltração, enquanto que os dentes armazenados e refrigerados por 48 dias ou mais demonstraram aumento da infiltração marginal. CRIM ${ }^{24,} 25$ testando o tempo de armazenagem dos dentes por períodos de 3 e 18 meses e 24horas e 6 meses, não detectou diferença estatística significante nos espécimes quanto à infiltração marginal. Levando-se em conta tais observações, o tempo de estocagem pode, possivelmente, ter produzido certa alteração em nosso experimento, porém esta foi minimizada uma vez que todos os dentes foram armazenados por período maior de 48 dias, produzindo, portanto, certa homogeneidade em nossos resultados, reforçada pelo fato de que os dentes foram misturados quando coletados e então utilizados para confecção das cavidades e restaurações. Assim, foi mantido um padrão aleatório o qual, esperadamente, minimizou a interferência do armazenamento no resultado da infiltração marginal.

Em nosso trabalho foram realizadas 100 cavidades classe $V$, na face vestibular e lingual $\left.\right|^{8,24}$ em 50 dentes pré molares. Neste aspecto, BARNES et $a l^{8}$, compararam a infiltração marginal em cavidades classe $V$ na vestibular e lingual em dentes restaurados com resina composta e concluíram que não foi estatisticamente significante a diferença entre as faces vestibular e lingual, do esmalte e cemento das superfícies dentárias. Entre a metade mesial e distal também não houve diferença significante, porém esta esteve presente entre a margem de esmalte e cemento, com menor infiltração marginal no esmalte e maior no cemento ${ }^{8,16,99}$. O bisel de $45^{\circ}$ em esmalte tem sido utilizado para aumentar a superfície de união e, conseqüentemente, a retenção do material restaurador resinoso $26,88,90,95$. Mas, para o cimento de ionômero de vidro não 
se usa bisel em seu preparo cavitário $^{25,} 49$ e, como queríamos uma padronização de tais preparos, todas as cavidades foram preparadas sem bisel, isto tanto no esmalte como no cemento.

As cavidades foram preparadas com $3 \mathrm{~mm}$ de diâmetro e 1,5 mm de profundidade, sendo o término da parede oclusal em esmalte e da parede cervical em cemento. Para o acabamento das margens, foram utilizadas brocas carbide em baixa rotação e recortadores de margens gengivais para que o alisamento das superfícies fosse o melhor possível. As cavidades utilizadas

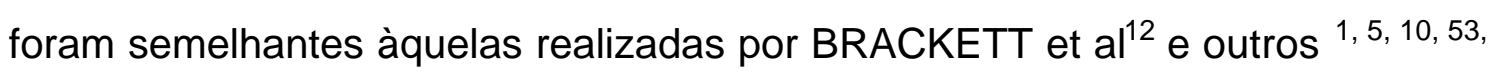
55, 58, 60, 77, 82, 98, 99,102 e permitiram boa inserção do material restaurador, atingiram o esmalte e o cemento adequadamente para o teste proposto, assim como a dentina coronária e radicular foi suficiente para a utilização dos adesivos de esmalte e dentina.

TAY et $\mathrm{al}^{91}$ e BOUSCHLICHER et $\mathrm{al}^{10}$ recomendam a técnica úmida da dentina para utilização do primer e adesivos dentinários, pois a secagem excessiva da dentina forma espaços interfibrilares na área do colágeno, produzindo na matriz intertubular uma região hibridóide. Nos grupos da técnica da dentina úmida observourse a formação da camada híbrida ${ }^{67}$, enquanto que um aumento da microinfiltração marginal foi constatado nos dentes dessecados. Neste trabalho utilizamos a técnica da dentina úmida, somente diferindo quanto à secagem do excesso de água, a qual foi removida com papel absorvente, conforme preconizado pela maioria dos autores, e contrastando com outros que procederam com a secagem através de jatos de ar comprimido. 
DAVIDSON et al ${ }^{29}$ analisaram a contração de polimerização das resinas compostas e relataram que o fator $\mathrm{C}$ é diretamente proporcional às superfícies aderidas e inversamente proporcional às superfícies livres, ou seja, a contração de polimerização é tanto maior quanto o número de paredes cavitárias envolvidas. As restaurações nesse trabalho foram realizadas por meio de uma espátula de titânio, com a técnica incremental, em duas paredes, para diminuir o fator C. A primeira camada foi inserida da parede gengival em direção axial até alcançar o ângulo áxio-oclusal, quando então foi fotopolimerizada, sendo posicionada a extremidade do aparelho de encontro à parede gengival. A inserção da segunda camada foi iniciada no ângulo cavosuperficial da parede oclusal, estendendo-se até a metade da primeira camada sendo que a extremidade do aparelho fotopolimerizador foi posicionada de encontro à parede oclusal. Por fim, a terceira camada foi adicionada por vestibular (ou lingual), recobrindo toda a cavidade, e a fotopolimerização realizada em direção à mesma face. Cada incremento foi fotopolimerizado segundo as instruções dos fabricantes. O cimento de ionômero de vidro foi colocado no interior da cavidade com uma seringa Centrix em uma única vez e então fotopolimerizado por 40 segundos. A utilização da seringa Centrix para o ionômero de vidro também minimiza a formação de bolhas e porosidade que aumentariam, por sua vez, a infiltração marginal.

O acabamento das restaurações consistiu na remoção dos excessos grosseiros com a lâmina de bisturi Barder-Parker № 15, seguido de imersão dos espécimes em água destilada, por 24 horas. Decorrido este tempo, foi realizado o polimento com discos Sof-Lex ${ }^{11,38,55,56,74}$, do mais grosseiro para 
o mais fino, evitando-se a utilização de pontas diamantadas e brocas multilaminadas, as quais poderiam desgastar demasiadamente a superfície restaurada, além de torná-la mais rugosa, fato este que poderia interferir no resultado do selamento marginal ${ }^{11}$.

Os procedimentos de ciclagem térmica, procurando simular as variações de temperatura da cavidade bucal principalmente durante as refeições, têm sido aplicados na maioria dos trabalhos laboratoriais, com pequenas discordâncias entre as temperaturas mínima e máxima e quanto ao número de ciclos. CRIM e GARCIA- GODOY27 observaram que o tempo de estocagem dos dentes antes do tratamento térmico ou a duração das ciclagens térmicas, não alteraram a infiltração marginal e concluíram que as ciclagens térmicas em curto prazo são tão efetivas quanto às ciclagens realizadas por um período mais prolongado, para demonstrar a infiltração marginal

Neste trabalho utilizamos as temperaturas de $5^{\circ} \mathrm{C}$ e $55^{\circ} \mathrm{C}$, por 30 segundos cada banho, visto que este tempo deve ser sempre superior a 10 segundos $^{78}$, perfazendo um total de 200 ciclos. Isto porque não tem sido revelada diferença estatística significante entre as ciclagens térmicas de 100 e 1000 ciclos $^{27}$, nem na imersão dos espécimes em água destilada ou no próprio corante, quando do teste de infiltração marginal. Portanto, desde a restauração até o término das imersões e lavagem, transcorreram aproximadamente 60 horas.

O corante utilizado foi o azul de metileno a $2 \%$, que possui um $\mathrm{pH}$ de 6.5, e apresenta maior constância e estabilidade, isto possivelmente relacionado com a sua característica de neutralidade hidrogeniônica, quando 
comparado com a violeta de genciana a $2 \%$, rhodamine B a $1 \%$ e fluoresceina a $2 \%$, que apresentam $\mathrm{pH}$ de 3,$1 ; 2,6$ e 7,8 , respectivamente ${ }^{87}$. Segundo citação de ALFIERR, o azul de metileno a $2 \%$ utilizado como marcador da infiltração marginal, tem a vantagem de difundir-se bem nas interfaces, sua visualização é direta e exibe bom contraste de cor com o dente e materiais testados, fixando-se estavelmente nas estruturas coradas devido ao seu $\mathrm{pH}$ neutro, sem comprometimento de áreas particulares, fato este que ocorre quando da utilização do rhodamine B a 1\%, que sendo um corante ácido tende a fixar-se em estruturas básicas através de uma reação tipo ânion-cátion (ácido-básica), inversamente à utilização da fucsina básica que, por sua vez, liga-se pela mesma reação a estruturas ácidas. Segundo SOUZA $^{87}$ a utilização de um corante neutro como o azul de, etileno a $2 \%$, tornam os resultados dos testes de microinfiltração mais fidedigno. E isento de periculosidade à saúde e é de baixo custo, argumentos estes que também favoreceram a sua escolha em relação aos demais. TAYLOR e LYNCH ${ }^{92}$ observaram através de uma revisão de literatura sobre os diversos métodos para demonstração de microinfiltração com materiais restauradores, tais como a pressão do ar, utilização de bactérias, radioisótopos, microscopia eletrônica de varredura, estudos eletroquímicos e uso de corantes, concluindo que dentre todos estes a utilização do corante, além de ser a técnica mais correntemente aplicada é favorecida pelo fato de associar- se com secções dos dentes e análise de toda a interface do material restaurador e dente, razão esta que também justifica nossa escolha. 
A avaliação da infiltração marginal pela atribuição de escores baseou-se no trabalho de CRIM et $\mathrm{al}^{28}$, onde foi atribuído o escore 0 quando não havia infiltração marginal; escore 1, quando esta alcançava até a junção amelodentinária; escore 2, quando esta alcançava toda a parede circundante; escore 3, com penetração do corante nas paredes circundantes e em toda a parede axial. Os nossos critérios foram modificados e passaram a assemelharse com os escores utilizados por VIEIRA ${ }^{99}$, em cavidades tipo classe II, o que acreditamos proporcionou uma classificação mais completa e abrangente, conforme necessitávamos em nossas cavidades classe V. O critério utilizado foi: escore 0 , nenhuma infiltração; escore 1 , até a metade da parede circundante; escore 2, infiltração em toda a parede circundante; escore 3, na parede circundante e axial e escore 4, infiltração na parede circundante, axial e em direção à polpa.

A análise estatística é de natureza não paramétrica ${ }^{63}$, pois é aplicada sobre escores classificatório-ordenativos, em escala intervalar. Neste trabalho, o Quadro 1 é básico. Os dados estão agrupados ou distribuídos considerando duas fontes de variação principais: a dos materiais restauradores, objetivo mor da proposição, e a das paredes cavitárias, secundária e conseqüente. Como são fontes pressupostamente interdependentes é pertinente considerá-las em conjunto em uma análise de variância não paramétrica a dois critérios. O teste disponível é o de MackSkilling ${ }^{57}$. Tal como o teste de KruskarWallis ${ }^{63}$, do qual é originado, ele fundamenta-se nos postos médios resultantes de suas somas, porém, com interdependências recíprocas decorrentes das duas fontes de variação, como 
consta no Quadro 3. O discernimento da significância ou não das diferenças entre variáveis de qualquer das fontes de variação é alcançado pela comparação de tais diferenças com o valor crítico, especialmente calculado considerando o número de variáveis em cada fonte. Se o nível de inferência, no caso $P$ 0,05, não for alcançado entre quaisquer variáveis de uma das fontes, esta passa a ser desconsiderada como influenciável sobre a outra fonte. Foi o que aconteceu com as paredes cavitárias em relação aos materiais restauradores. Independente disso, ainda pelo teste de Mack-Skillings, é possível verificar, como fizemos, as diferenças estatisticamente significantes entre os materiais. Todavia, o poder de teste sobre os materiais restauradores pelo Mack-Skillings é menor do que pelo Kruskal-Wallis. Como este se tornou viável pela neutralização do efeito paredes cavitárias, o segundo foi aplicado sobre os materiais alcançando alto nível de significância $(P<0,01)$, permitindo seu complemento pelos contrastes de Miller comparando suas variáveis. Assim, cumpre salientar o valor maior dos resultados aferidos pelo teste de Kruskal-Wallis, em relação ao Mack-Skillings, no caso dos materiais restauradores.

Isto posto, os resultados libertaram-se das paredes cavitárias, mas poderiam ainda ser dependentes dos dentes. Para contornar a dúvida passamos a considerar o escore médio das paredes cavitárias de cada dente como representante do próprio dente, gerando o Quadro 4. Assim, a amostragem de cada material que era de 40 cavidades passou a ser de 10 dentes. Por essa redução o poder diferenciador do teste também diminuiu, 
mas, por outro lado incluiu também o efeito dente na análise sobre os materiais restauradores.

Das três análises realizadas fez-se uma sinopse geral que consta no Quadro 5, procurando conciliá-las numa decodificação geral sobre os materiais testados. As inferências dessa decodificação foram fundamentais para as conclusões. Todavia, convêm salientar o maior poder de teste do KruskallWallis quando considera as cavidades como unidades amostrais.

Isto confirmaria a alta permeabilidade marginal do Solitaire, com tendência de possível influência do fator dente (e não de paredes) ${ }^{15}{ }^{29}$, passível de ter ocorrido por alguma dificuldade de manipulação, de aplicação, ou de outro fator técnico, isolados ou associados entre si, atinentes e intrínsecos. A ausência do selante de superfície neste material, mormente considerado suas macropartículas ${ }^{60,66}$, é um fator suspeito.

Preocupamo-nos ainda quanto a possíveis diferenças de comportamento entre os dentes e entre suas respectivas paredes cavitárias, representativos de cada material restaurador ${ }^{15,}{ }^{29}$. Assim, concebeurse 0 cruzamento entre linhas (representativas de dentes) e colunas (representativas de paredes cavitárias) no Quadro 1 para cada material, aplicando-se a análise de Friedman ${ }^{57}$ baseada em postos (como no KruskatWallis).

Entre paredes (esmalte vestibular e lingual e cemento vestibular e lingual) não se encontrou qualquer diferença significante, pois as probabilidades encontradas foram, para os respectivos materiais restauradores: Alert $=0,921$; Solitaire $=0,745 ; Z-250=0,739 ;$ Dyract $A P=0,827$ e Vitremer $=$ 0,337; portanto, $P>0,05$. 
Entre dentes (1 a 10 para cada material) não se encontrou também diferença significante, pois as probabilidades de Ho foram: Alert = 0,835; Solitaire $=0,932 ;$ Z-250 $=0,472 ;$ Dyract $A P=0,380$ e Vitremer $=0,307$. Convém registrar que, aplicando o teste de Kruskal-Wallis sobre os dados desta questão, mas independente das paredes cavitárias, observou-se $P=$ 0,224; 0,057; 0,101; 0,899 e 0, 385, para o Alert, Solitaire, Z-250, Dyract AP e Vitremer, respectivamente. Portanto, com forte aproximação de haver diferenças significantes entre dentes do Solitaire $(H=16,49$, contra Quiquadrado $9 \mathrm{~g} . \mathrm{I}$ a $5 \%=16,92)$. Isto confirmaria a alta permeabilidade marginal do Solitaire, com tendência de possível influência do fator dente (e não de paredes) ${ }^{15,29}$.

Sintetizando, a superfície e a massa ou corpo dos materiais restauradores mostraram-se geralmente impermeáveis ao corante. Isto denota, como era de se esperar, que eles - os materiais - foram imunes à coloração, pelo menos a curto prazo e nas condições experimentais adotadas. Contudo, registra-se que outro fator a considerar seria - no caso de infiltração no corpo do material - a desidratação dele, gerando trincas e até alguma força de tração na interface dente/material, tendendo abri-la e, aí sim, dando registro de infiltração marginal. Como não foram vistos sinais marginais, fica afastada esta hipótese.

Na verdade, quando ocorreu a infiltração marcada pelo corante, ela foi marginal, isto é, na interface dente/material, seja por capilaridade ou por difusão. O inverso, portanto quando não houve infiltração, como verdade ocorreu integração persistente entre dente/material, resistente aos efeitos de 
percolação, seja pela polimerização ou reações de endurecimento do material, seja pela ciclagem térmica. Isto mostra, que nestes casos, ou os coeficientes de dilatação térmica tanto do material como do dente foram perfeitamente equilibrados ou equivalentes, ou a embricação entre eles foi tão perfeita, a ponto de resistir às eventuais forças de tração decorrentes de diferenças consignáveis entre tais coeficientes. Foi o que ocorreu com muita freqüência principalmente com o Alert e o Dyract AP. O contrário deu-se, mormente com o Vitremer e o Solitaire.

Considerando, portanto, o referido embricamento como fator fundamental, cabe comenta-lo sob outros enfoques. Ao cabo do preparo cavitário a superfície dentária, principalmente na dentina e no cemento, menos no esmalte, fica reaberta com o "Smear Layer". Usa-se um ácido ou um quelante (geralmente ácido) para removê-lo. Simultaneamente com essa limpeza, ocorre o ataque ácido das superfícies então expostas, liberando e ampliando os túbulos dentinários, expondo o esmalte prismático, formando nichos, "gapes" ou ganchos de retenção para o material restaurador. Esse microcondicionamento mecânico é controlado pela efetividade e tempo de exposição ao ácido. Ele é seguido por outro condicionamento, físico-químico, desses nichos "gapes" ou ganchos, reduzindo a tensão superficial seletiva para o material restaurador, obtido pelos chamados "primers". Modernamente há tendência de ser usar um único material condicionante mecânico e físicomecânico - o "primer" acidificado. Como preparo prévio final, tem sido recomendado o uso de adesivos, isto é, um material que se imbrica efetivamente nos condicionamentos (nichos, "gapes" ou ganchos) tendo alta 
afinidade também com o material restaurador, servindo de intermediário entre ele e a superfície dentária. Os adesivos de $5^{\mathrm{a}}$ e última geração já incorporam o ácido, o "primer" e o adesivo num só material. O material restaurador, por sua vez, deve apresentar um coeficiente mínimo de contração de presa e/ou permitir o fracionamento desta eventual contração pela adoção da técnica de preenchimento e ativação de presa incremental da cavidade. Entende-se que, com a adoção racional dessas alternativas somatórias, consegue-se os melhores resultados. Esse trabalho confirma a validade geral desta filosofia.

\section{2 - Dos resultados}

A análise dos índices de infiltração marginal atribuído para as margens oclusais e gengivais das cavidades vestibulares e linguais demonstrou não haver diferença estatisticamente significante entre as cavidades classe $\mathrm{V}$ vestibular e lingual, nem entre a margem oclusal (em esmalte) e gengival (em cemento). Alguns autores ${ }^{8,16,99}$ têm encontrado, quando comparada à infiltração marginal em cemento, menor infiltração nas margens do esmalte. Isto se deve ao bisel de $45^{\circ}$ no esmalte, o que permite uma maior área de ataque ácido e conseqüentemente promove maior retenção em maior área. Neste trabalho as margens de esmalte e cemento eram isentas de bisel para que pudéssemos padronizar o preparo cavitário, visto que o ionômero de vidro não permite que o mesmo seja realizado ${ }^{25,49}$.

O quadro com a soma dos postos médios mostrou que a resina composta Alert obteve menor infiltração marginal tanto em esmalte como em cemento, em parte isto pode ter ocorrido devido ao uso da resina composta 
"Flow-It", base do material restaurador, como agente forrador, que possui baixa viscosidade, excelente escoamento, boa fluidez e elasticidade e bom vedamento das paredes internas da cavidade $89,92,93,95$. Outro fator que justifica a menor infiltração marginal desta resina foi a utilização do selante de superfície Protect-It, que é eficaz para reduzir a infiltração marginal tanto no esmalte como no cemento ${ }^{60,66}$. A eficiência do uso de selantes de superfície aumenta a longevidade das restaurações. O Alert, dentre as resinas condensáveis, apresenta uma maior microdureza e pequena contração de polimerização, fatores estes importantes na diminuição da infiltração marginal. O Alert apresenta, por sua vez, maior rugosidade, fator este desfavorável, porém compensado pelo selante de superfície.

O compômero Dyract-AP tem o volume das partículas de carga em torno de $50 \%$ e o seu tamanho médio em torno de 0,8 micrometro, uma das menores, comparando-se com outros compômeros; a sua resistência adesiva ao esmalte e dentina é por volta de 20 a $24 \mathrm{Mpa}$, fato este que provavelmente influenciou na menor infiltração marginal ${ }^{20}$. O compômero citado teve pior desempenho que a resina composta condensável Alert, porém melhor que a resina composta Z-250, o ionômero de vidro Vitremer e a resina composta Solitaire.

A resina composta avançada Z-250 manteve o terceiro posto, com uma infiltração marginal maior que o Alert e o Dyract-AP e menor que o cimento de ionômero de vidro Vitremer e a resina composta Solitaire. Ela possui alta concentração de carga inorgânica, em torno de $60 \%$, com o tamanho de sua partícula por volta de 0,6 micrometro e com contração de 
polimerização menor que as outras resinas compostas avançadas ou as condensáveis. Alguns pesquisadores ${ }^{15,} 29$ consideram a contração de polimerização como a maior causa inicial da infiltração marginal. GORACCl et $\mathrm{al}^{45}$ observaram que durante o processo de polimerização pode haver sub ou sobre polimerização, sendo esta última favorável à resina composta, visto que isto evita falhas na polimerização e conseqüentemente diminuição da porosidade por perda do material restaurador (matriz resinosa) e conseqüente desadaptação marginal, recomendando polimerização gradual das camadas de resinas compostas.

O cimento de ionômero de vidro Vitremer ficou em $4^{\circ}$ lugar, juntamente com a resina composta Solitaire. A adesão ao esmalte e dentina é moderada em ambos os casos e a resistência à compressão atinge índice de moderado a alto, sendo que a sorpção de água é moderadamente baixa.

A resina composta condensável Solitaire obteve os piores resultados quanto à infiltração marginal, pois possui uma alta carga inorgânica (66\%), com macropartículas de 2 a 20 micrometros, portanto maiores que as demais resinas compostas condensáveis; contração de polimerização maior que a maioria das resinas compostas condensáveis; sua microdureza e rugosidade são menores que as demais resinas compostas condensáveis. A utilização da resina sem selante de superfície é fator desfavorável, pois este poderia minimizar estas falhas e atenuar a infiltração marginaf0, 66.

Todos os materiais testados tiveram infiltração marginal, porém em graus variáveis, apesar da técnica do condicionamento ácido aliado ao uso de adesivos dentinários, da técnica da dentina úmida, da técnica incremental para 
inserção da resina composta, a fim de reduzir o fator $\mathrm{C}$, o acabamento e polimento após 24 toras. Todos estes cuidados visam diminuir a expansão higroscópica da resina composta, enquanto que a utilização de selantes de superfície minimiza a infiltração marginal. 
7 - CONCLUSÕES C 


\section{7 - CONCLUSÕES}

Com base nas análises estatísticas aplicadas globalmente aos resultados experimentais podemos, como conclusão concisa e básica ordenar os materiais restauradores quanto à eficiência seladora marginal, do maior ao menor:

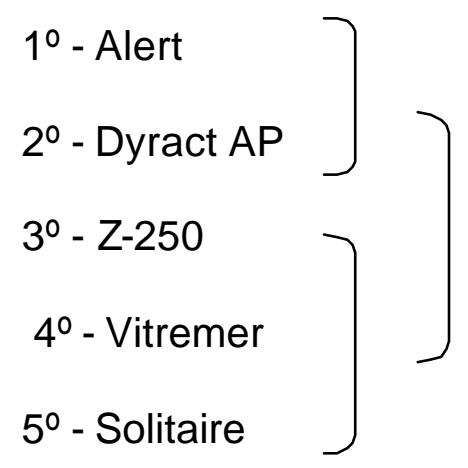

Entre o primeiro e segundo colocados não houve diferença estatisticamente significante, assim como entre o segundo até o quarto e entre o terceiro até o último colocado. Entre o primeiro e o terceiro em diante e entre o segundo e o último colocado às diferenças foram estatisticamente significantes.

Assim nos parece lícito concluir, conseqüentemente:

1 - A resina composta Alert não mostrou diferença estatística quanto à infiltração marginal com o Dyract AP.

2 - A resina composta Alert mostrou menor infiltração marginal, estatisticamente significante, comparada com a resina composta Z-250, ionômero de vidro Vitremer e a resina composta Solitaire. 
3 - A resina composta modificada por poliácidos Dyract AP destacou-se com menor infiltração marginal que a resina composta Z-250, o ionômero de vidro Vitremer e, atingindo significância estatística $(p<0,05)$ a resina composta Solitaire.

4 - O grau de infiltração marginal produzido pela resina composta Z250, ionômero de vidro Vitremer (grupo controle) e a resina composta Solitaire foram estatisticamente semelhantes $(p>$ $0,05)$.

5 - A resina composta Alert permitiu a menor infiltração marginal, enquanto que a resina composta Solitaire demonstrou maior infiltração marginal.

6 - Entre as cavidades vestibular e lingual ou entre suas paredes de esmalte ou de cemento não se registrou infiltração marginal estatisticamente diferente. 


\section{REFERÊNCIAS BIBLIOGRÁFICAS*}

1- AIROLDI, R. L.; KREJCI, I.; LUTZ, F. In vitro evaluation of dentinal bonding agents in mixed Class V cavity preparations. Quintessence Int., v. 23, p.355-362, 1992.

2- ALFIERI, N Tempo de presa, resistência à compressão e capacidade impermeabilizante de materiais restauradores provisórios e intermediários. Bauru, 1984. Tese (Doutorado) - Faculdade de Odontologia de Bauru, Universidade de São Paulo.

3- AMERICAN DENTAL ASSOCIATION. Council on Dental Materials, Instruments and Equipment. Obstacles to the development of a standard for posterior composite resins. J. Amer. dent. Ass., v.118, n. 5, p. 649-651, 1989.

4- APPLEQUIST, E. A.; MEIERS, J. C. Effect of bulk insertion, prepolymerized resin composite balls, and beta-quartz inserts on microleakage of class $\mathrm{V}$ resin composite restorations. Quintessence Int., v.27, p.253-8, 1996.

5- ARBABZADEH, F. et al. Gap measurement and bond strength of five selected adhesive systems bonded to tooth structure. Aust. dent. J., v.43, n.3, p.175-80, 1998.

\footnotetext{
* Normas recomendadas para uso no âmbito na Universidade de São Paulo, com base no documento "Referências Bibliográficas: exemplos", emanado do Conselho Supervisor do Sistema Integrado de Bibliotecas da USP, em reunião de 20 de setembro de 1990.
} 
6- ASMUSSEN, E.; MUNKSGAARD, E. C. Bonding of restorative resins to dentine promoted by aqueous mixtures of aldehydes and active monomers. Int. dent. J., v. 35, p.160-5, 1985.

7- ATTIN,T.; BUCHALLA,W.; HELLWIG, E. Influence of enamel conditioning in bond strength of resin modified glass ionomer restorative materials and polyacid-modified composites. J. prosth. Dent., v.76, p. 29-33, 1996.

8- BARNES, D.M. et al. Microleakage in facial and lingual class 5 composite restorations: a comparison. Oper. Dent., v.19, p.133-7, 1994.

9- BAUER, G. J.; HENSON, J. L. Microleakage a measure of the performance of direct filling materials. Oper. Dent., v.9, n.1, p.2-9, 1984.

10- BOUSCHLIC HER, M. R. et al. Effect of desiccation in microleakage of five class 5 restorative materials. Oper. Dent., v. 21, p. 90-95, 1996.

11- BRACKETT,W. W.; GILPATRICK, R. O.; GUNNIN, T. D. Effect of finishing method on the microleakage of class $\mathrm{V}$ resin composite restorations. Amer. J. dent., v.10, p.189-1, 1997.

12- BRACKETT, W. W. et al. Microleakage of class $V$ compomer and lightcured glass ionomer restorations. J. prosth. Dent., v.79, p.261-3, 1998. 
13- BRÄNSTRÖM, M. et al. The inicial gap around large composite restorations in vitro: the effect of etching enamel walls. J. dent. Res., v.63, n.5, p.681-4, 1984.

14- CAMPS, J. et al. Influence of tooth cryopreservation and storage time an microleakage. Dent. Mat., v.12, p.121-6, 1996.

15- CARVALHO, R. M. et al. A review of polymerization contraction: the influence of stress development versus stress relief. Oper. Dent., v.21, p.17-24, 1996.

16- CASTELNUOVO, J. Microleakage of multi-step and simplified-step bonding systems. Amer. J. Dent., v, 9, p.245-248, 1996.

17- CAUSTON, B. E.; SEFTON, J. Some bond characteristics of a HEMA/ maleic acid adhesion promoter. Brit. dent. J., v.167, n.9, p.308-11, 1989.

18- CHERSONI, S. et al. Laboratory evaluation of compomers in class $\mathrm{V}$ restorations. Amer. J. Dent., v.10, p.147-51, 1997.

19- CHEUNG, G. S. P. Reducing marginal leakage of posterior composite resin restorations: a review of clinical techniques. J. prosth. Dent., v.63, n.3, p.286-8, 1990. 
20- COMPÔMEROS. The Dental Advisor , v.5, n.9, p.1-4, out.1998.

21- CORREA, I. L. V. Influência na infiltração marginal de diferentes formas de tratamentos da umidade em cavidades restauradas com Scotchbond Multi-Uso/Z. Bauru, 1996. 140p. Dissertação (Mestrado) - Faculdade de Odontologia de Bauru, Universidade de São Paulo.

22- CORTES, O. et al. Marginal microleakage around enamel and cementum surfaces of two compomers. J. clin. pediat. Dent., v.22, n.4, p.307315, 1998.

23- CRIM, G. A. Effect of composite resin of the microleakage of Scothbond 2 and Gluma. Amer. J. Dent., v.1, p.215-6, 1988.

24- CRIM, G. A. Effect of substrate age on microleakage of dentine adhesive agents. J. oral Rehab., v.16, p.555-7, 1989.

25- CRIM, G. A. Effect of aging in microleakage of restorative systems. Amer. J. Dent., v. 6, p.192-4, 1993.

26- CRIM, G. A. Marginal leakage of visible light-cured glass ionomer restorative materials. J. prosth. Dent., v.69, p.561-3, 1993. 
27- CRIM, G. A.; GARCIA-GODOY, G. F. Microleakage: the effect of storage and cycling duration. J. prosth. Dent., v.57, p.574-6, 1987.

28- CRIM, G. A. et al. Comparison of four thermocycling techniques. J. prosth. Dent.,v.53, n.1, p.50-3, 1985.

29- DAVIDSON, C. L.; GEE, A. J. Relaxation of polymerization contraction stress by flow in dental composites. J. dent. Res., v.63, n.2, p.146-8, 1984.

30- DAVIDSON, C. L.; ABDALLA, A. I. Effect of occlusal load cycling on the marginal integrity of adhesive class $\mathrm{V}$ restorations. Amer. J. Dent., v. 7, p.111-4, 1994.

31- DAVIS, E. L. et al. Shear strength and microleakage of light-cured glass ionomers. Amer. J. Dent, v. 6, p.127-9, 1993.

32- DEJOU, J.; SINDRES, V.; CAMPS, J. Influence of criteria on the results of in vitro evaluation of microleakage. Dent. Mat., v. 12, p.342-9, 1996.

33- DOERR, C. L.; HILTON, T. J.; HERMESCH, C. B. Effect of thermocycling on the microleakage of convencional and resin-modified glass ionomers. Amer. J. Dent, v.9, p.19-21, 1996. 
34- FERRARI, M.; DAVIDSON, C. L. Sealing capacity of a resin - modified glass-ionomer and resin composite placed in vivo in class 5 restorations. Oper. Dent., v.21, p.69-72, 1996.

35- FERRARI, M. et al. Clinical and laboratory evaluation of adhesive restorative systems. Amer. J. Dent., v.7, p.217-9, 1994.

36- FERRARI, M. et al. Sealing ability of two "compomers" applied with and without phosphoric acid treatment for class $\mathrm{V}$ restorations in vivo. J. prosth. Dent, v.79, p.131-5, 1998.

37- FITCHIE, J. G.; PUCKETT, D.; COBB JUNIOR, G. Microleakage of two new combined primer/adhesive resin systems. Gen. Dent., p.302-7, 1999.

38- FITCHIE, J. G. et al. Microleakage of two new dentinal bonding systems. Quintessence Int., v. 21, p.749-752, 1990.

39- FITCHIE, J. G. et al. Microleakage of a new dental adhesive comparing microfilled and hybrid resin composites. Quintessence Int,, v. 26, p.505-10, 1995. 
40- FRIEDL, K. H. et al. Marginal adaptation of composite restorations versus hybrid ionomer/composite sandwich restorations. Oper. Dent., v. 22, p.21-9, 1997.

41- GARCIA-GODOY, F. ; MALONE, W. F. P. Microleakage of posterior composite resins using, glass ionomer cement bases. Quintessence Int., v.19, n.1, p.13-7, 1988.

42- GILPATRICK, R. O. et al. Microleakage of composite resin restorations with various etching times. Quintessence Int., v.25, p.573-6, 1994.

43- GLADYS, S. et al. Marginal adaptation and retention of a glass-ionomer, resin-modified glass-ionomers and a polyacid-modified resin composite in cervical class V lesions, Dent Mat., v.14, p.294-306, 1998.

44- GOING, R. E. Reducing marginal leakage: a review of materials and techniques. J. Amer. dent. Ass., v.99, p.646-51, 1979.

45- GORACCI, G.; MORI, G.; MARTINIS, L.C. Curing light intensity and marginal leakage of resin composite restorations. Quintessence Int., v.27, p.355-62, 1996.

46- GORDAN, V. V. et al. Evaluation of acidic primers in microleakage of class 5 composite resin restorations. Oper. Dent., v.23, p.244-9, 1998. 
47- GWINNETT, A. J.; YU, S. Effect of long-term water storage on dentin bonding. Amer. J. Dent., v.7, p.109-11, 1994.

48- HAKIMEH, S. et al. Microaleakage of compomer class $V$ restorations: effect of load cycling, thermal cycling, and cavity shape differences. J. prosth. Dent.; v.83, p.194-203, 2000.

49- HALLETT, K. B.; GARCIA-GODOY, F. Microleakage of resin-modified glass ionomer cement restorations: an in vitro study. Dent. Mat., v.9, p.306-11, 1993.

50- KANCA, J. A Method for bonding to tooth structure using phosphoric acid as a dentin-enamel conditioner. Quintessence Int., v.22, p.285-90, 1991.

51- KIDD, E. A. M. - Microleakage: a review. J. Dent., v.4, p.199-206, 1976.

52- KIDD, E. A. M.; TOFFENETTI, F.; MJOR, I. A. Secondary caries. Int. dent. J., v.42, n.3, p.127-38, 1992.

53- KÖPRÜLÜ, $H$. et al. Marginal seal of a resin modified glass-ionomer restorative material: An investigation of placement techniques. Quintessence Int., v. 26, p.729-32, 1995. 
54- KUGEL, G. et al. Dyract compomer: Comparison of total etch vs. no etch technique. Gen. Dent., p.604-6, Nov./Dec. 1998.

55- LEINFELDER, K. F. et al. Efficacy of the dentin bonding agents. Part I. Their effectiveness in reducing microleakage. J. Ala. dent. Ass., v.70, p.13-9, 1986.

56- LIM , C. C.; NEO, J. ; YAP, A. The influence of finishing time on the marginal seal of a resin-modified glass-ionomer and polyacid-modified resin composite. J. oral Rehab; v.26, p.48-32, 1999.

57- MACK, G. A.; SKILLINGS, J. H. A Friedman - type tank test for main effects in a two-factor ANOVA. J. Amer. Statist. Ass., v.75, n..372, p.947-51, 1980.

58- MANDARINO, F. et al. Avaliação da infiltração marginal dos sistemas restauradores indiretos de resina composta. J. bras. clin. estet. Odonto, v.3, n.17, p.58-62, 1999.

59- MATERIAIS restauradores que liberam flúor. Dental Advisor, v. 6, n.1, p. 1-5, fev. 1999.

60- MAY JUNIOR, K. N. et al. Effect of a surface sealant on microleakage of class V restorations. Amer. J. Dent., v.9, p.133-136, 1996. 
61- McLEAN, J. W. et al. The use of glass-ionomer cements in bonding composite resins to dentine. Brit. dent. J., v.8, p.410-4, 1985.

62- MEIERS, J. C.; KRESIN, J. C. Cavity disinfectants and dentin bonding. Oper.Dent., v.21, p.153-9, 1996.

63- Miller JUNIOR, R. G.; HOLlANDER, M.; WOlFE, D. A. Non parametric statistical methods . New York, John Willey Sons, 1973. p.124-30.

64- MIXSON, J. M. et al. Comparison of two-surface and multiple-surface scoring methodologies for in vitro microleakage studies. Dent. Mat., v.7, p.191-6, 1991.

65- MIXSON, J. M. et al. Effect of two dentin bonding agents an microleakage in two different cavity designs. J. prosth. Dent., v.67, p.441-5, 1992.

66- MUNRO, G. A.; HILTON, T. J.; HERMESCH, C. B. In vitro microleakage of etched and rebonded class 5 composite resin restorations. Oper. Dent., v.21, p.203-8, 1996.

67- NAKABAYASHI, N.; NAKAMURA, M.; YASUDA, N., Hybrid layer as a dentin bonding mechanism. J. Esth. Dent., v.3, n.4, p.133-8, 1991. 
68- OWENS, B. M. et al. Microlekage of tooth.-colored restorations with a beveled gingival margin. Quintessence Int., v. 29, p.356-61, 1998.

69- PACHUTA, S. M.; MEIERS, J. C. Dentin surface treatments and glass ionomer microleakage. Amer. J. Dent., v.8, p.187-90, 1995.

70- PILO, R.; BEN-AMAR, A. Comparison of microleakage for three one-bottle and three multiple-step dentin bonding agents. J. prosth. Dent., v.82, p.209-13, 1999.

71- POWIS, D. R. et al - Improved adhesion of glass ionomer cement to dentin and enamel. J. dent. Res., v.61, p.1416-22, 1982.

72- PRATI, C. et al. Marginal morphology of class $\mathrm{V}$ composite restorations. Amer. J. Dent., v.10, p.231-6, 1997.

73- RESINAS compostas condensáveis. The Dental Advisor, v.5, n.8, p.1-4, set. 1998.

74- RETIEF, D. H. -Are adhesive techniques sufficient to prevent microleakage. Oper. Dent., v.12, p.140-5, 1987.

75- RETIEF, D. H. Do adhesives prevent microleakage? Int. dent. J., v.44, p.19-26, 1994. 
76- RETIEF, D. H. et al. Shear bond strength required to prevent microleakage at the dentin/ restoration interface. Amer. J. Dent., v.7, p.43-6, 1994.

77- RODRIGUES, J. A. et al. In vitro microleakage of glass-ionomer composite resin hybrid materials. Oper. Dent., v.24, p.89-95, 1999.

78- ROSSOMANDO, K.J.; WENDT, S.L. Termocycling and dwell times in microaleakage evaluation for bonded restorations. Dent. Mat., v.11, p.47-51, 1995.

79- RUSSO, E. M. A. et al. Influência da hidratação e do glazeamento na infiltração marginal em restaurações classe $\mathrm{V}$ de resina composta. In: ENCONTRO DO GRUPO BRASILEIRO DE PROFESSORES DE DENTíSTICA, 8, GBPD, Recife, 1999.Anais. Recife, GBPD, 1999, p.65.

80- SALAMA, F. S. et al. Microleakage and marginal gap formation of glass ionomer resin restorations. J. clin. pediat. Dent., v.20, p.31-6, 1995.

81- SANO, H. et al. Nanoleakage: leakage within the hybrid layer. Oper. Dent., v.20, p.18-25, 1995.

82- SANTINI, A.; MITCHELL, S. Effect of wet and dry bonding techniques on marginal leakage. Amer. J. Dent., v.11, p.219-24, 1998. 
83- SAUNDERS, W. P.; SAUNDERS, E. M. Microleakage of bonding agents with wet and dry bonding techniques. Amer. J. Dent., v.9, p.34-6, 1996.

84- SETTEMBRINI, L. et al. A single-component bonding system microleakage study. Gen. Dent., p.341-3, July/Aug. 1997.

85- SIDHU, S. K. Marginal contraction gap formation of light-cured glass ionomers. Amer. J. Dent., v.7, p.115-8, 1994.

86- SOUZA JUNIOR, M.H. S. Adesivos dentinários, evolução, estágio atual e considerações clínicas para sua utilização. Maxi-Odonto Dentística, v.1, n.1, 1995.

87- SOUSA, M. C. Avaliação “in vitro" da infiltração marginal em obturações de canais radiculares, em função de corantes marcadores, tempo de imersão nestes e tipos de cimentos obturadores. Bauru, 1991. Dissertação (Mestrado)-Faculdade de Odontologia de Bauru, USP.

88- SWIFT JR., E. J.; LE VALLEY, B. D.. Microleakage of etched-dentin composite resin restorations. Quintessence Int., v.23, p.505-8, 1992. 
89- SWIFT JR., E. J. et al. Effect of low-viscosity resins on the performance of dental adhesives. Amer. J. Dent., v.9, p.100-4, 1996.

90- TAY, F. R. et al. A method for microleakage evaluation along the dentin/restorative interface. Amer. J. Dent, v. 8, p.105-8, 1995.

91- TAY, F. R. et al. Resin permeation into acid-conditioned, moist, and dry dentin: a paradigm using water-free adhesive primers. J. dent Res., v. 75, n.4, p. 1034-44, 1996.

92- TAYLOR, M. J.; LYNCH, E. Microleakage. J. Dent., v.20, n.1, p.3-10, 1992.

93- TAYLOR, M. J.; LYNCH, E. Marginal Adaptation, J. Dent., v.2 1, p.265-73, 1993.

94- TJAN, A. H. L. Effect of various incremental techniques on the marginal adaptation of class II composite resin restorations. J. prosth. Dent., v. 67, p. 62-6, 1992.

95- TJAN, A. H. L.; TAN, D. E. Microleakage at gingival margins of class $V$ composite resin restorations rebonded with various low viscosity resin systems. Quintessence Int., v. 22, p.565-73, 1991. 
96- TORRES, C. R. G.; ARAÚJO, M. A. M. Adesivos de quinta geração condicionamento ácido total $\mathrm{X}$ primers auto-condicionantes. J. bras. Clin. Estet. Odonto, v.4, n.20, p.52-60, 2000.

97- TRUSHKOWSKY, R. D.; GWINNETT, A. J. Microleakage of class V composite, resin sandwich, and resin-modified glass ionomers. Amer. J. Dent., v.9, p. 96-9, 1996.

98- UNO, S.; FINGER, W. J.; FRITZ, U. B. Effect of cavity design on microleakage of resin-modified glass ionomer restorations. Amer. J. Dent., v.10, p.32-5, 1997.

99- VIEIRA, L. C. C.-Avaliação da infiltração marginal nas margens de esmalte e cemento em cavidades de classe II M.O.D. restauradas com cinco sistemas adesivos. Bauru, 1988. Dissertação (Mestrado)Faculdade de Odontologia de Bauru, Universidade de São Paulo.

100- WENDT., J. S. L. et al. The effect of thermocycling in microleakage analysis. Dent. Mat., v.8, p.181-4, 1992.

101- YAP, A. U. J. Effects of storage, thermal and load cycling on a new reinforced glass-ionomer cement. J. oral Rehab., v. 25, p.40-4, 1998. 
102- YAP, A. U. J.; MOK, B. Y. Y. Reinforced glass ionomer cements: the influence of conditioners on marginal leakage. J. oral Rehab., v.24, p.477-81, 1997.

103- YAP, A. U. J. et al. Marginal sealing ability of three cervical restorative systems. Quintessence Int., v. 26, p. 817- 20, 1995.

104- YEDID, S. E.; CHAN, K. C. - Bond strength of three esthetic restorative materials. J. prosth. Dent, v. 44, p.573-6, 1980.

105- ZYSKIND, D. et al. Marginal leakage around V-shaped cavities restored with glass-ionomer cements: an in vitro study. Quintessence Int., v. 22; p. 41-5, 1991. 
ABSTRACT and 


\begin{abstract}
This study compares the marginal leakage of four restorative materials: condensable resin composites (Group I: Alert and Group II: Solitaire), hybrid resin composite (Group III: Z-250) and polyacid-modified resin composite (Group IV: Dyract). Vitremer (Group V), resin modified glass ionomer was chosen as the control group.

Fifty sound pre-molars extracted for orthodontic reasons were cleaned, fixed in $10 \%$ formalin and stored in destiled water. Class $\mathrm{V}$ restorations (diameter $=3 \mathrm{~mm}$, depth $=1,5 \mathrm{~mm}$ ) were prepared in the vestibular and lingual surfaces.

Following restorations placement $(\mathrm{N}=100)$, the samples were immersed in destiled water for 24 hours at $37^{\circ} \mathrm{C}$ and polished with Sof-Lex discs. The samples were made impermeable (varnish) excluding $2 \mathrm{~mm}$ area around the restoration. The teeth were dried and submitted to 200 termic cicles $\left(5^{\circ} \mathrm{C} / 55^{\circ} \mathrm{C}\right)$ each one lasting 30 seconds. The samples were immersed in $2 \%$ methylene blue dye for 24 hours and sliced longitudinally (vestibular to lingual surfaces) with diamond disc. A 7-fold magnifying glass was used to classify the samples (0-4 score) according to maximum dye penetration level and number of infiltration sites.
\end{abstract}

The difference was significant $(\mathrm{P}<0,05)$ for Group I: Alert and Group IV: Dyract. The other three groups showed non statistically significant results with the poorest performance by Solitaire. 
ANEXOS

(2)




\section{ANEXOS}

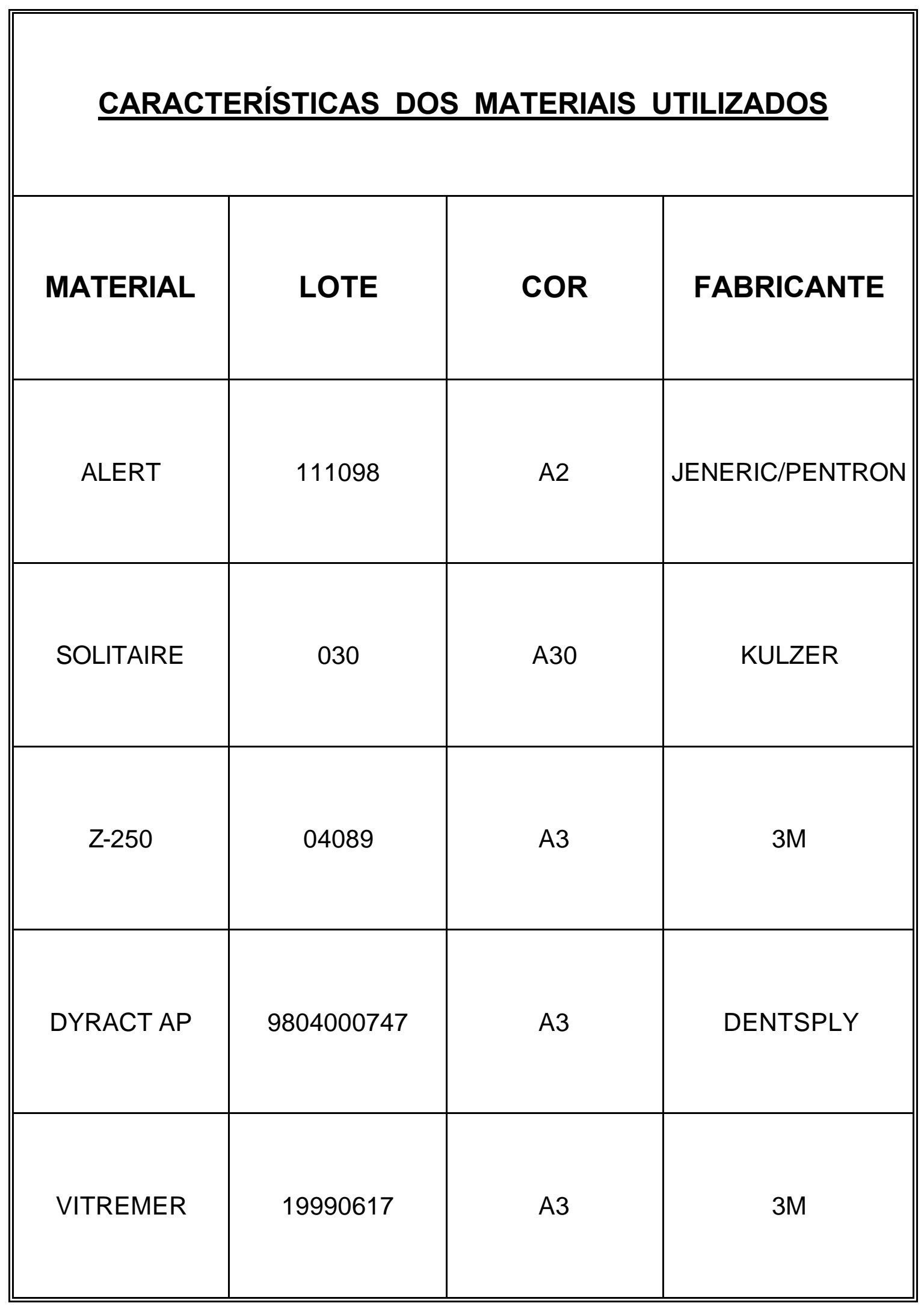




\begin{tabular}{|c|c|c|c|c|c||}
\hline \hline \multirow{2}{*}{$\begin{array}{c}\text { FREQUÊNCIA DOS ESCORES DA MICROINFILTRAÇÃO NAS } \\
\text { PAREDES DE ESMALTE ( VESTIBULAR ) DAS CAVIDADES }\end{array}$} \\
\hline \multirow{5}{*}{ MATERIAL } & $\mathbf{5}$ & $\mathbf{1}$ & $\mathbf{2}$ & $\mathbf{3}$ & $\mathbf{4}$ \\
\cline { 2 - 6 } & $\mathbf{0}$ & 3 & - & - & - \\
\hline ALERT & 7 & - & 1 & 1 & 5 \\
\hline SOLITAIRE & 3 & 6 & - & - & 1 \\
\hline Z-250 & 3 & 2 & 1 & 1 & - \\
\hline DYRACT AP & 6 & 5 & 3 & 1 & - \\
\hline VITREMER & 1 & & & & \\
\hline \hline
\end{tabular}

\begin{tabular}{|c|c|c|c|c|c||}
\hline \hline \multirow{2}{*}{$\begin{array}{c}\text { FREQUÊNCIA DOS ESCORES DA MICROINFILTRAÇÃO NAS } \\
\text { PAREDES DE ESMALTE ( LINGUAL ) DAS CAVIDADES }\end{array}$} \\
\hline \multirow{5}{*}{ MATERIAL } & $\mathbf{5}$ & $\mathbf{1}$ & $\mathbf{2}$ & $\mathbf{3}$ & $\mathbf{4}$ \\
\cline { 2 - 7 } & $\mathbf{0}$ & 1 & 1 & - & - \\
\hline ALERT & 8 & 1 & - & 1 & 5 \\
\hline SOLITAIRE & 3 & 5 & - & 1 & 2 \\
\hline Z-250 & 2 & - & - & 1 & 2 \\
\hline DYRACT AP & 7 & 7 & 2 & - & - \\
\hline VITREMER & 1 & & & & \\
\hline \hline
\end{tabular}




\begin{tabular}{|c|c|c|c|c|c||}
\hline \hline \multirow{2}{*}{$\begin{array}{c}\text { FREQUÊNCIA DOS ESCORES DA MICROINFILTRAÇÃO NAS } \\
\text { PAREDES DE CEMENTO ( VESTIBULAR ) DAS CAVIDADES }\end{array}$} \\
\hline \multirow{5}{*}{ MATERIAL } & \multicolumn{5}{|c||}{ ESCORE DA MICROINFILTRAÇÃO } \\
\cline { 2 - 6 } & 0 & 1 & 2 & 3 & 4 \\
\hline ALERT & 6 & 4 & - & - & - \\
\hline SOLITAIRE & 4 & - & - & - & 6 \\
\hline Z-250 & 4 & 1 & 2 & - & 3 \\
\hline DYRACT AP & 7 & 1 & - & - & 2 \\
\hline VITREMER & 1 & 4 & 2 & 1 & 2 \\
\hline \hline
\end{tabular}

\begin{tabular}{|c|c|c|c|c|c||}
\hline \hline \multirow{2}{*}{$\begin{array}{c}\text { FREQUEN } \\
\text { PAREDES DOS ESCORES DA MICROINFILTRAÇÃO NAS }\end{array}$} \\
\hline \multirow{2}{*}{ MATERIAL } & \multicolumn{5}{|c||}{ ESCORE DA MICROINFILTRAÇÃO } \\
\cline { 2 - 6 } & 0 & 1 & 2 & 3 & 4 \\
\hline ALERT & 7 & 3 & - & - & - \\
\hline SOLITAIRE & 2 & 1 & - & - & 7 \\
\hline Z-250 & 3 & 5 & 1 & - & 1 \\
\hline DYRACT AP & 8 & - & - & 1 & 1 \\
\hline VITREMER & 1 & 4 & 2 & - & 3 \\
\hline \hline
\end{tabular}

